\title{
Protein Multifunctionality: Principles and Mechanisms
}

\author{
Joseph Z. Zaretsky and Daniel H. Wreschner \\ Department Cell Research and Immunology, George Wise Faculty of Life Sciences, \\ Tel-Aviv University, Ramat-Aviv, Haim Levanon St., 69978 Tel-Aviv, Israel.
}

\begin{abstract}
In the review, the nature of protein multifunctionality is analyzed. In the first part of the review the principles of structural/functional organization of protein are discussed. In the second part, the main mechanisms involved in development of multiple functions on a single gene product(s) are analyzed. The last part represents a number of examples showing that multifunctionality is a basic feature of biologically active proteins.
\end{abstract}

Keywords: protein, structure, function, multifunctionality

\section{Main Principles of Protein Organization: Structural Compactness and Functional Variability}

1. General consideration on the factors determining protein multifunctionality

The cell fulfills two main functions: (1) storage of genetic information and transfer it to the next cell generation; (2) synthesis of different molecules, protein molecules in particular, for fulfillment of numerous cell processes.

The compactness (maximum information packed in minimum DNA space) is one of the main principles of genetic information storage. The fulfillment of the first cell function is based on this principle. On the contrary, the abundance, variability and diversity of the protein molecules are necessary for realization of the second function. In contrast to DNA, proteins exhibit an apparently unlimited variety of structure. This is a necessary requirement of the vast array of different functions that they perform in maintenance of life "in contrast to the relatively static archival function of DNA" (Lesk, 2001). In the protein world, not only "a bewildering variety of form is observed but even within a common structure, there is variation in the lengths and orientation of substructures. Such variation is both a reflection of the very long evolution of protein structures and also a consequence of the fact that proteins cannot be completely rigid bodies but must have flexibility to accommodate the structural changes that are almost always necessary for them to perform their functions" (Lesk, 2001).

All multiple variations in protein structures and functions are genetically determined by DNA sequence fixed in amino acid primary structure of a protein and can be achieved by different mechanisms operating at different levels.

At the level of genome, a single gene may undergo duplication followed by rearrangement and/or mutations thus leading to appearance of homologous proteins possessing partially similar and/or different functions (Fig. 1, A).

At the next level of variability and complexity, transcriptome level, the gene transcription can be altered by several mechanisms including usage of alternative promoters, different transcription initiation sites, mRNA splicing and mRNA stability (Fig. 1, B). The extent of variability that may be obtained by mRNA alternative splicing is almost unlimited. An exelent example of this statement is the Drosophila gene Dscam, encoding Down syndrome cell-adhesion protein. Althernative splicing of Dscam pre-mRNA potentially generates 38016 isoforms of a cell-surface recognition protein (Schmucker et al. 2000; Zipursky et al. 2006).

Further complexity is observed at the proteome level. A variety of the protein products encoded by the same gene can be achieved by three groups of specific mechanisms: those operating at the translational

Correspondence: Joseph Z. Zaretsky, Department Cell Research and Immunology, George Wise Faculty of Life Sciences, Tel-Aviv University, Ramat-Aviv, Haim Levanon St., 69978 Tel-Aviv, Israel. Email: josephz@post.tau.ac.il

Copyright in this article, its metadata, and any supplementary data is held by its author or authors. It is published under the Creative Commons Attribution By licence. For further information go to: http://creativecommons.org/licenses/by/3.0/. 
level; the mechanisms that determine posttranlational modifications and mechanisms controlling the intermolecular interactions. Multiple translation products can be synthesized by usage different cap-dependent and cap-independent internal ribosome entry site (IRES) determined initiation mechanisms (Fig. 1, C) including leaky scanning, ribosome-shunting, termination-initiation and mix (or alternative) initiation (Cai et al. 2006; Candeias et al. 2006; Holcik et al. 2000; Huez et al. 1998; Kochetov, 2006; Kozak, 2002; Lu et al. 2004; Yueh and Schneider, 1996). At elongation stage of protein synthesis, frameshifting and "hopping" (Fig. 1, D) also make substantial impact in protein diversity (Atkins et al. 2001; Herr et al. 2000b; Namy et al. 2004). Stop codon readthrough (Fig. 1, E) is the main mechanism that determines appearance of new protein isoforms at the last stage of translation (Keeling et al. 2004; Namy et al. 2002).

Post-translation modifications of the primary polypeptide molecule (Fig. 1, F) include such mechanisms as different types of glycosylation, phosphorylation, acylation, specific restricted proteolysis, protein splicing and many others (Hanada et al. 2004; Rehfeld and Goetze, 2003). The intermolecular interactions that modify protein properties and functions occur between protein and metal, protein and carbohydrate, protein and lipid and protein and protein. These interactions lead to multiple folding variants which in their turns determine topology and functions of multiple products encoded by one and the same gene.
It is important to underline once again that all possible modifications and interactions of a given gene product(s) are encoded in its nucleotide sequence and, as a consequence, in amino acid structure of polypeptide molecule(s). The reactions described above are based on the natural mechanisms by which condensed genetic information can be transformed into variable and multiple protein structures and functions.

The wisdom of Nature [G-d] is that it does not create anything without specific purpose. There is nothing in nature what is superfluous or unnecessary. This is the main principle of nature. If amino acid sequence of a protein contains genetically determined possibilities for any type of modifications (by proteolysis, folding, glycosylation, phosphorylation etc), there should be definite conditions in a definite cell or tissue in an appropriate point of time which would allow realization of the encoded modifications.

Although the principle of structural and functional compactness is the most evident in nucleic acids, it would be mistake to think that this principle does not work in protein molecules. Actually, the genetic information contained in the DNA sequence is realized in two ways: each protein molecule produced by a gene contains maximum of functional possibilities, and each gene produces as much protein molecules as necessary for performing all functions encoded by the gene. These principles lead to multifunctionality of protein molecules. The following example from the virus
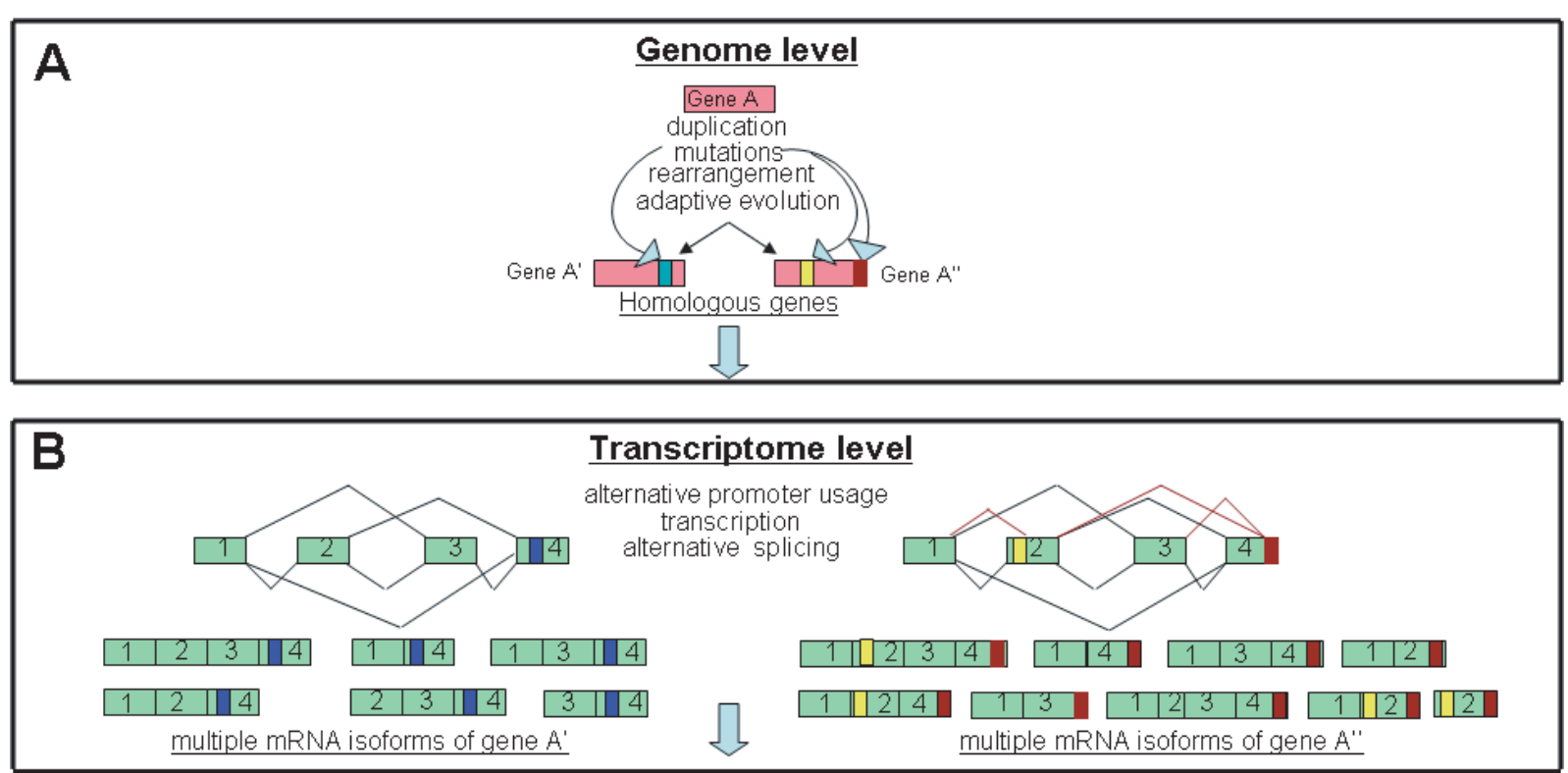
C $\quad \frac{\text { Proteome level }}{\text { Initiation stage }}$

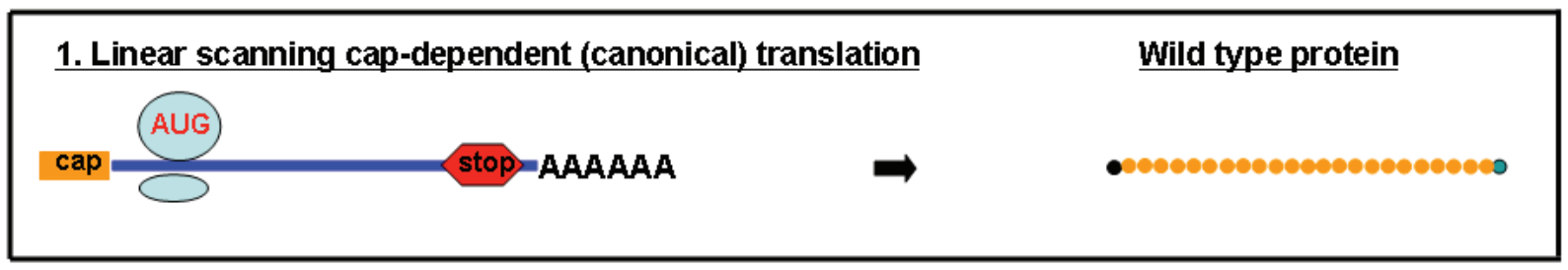

2. Leaky scanning cap-dependent translation

N-terminal extended protein

$\begin{array}{ll}\text { a) } & \text { AUG } \\ \text { cap } & \text { StopAAAAA } \Rightarrow \text { D } \rightarrow 00000000000000000000000000\end{array}$

b)

cap AUG (dAUG

N-terminal truncated protein

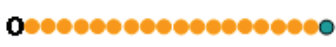

3. Ribosome-shunting translation

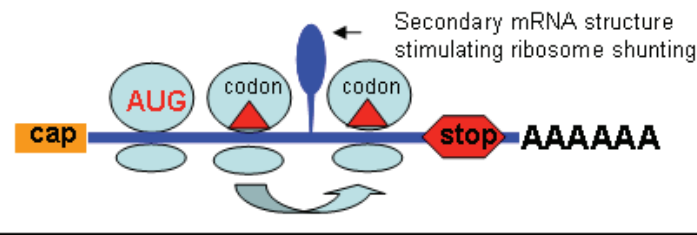

Polypeptide lacking internal part of the wt protein Internal part of the wh protein
excluded from the gene product

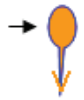

•

(2)

4. Termination-initiation translation of polycistronic mRNA

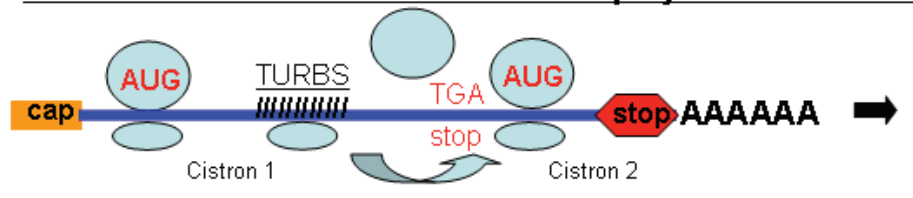

Cistron specific proteins

- 000000000000000000000 Cistron 1 specific protein

Cistron 2 specific protein

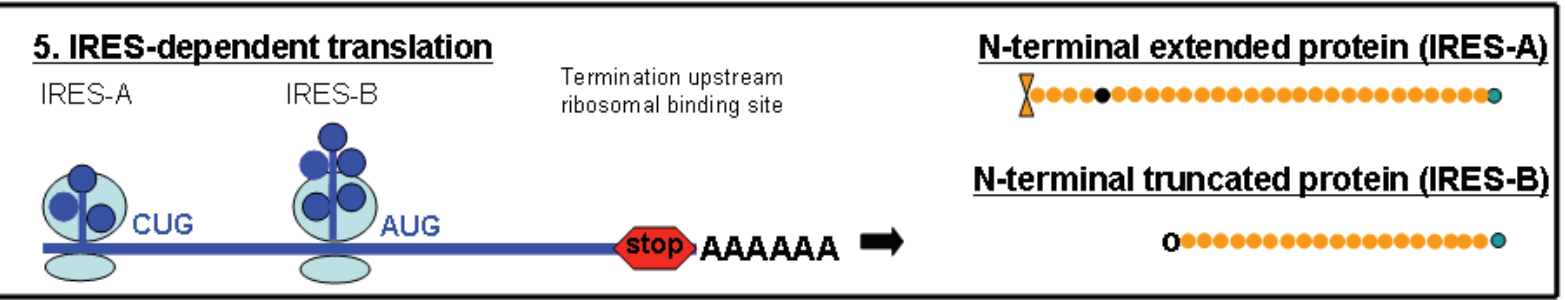

6. Mix-initiation type of translation

N-terminal cap-initiated wild type protein
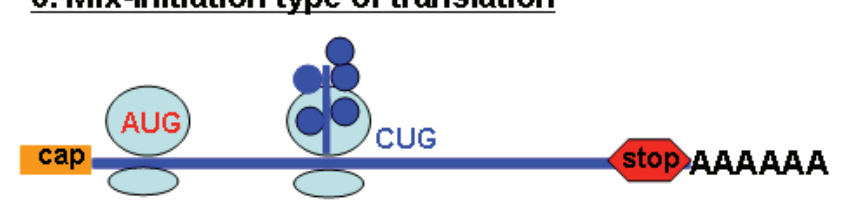

stop AAAAAA

N-terminal truncated IRES-dependent protein

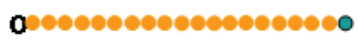


D<smiles>C1=CC=C1</smiles>

Proteome level

Elongation stage

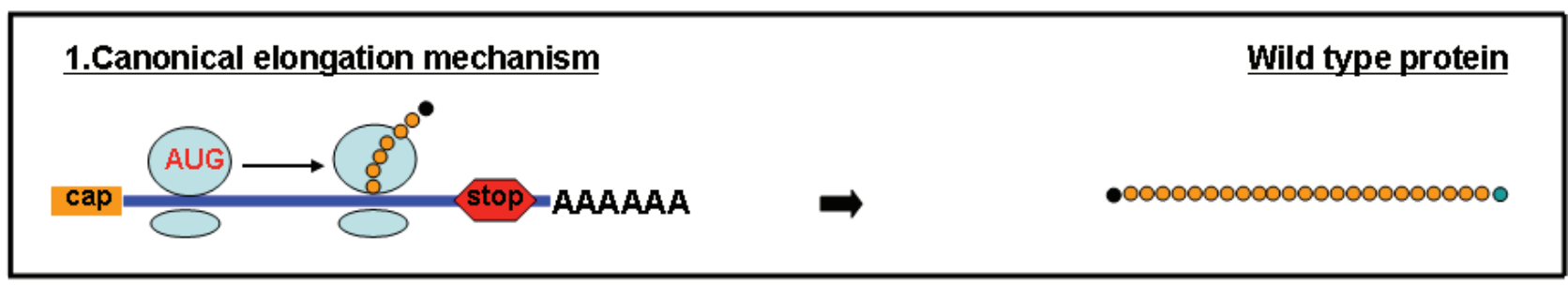

2. Programmed ribosomal frameshifting (PRF)

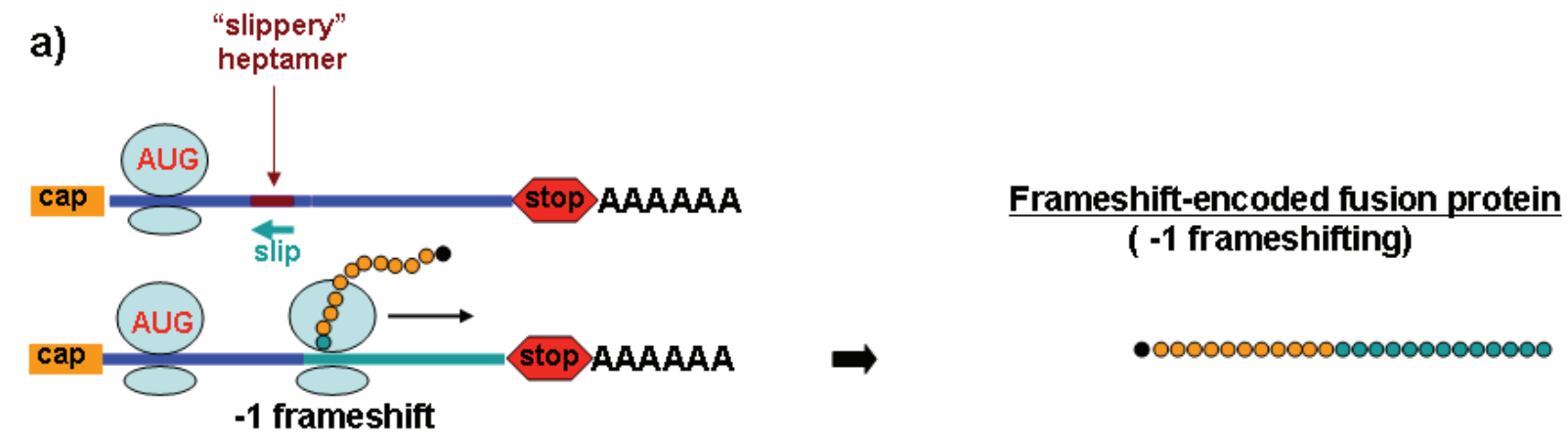

b) "slippery"

heptamer

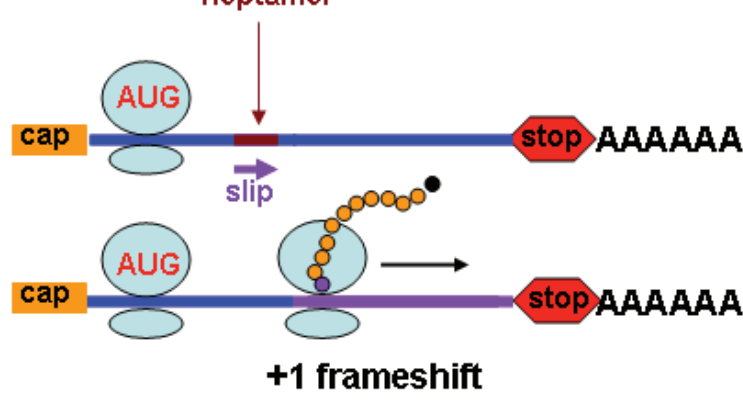

Frameshift-encoded fusion protein (+1 frameshifting)

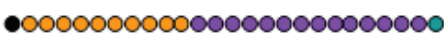

+1 frameshift

3. "Hopping" elongation mechnism

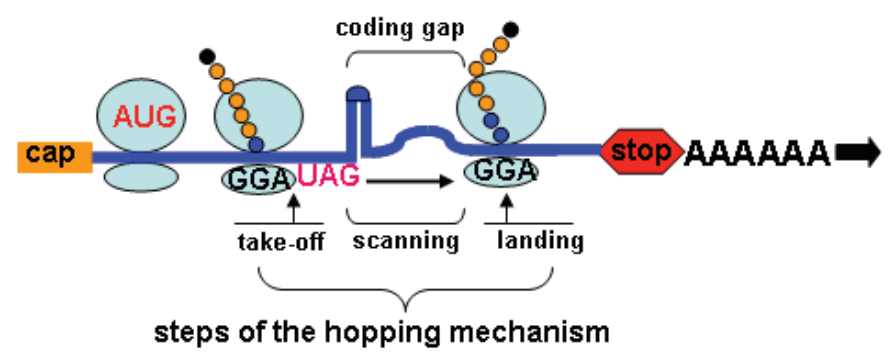

Internal segment-lacking protein

-0000000000000000

Internal gap-coded fragment excluded from the gene product

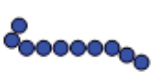


E

Proteome level

Termination stage

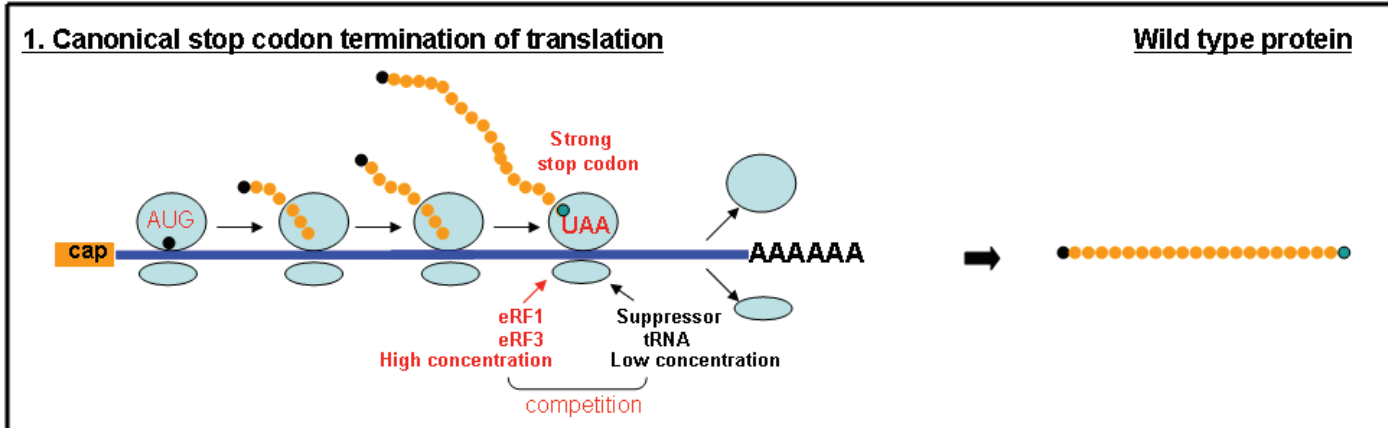

2. Stop codon "read-through" translational mechanism

C-terminal extended protein

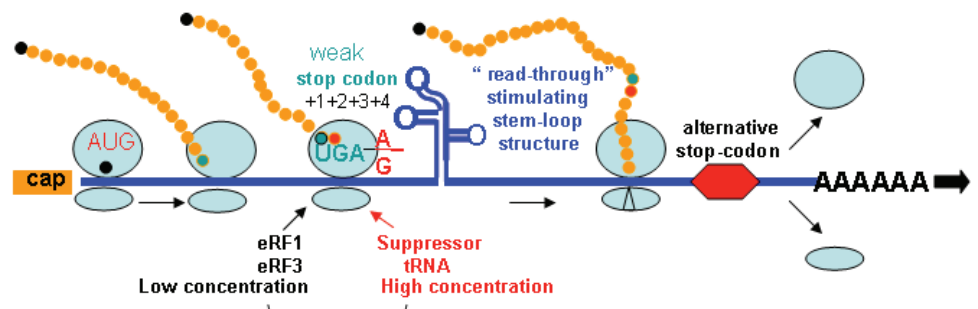

competition

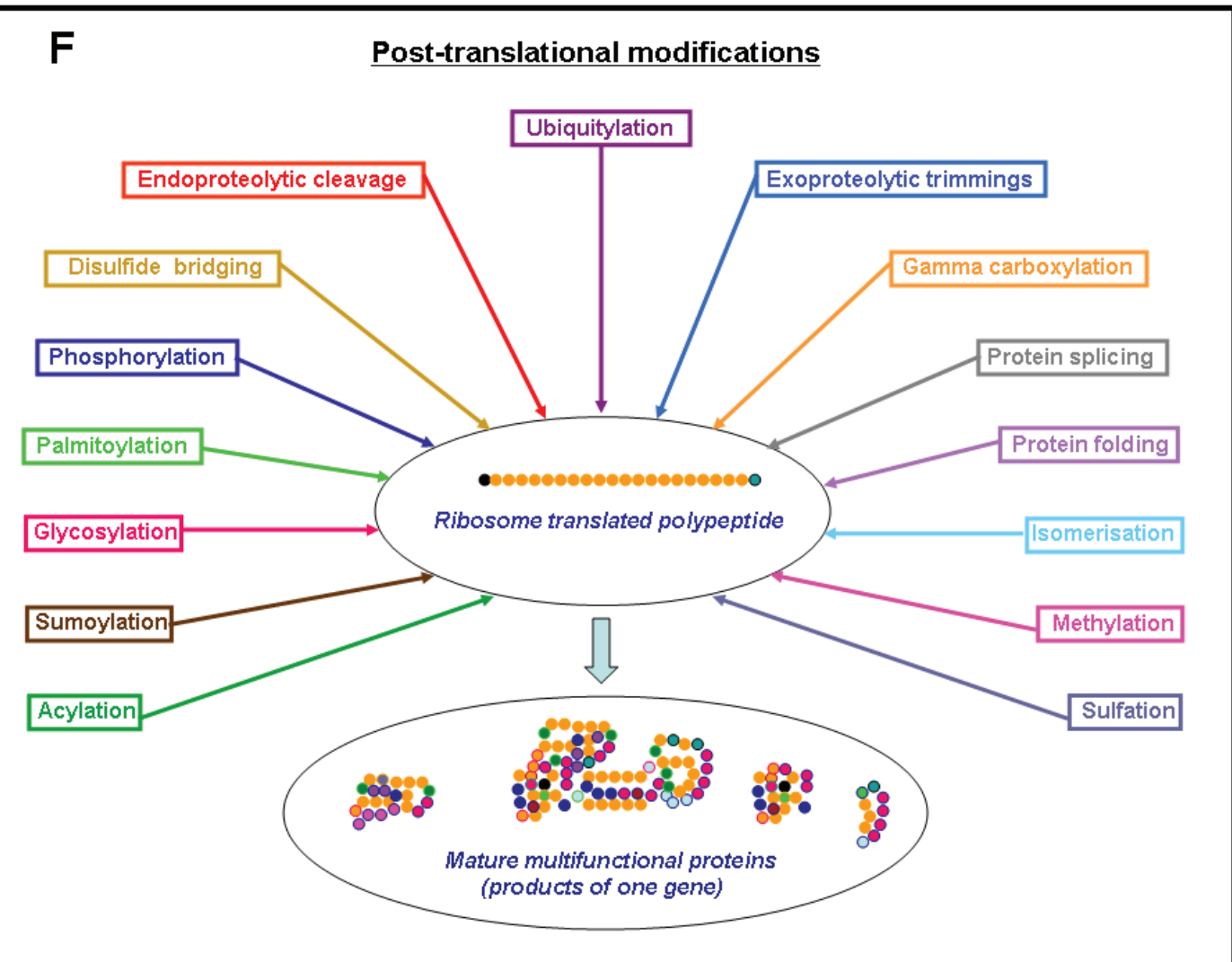

Figure 1. Mechanisms involved in development of protein multifunctionality. Mechanisms operating at genome (A), transcriptome (B), proteome (C-E) and post-translational $(\mathbf{F})$ levels. 
world may illustrate this idea. Owing to the small size of their genome, viruses have evoleved by packing a maximum of genetic information in a minimum of polypeptide sequence. As a consequence, many of the proteins or protein domains encoded by viruses are multifunctional. The transmembrane (TM) domains of Hepatitis C Virus envelope glycoprotein are extreme examples of such multifunctionality. Indeed, these TM domains bear ER retention signals, demonstrate signal function and are involved in E1:E2 heterodimerization (Cocquerel et al. 1999; Cocquerel et al. 1998; Cocquerel et al. 2000). All these functions are partially overlapped and present in the sequence of $<30$ amino acids thus evidently demonstrating the principle of structure/functional compactness reflected in protein structure as well as in its functional map (Cocquerel et al. 2002).

\section{Hierarchical nature of protein architecture} For better understanding ability of a protein to develope multiple functions and to discover potentials hidden in protein molecule, one should get insight the hierarchical nature of protein architecture. As pointed out by A. Lesk, several hierarhial levels of structural complexity can be observed in protein molecules (Lesk, 2001):

1. The first level is the sequence of amino acids in a polypeptide (primary structure).

2. The assignment of $\alpha$-helices and $\beta$-sheets is the hydrogen-bonding pattern of the main polypeptide chain (secondary structure). This is the second level of complexity. Many proteins demonstrate recurrent patterns of interaction between helices and sheets present in one polypeptide molecule. These interactions form supersecondary structure.

3. The most of the protein molecules contain compact units within the folding patterns of a single chain, domains, that demonstrate definite structural stability and functional independence. Protein domains can be defined as segmented portions of a polypeptide sequence that assume stable three-dimensional structure (Richardson, 1981; Wriggers et al. 2005). A domain usually fulfills specific function(s). Assembly of domains and intervaining flexible stretches of short peptide chains develops multidomain protein molecule characterized by the tertiary structure (the third level of structural complexity).
4. Within multidomain proteins, each domain is capable of autonomous function, however, some of them also mediate the formation of complexes with partner proteins (intermolecular interactions) giving rise for new functions and forming so called a domain network (Santonico et al. 2005). The multidomain proteins containing more than one polypeptide chain compose the assembly of the monomers that represents the fourth level of complexity - the quaternary structure.

Multidomain proteins containing several copies of closely related domains are so called modular proteins. The modular protein can "mix and match" sets of domains. For example, fibronectin, a large extracellular protein, contains 29 domains including multiple tandem repeats of three types of domains, F1, F2 and F3 (Lesk, 2001). These and many other domains such as EGF, Ig, PZS etc are integral parts of the multiple modular proteins. Such recurring protein motifs, domains, are significant because it is increasingly recognized that "there are only a limited number of domain families in nature" (Wriggers et al. 2005). These domains are duplicated and combined in different ways to form the set of proteins (Apic et al. 2003).

Most of the known proteins are multifunctional molecules. The presence in a protein molecule of several domains that possess different functions indicates on its multifunctionality. At the beginning of the 1990s, K. Mizejewsky proposed the hypothesis of the "modular cassette" (Dauphinee and Mizejewski, 2002; Mizejewski, 1993). According to this hypothesis, the presence of amino acid stretches (domains) in a protein that are similar to those in physiologically active proteins implies that they may have similar functions. This hypothesis allows prediction of functional activities of newly discovered proteins or proteins which function have not yet been well studied. For example, more than 20 types of functionally important sites (domains) have been predicted and later on identified in $\alpha$-fetoprotein (Terentiev and Moldogazieva, 2006). Among these sites, there are sites responsible for binding of hydrophobic ligands (metal ions, estrogens, bilirubin, retinoids, flavonoids, exotoxins, various dyes and drugs (Aoyagi et al. 1979; Aussel and Negrel, 1986; Birkenmeier et al. 1983; Iturralde et al. 1991; Milligan et al. 1998; Nagai et al. 1982; Nishi et al. 1991; Ruiz-Gutierrez 
et al. 2001; Ruoslahti et al. 1979; Tatarinov et al. 1991), sites that demonstrate immunosuppressive activity (Naval et al. 1985; Suzuki et al. 1992; Torres et al. 1992; Torres et al. 1989) and sites that regulate cell proliferation and tumor growth (Allen et al. 1993; Jacobson et al. 1990; Leffert and Sell, 1974; Li et al. 2002; Mizejewski et al. 1983).

It has become clear over the past decade that unrelated modular proteins frequently share significant portions of sequence similarity (Bork et al. 1997; Cesareni, 2004; Pawson and Nash, 2003; Santonico et al. 2005). Thus, a large number of functionally diverse proteins can be thought of as molecules built by combining a limited number of structurally stable folded domains. A good example of such "building bricks" is the $S A M$ domains. The SMART database identifies more than 1300 SAMcontaining proteins in genomes of all organisms from yeast to humans. They present in such different proteins as protein-kinases, lipid-kinases, scaffolding proteins, RNA-binding proteins and transcription factors. Although SAM domains adopt similar folds, they are remarkably versatile in their binding properties. Some identical SAM domains can interact with each other to form homodimers or polymers. In other cases, $S A M$ domains can bind to other related $S A M$ domains, to non-SAM domaincontaining proteins, and even to RNA. Such versatility earns them multiple functional roles in different biological processes such as signal transduction, transcriptional regulation and translational control (Qiao and Bowie, 2005).

Speaking about protein architecture and function, it is important to underline the role which flexible linkers play in interconnection of the various domains in multidomain proteins. These linkers are stretches of amino acid residues that establish communication between different domains and functional modules (Gokhale and Khosla, 2000). A number of examples (e.g. immunoglobulin, diphtheria toxin, tomato bushy stunt virus protein) established a clear relationship between linker peptides and the functional dynamics they enable. Conformational transitions in multiple identical or homologous proteins have been observed. This gained widespread acceptance to the concept of hinge-bending (Dobson, 1990), whereby the relative flexibility of short regions of the polypeptide chain allow significant movement of structural domains.

One important consequence of the flexibility afforded by soft peptide linkers is the ability of linked domains to move to and from close spatial proximity. The flexibility and hydrophilicity of the linker are important factors in preventing the disturbance of the domain functions, thereby imparting stability to the domains (Arai et al. 2004). A range of stability occurs depending on rigidity of the linker peptides. Soft linkers confer flexibility, whereas more rigid peptides may act to keep domains apart (Wilchek and Miron, 1974).

Due to their ability to break or form contacts among adjacent domains, soft linkers often facilitate essential catalytic events in the overall function of a protein, as seen, for instance, in the tomato bushy stunt virus proteins (Harrison, 1981) or in the NFKB (Henkel et al. 1992). The hinge region of the NFKB is flexible enough to bring "p50" and "SW16/ANK" repeat domains into contact to regulate intracellular transport of the transcription factor (Henkel et al. 1992).

The classical example of the flexible linker power to produce large number of diverse functional interactions using limited number of structural domains is calmodulin. Calmodulin contains four $\mathrm{Ca}^{2+}$-binding domains known as the EF-hand with highly conserved amino acid sequences in all eukaryotes (Ikura and Ames, 2006; Kretsinger and Nockolds, 1973). Calmodulin regulates numerous target proteins that are functionally and structurally diverse. It activates cyclic nucleotide phosphodiesterase (Cheung, 1970; Gopinath and Vincenzi, 1977; Kakiuchi and Yamazaki, 1970), $\mathrm{Ca}^{2+}$. transpotring ATPase (Gopinath and Vincenzi, 1977; Jarrett and Penniston, 1977), phosphorylase kinase (Cohen et al. 1978), nitric oxide synthetase (Stuehr et al. 1991) and many others. The list of known calmodulin dependent proteins exceeds 300 in number (Yap et al. 2000).

How calmodulin could bind and regulate all these different proteins? The structure determined for calmodulin in the complex with a target protein by NMR showed remarkable conformational change in calmodulin's two EF-hand domains upon binding to the target protein (Ikura et al. 1992; Meador et al. 1992; Yap et al. 2000). This structure revealed that central domain linker is magically flexible and can be bent dramatically upon binding to the target protein (Barbato et al. 1992; Persechini and Kretsinger, 1988; Trewhella, 1992). The flexibility of the linker enables calmodulin to change its conformation as needed depending on the structure of target protein. Such conformational plasticity of calmodulin protein allows it to gain 
multifunctionality: by simply connecting two EF-hand modules via a flexible linker, an exponential increase in the number of target interactions is achieved (Ikura and Ames, 2006).

\section{The Basic Mechanisms Ensureing Transformation of Protein Structural Pecularities into Functional Multiplicity}

Protein structural complexity and compactness may be achieved by different mechanisms operating at genome, transcriptome and proteome levels (Fig. 1, A-E). Several examples of multifunctional proteins described below may demonstrate how multifunctionality may be developed by these mechanisms.

\section{Genome level}

The main tools in generation of biological diversity at the genome level are mutations (insertion or deletion of nucleotides in DNA sequences), transposition of pieces of DNA and gene duplication followed by genetic divergencies in each duplicated genes. If these changes in genetic information induce changes in protein structure and function, they undergo evolutionary selection and can be traced phylogenically (Fig. 1, A).

\section{Mutations as sources for multifunctionality} The product of the mutated gene can be "either an alternative protein of equivalent function -a neutral mutation- or a protein that carries out the same function but with an altered rate or specificity profile. It can be a protein with an altered function, or a protein that does not function-or even foldat all" (Lesk, 2001). For instance, human adult and foetal haemoglobins differ by substitution of Ser (143ß) for His. Primarily, as a result of this mutation, foetal haemoglobin demonstrates lower affininty than adult homologue for the regulatory ligand diphosphoglycerate. This promotes the transfer of oxygen across the placenta to the foetus (Lesk, 2001).

Another example demonstrates role of minor genetic alterations in induction of fundamental functional changes in the homologous proteins. Haptoglobin is a chymotrypsin homologue. As a result of homologuos gene mutations, it lost proteolytic activity characteristic for chymotrypsin but obtained several other functions: haptoglobin may function as chaperon as well as factor preventing the loss of iron from erythrocytes and as protein mediating immune responses (Lesk, 2001).

\section{Gene duplication as the origin of genetic novelties}

It has been proposed that gene duplication is one of the important step for the origin of genetic novelties (Gu et al. 2002; Ohno, 1970). The following examples can confirm this proposition. GroEL is a $60 \mathrm{Kda}$ heat-shock protein ubiquitous in bacteria. Interestingly, the GroEL in Chlamydiae became duplicated at the origin of the Chlamydiae lineage presenting three distinct molecular chaperones, namely the original protein GroEL1, and its paralogous proteins GroEL2 and GroEL3 (Karunakaran et al. 2003; McNally and Fares, 2007). GroEL protein copies species have diverged functionally after the gene duplication events. The functional divergence has occurred in important functional regions of these proteins. Even though the three Chlamidiae GroEL proteins present substantial amino acid sequence conservation in important regions involved in polypeptide binding when compared to GroEL from the Escherichia coli, significant differences have been spotted in GroEL binding regions and at regions involved in ATP binding and hydrolysis. Most of the amino acid replacements that have affected interaction with protein partners and were responsible for the functional divergence between GroEL paralogs were fixed by adaptive evolution after the groEL gene duplication events (McNally and Fares, 2007).

Stromal interaction molecules (STIMs) represent another example demonstrating the role of gene duplication in functional divergence of homologous proteins. STIMs function as the $\mathrm{Ca}^{2+}$ sensor to detect changes of $\mathrm{Ca}^{2+}$ content in the intracellular stores. STIMs are single-span membrane proteins with unpaired N-terminal EF-hand $\mathrm{Ca}^{2+}$ binding domain critical for $\mathrm{Ca}^{2+}$ sensor function. In addition, STIMs contain an $\mathrm{N}$-terminal sterile $\alpha$ motif (SAM) domain and a C-terminal (cytoplasmic) coiled-coil ERM domain (Liou et al. 2005; Roos et al. 2005; Williams et al. 2001; Zhang et al. 2005). Human STIMs and invertebrate STIM share several functionally important protein domains, but diverge significantly in the C-terminus. 
The phylogeny and sequence analysis revealed early adaptation of the $\mathrm{C}$-terminal divergent domain in Urochordata, before the expantion of STIMs in Vertebrata. STIMs were subsequently subjected to one round of gene duplication as early as in the Euteleostomi lineage in vertebrates, with a second round of fish-specific gene duplication. After duplication, STIM-1 and STIM-2 molecules appeared to have undergone purifying selection. Furthermore, sequence analysis of the EF-hand $\mathrm{Ca}^{2+}$ binding domain and the SAM domain, together with functional studies, identified critical regions/residues likely underlying functional changes and proved evidence for the hypothesis that STIM-1 and STIM-2 might have developed distinct functional properties after gene duplication (Cai, 2007).

\section{Transcriptome level}

Alternative splicing is a common post-transcriptional process in eukaryotic organisms to produce multiple transcript isoforms from a single gene (Black, 2003). Alternative splicing and gene duplication are two sources of proteomic functional diversity (Fig. 1, A, B). According to the "independent model" alternative splicing and gene duplication are two independent mechanisms for increasing the proteomic complexity. Alternatively, the "function-sharing model" claims that some proteomic components can be performed either by alternatively spliced genes or duplicate genes [cited by ( $\mathrm{Su}$ et al. 2006)].

Alternative splicing can generate multiple transcripts encoding proteins with subtle or opposing functional differences that may have profound biological consequences. Recent estimates, based on analyses of expressed sequence tags (ESTs), suggest that the transcripts from $35 \%$ of human genes are alternatively spliced (Hanke et al. 1999; Mironov et al. 1999). However, as pointed out by B. Graveley, "this number is likely to be an underestimate" (Graveley, 2001). First, the human EST collection does not represent all protein coding sequences and for most genes, ESTs cover only a portion of the transcript. Because much of the functionally significant alternative splicing occurs in the coding region of the transcript, many alternative splicing events might be overlooked by EST comparisons. Second, and perhaps more important, many alternative splicing events are very rare and occur only in a specific tissue at a specific time in development and/or under certain physiological conditions. These types of splicing events will probably not be represented in EST collections (Graveley, 2001). Some genes produce several spliced mRNAs while it turns out that some other genes, in fact, encode transcripts that are alternatively spliced to produce tens of thousands of different mRNAs (Schmucker et al. 2000).

The neurexin proteins represent an example which demonstrates the role of alternative splicing in obtaining different functions by one gene products. The neurexins are a family of neural proteins present in vertebrates that have important functions as receptors for neuropeptides (Missler and Sudhof, 1998) and as adhesion molecules that participate in synaptogenesis (Scheiffele et al. 2000). It has been shown that more than 1000 different neurexin mRNA isoforms could potentially be synthesized virtue of alternative promoter usage and alternative splicing (Ullrich et al. 1995). The proteins encoded by these alternative spliced mRNA have altered specificities for their ligands (Ichtchenko et al. 1995; Sugita et al. 1999). Beside that, the diversity of neuroxin proteins might specify neural connectivity (Missler et al. 1998). It has been shown that interaction of $\beta$-neurexins present in pre-synaptic cells with neuroligins on the surface of post-synaptic cells is sufficient to trigger synapse formation (Scheiffele et al. 2000). Importantly, this interaction only occurs if the $\beta$-neurexin is encoded by an mRNA lacking an alternative exon 20. Proteins synthesized from exon 20-containing transcripts do not interact with neuroligins (Ichtchenko et al. 1995). Thus, alternative splicing of the neurexin transcripts might have a direct role in controlling the formation and maintenance of synapses.

\section{Proteome level}

Proteome is a set of proteins obtained by translation of mRNAs exported from nucleus to cytoplasm. Translation of mRNA into protein represents the final step in the gene-expression pathway, which mediates the formation of the proteome from genomic information (Gebauer and Hentze, 2004). As we have already underlined, at the genome level, the maximal volume of genetic information has to be encoded in minimal DNA space. At transcriptome level, the consealed diversity of future proteins encoded in DNA and mRNA is revealed by shuffling of different fragments of the primary transcript during the alternative splicing process. The alternative promoter usage in its turn discloses 
the diversity of genetic information contained in mRNA and destined for translation. At the proteome level, the maximum of structural and functional potentials contained in the genetic information embeded in mRNA can be elicited by translational mechanisms. Recent data obtained by sequencing of the human genome showed that the human genome composed of about 35000 genes which may express about 100000 proteins. Such protein outburst is possible only because numerous mechanisms exist by which functionally diverse polypeptides are produced from a single gene (Touriol et al. 2003).

The ability to produce different polypeptides by translation of one and the same mRNA molecule is installed in the translation mechanism by itself. Conceptually, the translation process can be divided into three stages - initiation, elongation and termination. During initiation the ribosome is reassembled on $\mathrm{mRNA}$, with initiator $\mathrm{tRNA}$ bound in the ribosomal $\mathrm{P}$ site and base paired with the start codon of the mRNA. Elongation refers to the polymerization of the peptide, the main function of the ribosome, while termination includes the sequence of events following recognition of the stop codon up to the disassembly of the ribosome into subunits and subsequent dissociation of the factors, tRNA, and mRNA (Touriol et al. 2003). The mechanisms operating at each stage determine the appearance of different isoforms of one and the same gene product (Fig. 1, C-E).

\section{A. Initiation stage}

\section{Cap-dependent initiation}

Translation initiation of eukaryotic mRNAs in general occurs by a scanning mechanism (Kozak, 2002). According to the linear scanning model, $40 \mathrm{~S}$ ribosomal subunit binds to the cap structure $(\mathrm{m} 7 \mathrm{GpppN})$ at the 5' end of mRNA and scanning downstream to the first in frame AUG initiation codon (Pestova and Hellen, 1999). The canonical scanning mechanisms (Fig. 1, C1) rules initiation of most mRNAs, but three non-classical capdependent initiation mechanisms have been also described: leaky scanning, ribosomal shunting and termination initiation (Lopez-Lastra et al. 2005).

\section{a) Leaky scanning}

It has been shown that the nucleotide context in the vicinity of the start codon is important for its interaction with the ribosome. If the context is not optimal, some ribosomes do not recognize the 5 'end proximal AUG codon as starting, skip it, and begin translation at the next AUG by mechanisms known as "leaky scanning" (Kochetov, 2006; Kozak, 2002). This leaky scanning mechanism (Fig. 1, C2) produces protein isoforms with alternative amino initiation sites. Hence, the genes may produce several versions of the encoded proteins, and the shorter versions, initiated from a downstream in-frame start codons, lack the N-terminal amino acids of the full-length isoform version ( $\mathrm{N}$-terminal truncated version) (Touriol et al. 2003).

Besides additional AUG codons located downstream to the main start codon, many mRNAs contain upstream located AUG (uAUG) which also may be chosen by translational mechanisms for synthesis of new isofunctional protein variants. Kochetov et al. (Kochetov et al. 2005) had analyzed more than 12000 of human mRNAs bearing uAUGs and found that $3 \%$ of mRNAs cantained uAUGs in the same reading frame as the coding sequences without stop codons in between. It means that such mRNAs can code for additional protein variants extended at the $\mathrm{N}$ ends. A comparison of their predicted subcellular locations showed that $31 \%$ of such N-extended proteins had a different location, and in $19 \%$ of the cases they had secretion signals absent from the annotated variants (Kochetov et al. 2005).

As the sequences that determine cell compartment targeting are located usually at the N-terminal region of a protein, the selection of alternative translation initiation codons may be used by cell to control cellular localization of the isoforms (Cai et al. 2006; Gandre et al. 2003; Packham et al. 1997). Cai et al. (Cai et al. 2006) showed that $85.7 \%$ of alternative translation events generated biological diversity, attributed to different subcellular localizations and distinct domain contents in alternative isoforms. Several examples presented below may illustrate how the leaky scanning mechanism is used by a cell for increasing diversity of protein isoforms produced by a single gene.

The Arabidopsis DNA ligase 1 gene (AtLIG1) is indispensable for cell viability. AtLIG1 expresses one major and two minor mRNA transcripts differing only in the length of the 5, untranslated leader sequences preceding a common open reading frame (ORF) (Sunderland et al. 2006). Control of AtLIG1 isoform production and intracellular targeting depends upon mechanisms 
controlling the choice of translation initiation site within the AtLIG1 ORF. Translation of AtLIG1 mRNA transcripts from the first in-frame start codon produces an AtLIG1 isoform that is targeted exclusively to the mitochondria. Translation initiation from the second in-frame start codon produces an AtLIG1 isoform targeted only to the nucleus. The length of the 5'-UTR and more significantly the nucleotide context around alternative start codons in the AtLIG1 transcripts affect translation initiation to ensure a balanced synthesis of both nuclear and mitochondrial AtLIG1 isoforms via a context-dependent leaky ribosome scanning mechanism (Sunderland et al. 2006). Instead of having distinct genes to code the different compartment-specific isoforms of DNA ligase proteins, eukaryotic species from yeast to humans appear utilize an evolutionarily conserved mechanism that relies upon choice of in-frame translation initiation start codons within the ORF of a ligase mRNA transcript to regulate the synthesis of the appropriate DNA ligase isoform destined for the nucleus or mitochondria. As the control of subcellular localization of proteins and their interaction with specific protein partners in vivo are crucial for cell physiology, the importance of the mechanisms controlling production of different forms of protein and their intracellular topology is difficult to overestimate (Sunderland et al. 2006).

Ion channels are composed of membranespanning proteins that allow ions to permeate at high rates. Voltage-gate $\mathrm{K}+(\mathrm{Kv})$ channels are indispensable for the electrical excitability of nerve and muscle fibers (Finol-Urdaneta et al. 2006). The N-terminal region of the Kv channels plays important regulatory roles, including inactivation kinetics, subunits recognition and redox modulation of the currents flowing through those channels. Thus, the differenes among N-terminal regions of $\mathrm{Kv}$ channels can result in important functional differences between molecular forms of Kv channels. The Kv 1.7 channels from mouse heart muscle are encoded by Kcna 7 gene. Its mRNA transcript has two putative translation initiation start sites that generate two channel isoforms, mKv1.7L (489 aa) and mKv1.7S (457 aa), with different electrophysiological characteristics. The presence of both of these isoforms is very important for normal functioning myocard as absence of one of them leads to different types of heart pathology (Finol-Urdaneta et al. 2006).
Insulin-degrading enzyme (IDE) is expressed in both insulin-sensitive and insulin-insensitive tissues. Within the cell, IDE is targeted predominantly to cytoplasm, however, in some cells it presents also in several subcellular compartments. The mechanisms responsible for the targeting of IDE to different cell compartments are not well understood. Studing this issue, Leissring et al. (Leissring et al. 2004) showed that alternative translation beginning at an in-frame initiation codon located upstream of the canonical start site generates earlier nonrecognized isoform of insulindegrading enzyme that in contrast to cytoplasm locating isoform is targeted to mitochondria. This example shows that $\mathrm{N}$-terminal extension achieved by usage of alterantive initiation codon can produce new protein isoform possessing new function.

These and many other examples (Porras et al. 2006; Sass et al. 2001) demonstrate the power of leaky scanning mechanisms in generating multiple functionally different protein isoforms from single mRNA transcript.

\section{b) Ribosome-shunting}

The next translation mechanism that also makes impact in diversity of protein product coding for by a single gene is ribosome shunting. The scanning model postulates that when a scanning 40S ribosomal subunit encounters a hairpin loop in the 5' UTR, it does not skip over the loop but unwinds it (Kozak, 1980; Lopez-Lastra et al. 2005). Nevertheless, there are some cases when a scanning $40 \mathrm{~S}$ ribosomal subunit encounters the structures present in the 5'UTR and skips or shunts over a large segment, bypassing intervening segments including AUG codons and strong secondary structures that normally would block the scanning process (Fig. 1, C3). The selective translation initiation in adenovirus-infected cells under heat shock is an example of ribosome jumping mechanism (Yueh and Schneider, 1996).

\section{c) Termination-initiation}

The third non-classical cap-dependent initiation mechanism, as it has already mentioned above, is termination-initiation. In the reinitiation mechanism, a second ORF located in the same mRNAs can be translated without the $40 \mathrm{~S}$ ribosome subunit becoming disengaged from the mRNA after reaching the first ORF stop codon (Fig. 1, C4). Strictly speaking this mechanism is more related to the 
elongation stage than to initiation one although the continuation of translation needs the reinitiation step at a downstream AUG triplet.

The exploration of the termination reinitiation mechanism for regulation of protein translation is observed in different cells and viruses. For example, stress-induced eIF $2 \alpha$ phosphorylation increases translation of ATF4, an activator of the integrated stress response (ISR) program, by reinitiation mechanism (Lu et al. 2004). The ATF4 mRNA has two conserved upstream ORF (uORF), uORF1 and uORF2. Scanning ribosomes initiate translation at both uORFs. After translation of the $\mathrm{UORF}$, the scanning ribosome efficiently reinitiate translation at downstream AUGs. In unstressed cells, low levels of eIF $2 \alpha$ phosphorylation favor early capacitation of such reinitiating ribosomes directing them to the inhibitory uORF2, which precludes subsequent translation of ATF4 and repress ISR. In stressed cells high levels of eIF2 $\alpha$ phosphorylation delays ribosome capacitation and favors reinitiation at ATF4 over the inhibitory uORF2 (Lu et al. 2004). Analogous mechanism operates in regulated translation of Gsn 4 protein in yeast (Hinnebusch and Natarajan, 2002).

Translation of human hepatitis virus polymerase is another example demonstrating involvement of different translation mechanisms participating in expression of the polycistronic mRNA. The human hepatitis B virus (HBV) has a compact genome encoding four major overlapping coding regions: the core, polymerase, surface and X. The polymerase initiation codon is preceded by the partially overlapping core and four or more upstream initiation codons. Several mechanisms are used to enable the synthesis of the polymerase protein, including leaky scanning and ribosome reinitiation. Chen et al. (Chen et al. 2005a) showed that core upstream open reading frame (CO uORF), highly conserved in all HBV subtypes, played an inhibitory role in downstream expression from the core initiation site, but also stimulated reinitiation at the polymerase start when in an optimal context. Thus, the CO uORF is a determinant in balancing the synthesis of the core and polymerase proteins.

\section{Cap-independent IRES-determined initiation}

The described examples demonstrate the possibilities of cap-dependent initiation mechanisms to generate multiple protein isoforms possessing new functions. However, the possibilities of translation process to increase and diversify the potentials embedded in mRNA are not restricted only to capdependent mechanisms as cap-independent translation mechanisms operate also in cells. Cap-independent translation (Fig. 1, C5) is mediated by internal ribosome entry sites, IRES (Holcik et al. 2000). These are usually comprised of structured regions in the 5' untranslated region and were initially identified in viruses, but have since been reported in eukaryotic mRNAs and are believed to constitute a major form of regulation of protein synthesis in mammalian cells (Candeias et al. 2006; Holcik et al. 2000). As a rule, there are no significant structural similarities between individual IRES. At present, IRESs are defined solely by functional criteria and cannot yet be predicted by the presence of characteristic RNA sequences or structural motifs (Lopez-Lastra et al. 2005). Examination of the available RNA structure prediction software and RNA motif searching programs indicates that while these programs are useful tools to fine tune the empirically determined RNA secondary structure, the accuracy of de novo secondary structure prediction of large RNA molecules and subsequent identification of new IRES elements by computational approaches, is still not possible (Baird et al. 2006).

\section{a) Mix (or alternative) initiation}

It is important that, although capped, some cellular mRNAs - including those encoding translation initiation factors, transcription factors, oncogenes, growth factors, homeotic gene products and survival proteins-contain also IRES elements in their 5'UTR sequences that may allow them to be translated under conditions when cap-dependent synthesis of proteins is impaired (Lopez-Lastra et al. 2005). Moreover, in some cases mRNA molecule contains both cap-dependent start codon and IRES element and upon different cell conditions may direct synthesis of different isoforms of a single protein by using cap-dependent or IRES-mediated translation mechanisms (Fig. 1, C6). For instance, expression of two p53 isoforms, full length (FLp53) and N-terminal truncated (p53/47), is controlled by alternative cap-dependent and IRES-mediated mechanisms of initiation govern the translation of the p53 mRNA (Candeias et al. 2006). In contrast to FLp53, the p53/47 isoform does not harbour the most of $\mathrm{N}$-terminal p53 transactivating domain 
(aa 1-40) nor the Mdm2-binding site (aa 17-23) demonstrating different functional parameters. The p53/47 may form complexes with FLp53 thus changing its stability and ability to induce activation of other p53-dependent genes. Changes in synthesis of FLp53 or p53/47 are regulated through distinct cell stress-induced pathways acting through separate regions of the p53 mRNA. The functional differences of two isoforms are manifested also in that that some cytotoxic agents require the presence of FLp53 to induce apoptosis, whereas for others p53/47 is sufficient. This indicates that by harbouring alternative translation initiation sites, the p53 mRNA gives rise to different levels of the p53 isoforms which help to orchestrate the cell biological outcome of $\mathrm{p} 53$ activation in response to different types of cell stress (Candeias et al. 2006).

Another example showing the role of alternative translation initiation in synthesis of protein isoforms possessing different functions is vascular endothelial growth factor (VEGF). The unusually long (1038 nucleotides) and structured 5' untranslated region (UTR) of VEGF mRNA contains two independent IRES (IRES A and IRES B). In the human sequence, four potential CUG translation initiation codons are located in between these IRES and are in frame with the classical AUG start codon. The VEGF IRES A located within 300 nucleotides upstream from the AUG codon directs a cap-independent translation initiation, which has been shown to allow VEGF synthesis in hypoxic conditions (Huez et al. 1998; Sass et al. 2001; Stein et al. 1998). It has been shown that IRES B located in the first half of the 5'UTR between nucleotides 379 and 483 controls the translation initiation of new VEGF isoform (L-VEGF) which is N-terminal extended by 206 amino acids in comparison to the classical AUG-initiated form. Translational initiation of this isoform occurs at the first of CUG codons. Different functions of two VEGF isoforms can be evidenced by different targeting of AUGand CUD-initiated isoforms: while the classical AUG-initiated VEGF isoform is a secreted protien, the CUG-initiated L-VEGF isoform demonstrates intracellular targeting. Besides that the L-VEGF undergoes post-translational partial cleavage into two fragments, namely a 206-a.a. N-terminal fragment that after cleavage remains in cell and a C-terminal fragment that is equeal to the AUGinitiated isoform by size and by ability to be secreted out of the cell (Huez et al. 2001).

\section{B. Elongation stage}

Thus, at the initiation stage of translation process the translation apparatus has numerous possibilities for material (molecular) realization of the information potentials consealed in mRNA. At the elongation stage other mechanisms may also make their impact in structural and functional diversity of synthesized protein isoforms. In contrast to the initiation and termination stages of translation, the machinery used during the course of translational elongation has been highly conserved and less variable across the three kingdom of life (Kapp and Lorsch, 2004). As noted by Namy et al. (Namy et al. 2004), the main mechanisms by which translation machinery may uncover the hidden genetic information at the elongation stage are the frameshifting (Fig. 1, D2) and to a less degree-hopping (Fig. 1, D3).

\section{Frameshifting}

Prediction the protein(s) encoded by a given DNA is difficult because of the lack of knowledge of the signals embedded in the genome that are involved in the translation of the genetic information. It has been shown that in many genes the standart rules of decoding postulated by the dogma of the universal genetic code are subverted by "recoding" signals found in DNA that promote alternative decoding events like programmed ribosomal frameshifting, hopping, or termination codon reassignment (Atkins et al. 2001; Gesteland and Atkins, 1996; Gesteland et al. 1992).

As noted by Namy et al. (Namy et al. 2004) "natural frameshift errors occur very reraly, but programmed ribosomal frameshifting signals increase the probability of tRNA slippage enormously, occasionally to such an extent that up to $50 \%$ of ribosomes change frame". Analysis of the frameshifting mechanisms is beyond this review scope. They were critically studied and described in several excellent publications (Atkins et al. 2001; Brierley and Pennell, 2001; Plant et al. 2003; Stahl et al. 2001). In principle, frameshifting is triggered by two elements - a slippery and stimulator sequences. A slippery sequence is the mRNA region where tRNA movement or misalignment is favored while a stimulator is the mRNA sequence that ehhances framshifting by induction of a ribosomal pause (Namy et al. 2004).

Different kinds of frameshifting were described both in prokaryotes and eukaryotes. For example, 
programmed frameshifting was observed in translation of the prokaryotic DNA polymerase III, $\alpha$-fucosidase and release factor 2 (RF2) as well as eukaryotic proteins such as antizyme-1 (AZ1), IL-10, ABP140 etc [cited by (Namy et al. 2004)]. The biological expediency and functions of such frameshifting are different in each case however it is always warranted. For instance, in the case of RF2 the recoding frameshift represents an autoregulatory mechanism controling the abundance of RF2. At high RF2 levels, the competition between termination and frameshifting is shifted in favor of termination, leading to a decrease of the RF2 concentration in the cell. When level of RF2 begins to decrease, frameshifting begins to predominate, raising the level of RF2 (Adamski et al. 1993).

The antizyme-1 (AZ1) is another well studied example of a protein which full length expression is regulated by programmed frameshifting. AZ1 is a protein that negatively regulates polyamine synthesis by inhibiting the key synthetic enzyme ornithine decarboxylase and targeting it for degradation by the $26 \mathrm{~S}$ proteasome (Heller et al. 1976; Murakami et al. 1992). Like RF2, the AZ1 full length protein expression depends on frameshifting which in its turn is linked to a feedback mechanism which regulates polyamine levels in mammalian cells. For AZ1, when cellular polyamine levels are low, the polypeptide corresponding to amino acid residues $1-68$ is produced and translation is terminated at the following UGA stop codon (Matsufuji et al. 1995). When cellular polyamine levels are high, +1 frameshifting occurs after the 68 th codon resulting in the full-length antizyme protein containing 227 amino acid residues (1-227 a.a.) (Ichiba et al. 1994). Frameshifting is employed in the expression of all known antizymes in different species and many other proteins. The concervation of this mechanism throughout evolution highlights a crucial role for frameshifting in the regulation of gene expression.

It should be pointed out that frameshifting determines multifunctionality of AZ1 only partially. Differential usage of alternative initiation sites also makes its impact in this phenomenone. AZ1 mRNA contains two initiation AUG codons separated by 32 codons. Both AUG triplets are utilized as translation start sites (Matsufuji et al. 1995; Rom and Kahana, 1994). It has been shown that N-terminal region of AZ1 contains nuclear export and mitochondrion targeting signals
(Gandre et al. 2003; Gritli-Linde et al. 2001; Murai et al. 2003). Depending on either AUG codon is used for translation, the resulting AZ1 isoform is targeted to nucleus, mitochondria or cytoplasm (Murai et al. 2003). The multifunctionality of antizyme was evidenced not only by targeting of its isoforms to different cell compartments and serving as ornithine decarboxylase inhibitor but also by recent finding that AZ1 functions as positive transcriptional regulator of the atoDAEB operon genes in E.coli (Filippou et al. 2007).

We have described here only two proteins which synthesis are directed by frameshifting. Many other examples in which this mechanism is used for development of protein diversity may be found in very informative review written by Namy et al. (Namy et al. 2004).

\section{Hopping (translational bypassing)}

An unusual frameshift event that also diversifies the protein structures and functions is "hopping" where the transition from frame 0 to another frame occurs by translational bypassing of an extended region of the mRNA sequence rather than by slippage past a single nucleotide, as has been described for most examples of frameshifting. When genetic code has been discovered, its translation seemed to be rigid. However, later on the reading of the genetic text (code) has been found to be quite flexible, and several alternatives in its expression have been described (Groisman and Engelberg-Kulka, 1995).

Translational bypassing joins the information found within two disperate open reading frames into a single polypeptide chain. The underlying mechanism centers on the decoding properties of peptidyl-transfer RNA (tRNA) and involves three stages: take-off, in which the peptidyl-tRNA/ mRNA complex in the P-site of the ribosome dissociates; scanning, at which the peptidyl-tRNA probes the mRNA sliding through the decoding center; and landing, in which the peptidyl-tRNA re-pairs with a codon with which it can form a stable interaction (Fig. 1, D3) (Herr et al. 2000a). The best characterized examples of this phenomenon are T4 gene 60 and plaA gene (the Prevotella loescheii adhesion gene). In T4 gene 60, a complex signals stimulates bypassing of 50 nucleotides between the two open reading frames (Herr et al. $2000 \mathrm{~b}$ ). In plaA, the translation of its mRNA requires bypassing of 29-nt of coding gap (ManchCitron et al. 1999). 
Herr et al. (Herr et al. 2000a) noted that although few examples of genes are known that rely on translational bypassing to couple ORFs, ribosomes appear to have innate capacity for bypassing. This suggests that the strategy of translational bypassing may be more common than presently appreciated.

\section{Termination stage}

Termination of protein synthesis involves the decoding of a stop signal through an interaction between ribosome, $\mathrm{mRNA}$ and release factors $(\mathrm{RF})$ that facilitates the hydrolytic release of the nascent polypeptide chain from the peptidyl-transferase center of the ribosome (Cridge et al. 2006). Stop codons are used to signal the ribosome to terminate the decoding of an mRNA template. Open reading frames within an mRNA are terminated by an inframe any one of three stop or nonsense codons (UAA, UAG or UGA) which are recognized during translation by the binding of RFs to the ribosomal A site (von der Haar and Tuite, 2007; Williams et al. 2004).

\section{Stop codon readthrough}

Translation termination is normaly a highly efficient process. It has been shown that stop codons are normally suppressed at a frequency of only $0.001 \%-0.1 \%$ (Loftfield and Vanderjagt, 1972; Stansfield et al. 1998). Two competing events, termination and stop codon readthrough (or nonsense suppression), can occur when stop codon reaches the A-site of a translating ribosome. Translation termination results in hydrolysis of the final peptidyl-tRNA bond and release of the completed nescent polypeptide. Alternatively, readthrough, in which the stop codon is erroneously decoded by a suppressor or near-cognate t-RNA, results in translation past the stop codon and production of a protein with a C-terminal extention (Fig. 1, E). The relative frequency of termination versus readthrough is determined by parameters such as the upstream and downstream stop codon nucleotide contexts, the activities of termination polypeptide-chain release factors and the abundance of suppressor near-cognate t-RNAs. All these parameters modulate the balance of termination to readthrough reactions in a cell-type-specific manner (Bonetti et al. 1995; Fearon et al. 1994; Janzen and Geballe, 2004; Keeling et al. 2004; Namy et al. 2002). Willams et al. (Williams et al. 2004) underline that "the potential for even short C-terminal extention (peptide tags) to alter the cellular localization or activity of a protein is great. Addition of even a single amino acid could complete a partial targeting signal already present at the $\mathrm{C}$-terminus of a protein. All protein extensions altering targeting could potentially act as genetically dominant, gain of function events. Thus, despite the generally low efficiency of stop codon readthrough events, such events may well have phenotypic consequence for the cell".

There are an increasing number of examples of stop codon readthrough, both in viral and cellular systems, and in many cases this readthrough has physiological consequences for the cell. It is become obviously that different cells and organisms not only accommodate stop codon as a mainstream termination signal, but also used it to provide these cells and organisms flexibility to respond physiologically to various changeable environments (Namy et al. 2002; Steneberg and Samakovlis, 2001; Tate et al. 1999; Yoshinaka et al. 1985). The alternative non-canonical usage of stop codons allows production of several polypeptides from one open reading frame thus increasing structural and functional diversity of one gene products (Doronina and Brown, 2006). The classical illustration to this statement is selenoproteins.

More that 15 animal selenoproteins have been described. Many selenoproteins, such as glutathione peroxidase (Sukenaga et al. 1987), type I iodothyronine 5'-deiodinase (5'DI) (Berry et al. 1991b) and thioredoxin reductase (Gasdaska et al. 1995) are enzymes which catalyze oxido-reduction reaction. All selenoproteins contain selenocysteine (Sec). Selenocysteine incorporation is specified by a UGA codon in the open reading frame of the mRNA that is accompanied by a "selenocysteine insertion sequence" element (SECIS) in the 3' UTR (Berry et al. 1991a; Goto et al. 2001). However, in definite conditions this UGA codon may also serve as a stop codon. The competition between UGA as a stop signal and as the code for the Sec has been observed during expression of the deiodinase gene. Both the termination product $(14 \mathrm{kD})$ and the complete iodinase protein $(28 \mathrm{kD})$ could be detected within cells (McCaughan et al. 1995). The relative amounts of these products could vary with cell type and expression system, reflecting a competition between the two UGA decoding mechanisms (Steneberg and Samakovlis, 2001). 
The selenoprotein P represents even more strong illustration of competition between UGA as a stop codon and UGA as a triplet that specifies Sec-incorporations. Selenoprotein $\mathrm{P}$ is an extracellular glycoprotein that has been suggested to serve in oxidant defense (Burk et al. 1995). Its mRNA contains 10 UGA codons in an open reading frame terminated by a UAA, implying 10 selenocysteines in the primary structure of the protein (Hill et al. 1991). Full-length selenoprotein $P$ and three smaller isoforms that have identical $\mathrm{N}$ termini but different affinity to heparin-Sepharose have been detected in rat plasma (Chittum et al. 1996). By mass spectrometric peptide analysis it was evidenced that the full-length isoform contains predicted amino acid residues, including its $\mathrm{C}$ terminus and all 10 selenocysteines. The shortened isoforms terminated where the second, third and seventh selenocysteines residues were predicted to be (Ma et al. 2002). This suggests that all isoforms arise from the same mRNA and that the UGAs that specify the second, third and sevenths selenocysteines in full-length selenoprotein $\mathrm{P}$ can alternatively serve to terminate translation, producing the shorter isoforms. As Ma et al. (Ma et al. 2002) pointed out, "it remains a theoretical possibility that the shorter isoforms are produced from the full-length protein by proteolysis". However, the protease that could cleave the protein at specific selenocysteine residue is unknown, and this excludes the possibility of proteolytical cleavage of the full-length isoform at the specific Sec-sites.

The Drosophila kelch gene is another example showing that translational control of gene expression may be realized through stop codon suppression and readthrough. It has been demonstrated by Robinson and Cooley (Robinson and Cooley, 1997) that the kelch gene produces a single transcript with a UGA stop codon separating two open reading frames (ORF1 and ORF2). From the transcript, $76 \mathrm{kDa}$ ORF1 and $160 \mathrm{kDa}$ full-length (ORF1+ ORF2) proteins are expressed. The expression of these two proteins is regulated in tissue-specific manner causing the ratio of two isoforms to vary in different tisuues (Robinson and Cooley, 1997).

The important role of "leaky" stop codon and readthrough mechanism for cell physiology can be illustrated also by the yeast $P D E 2$ gene which encodes the high affinity cAMP phophodiesterase. By synthesis the cAMP phosphodiesterase this gene may regulate the intracellular concentration of cAMP and thus protect the cell from extracellular cAMP (Wilson et al. 1993; Wilson and Tatchell, 1988). When the translation of the PDE2 mRNA is terminated at leaky stop codon, the pde2 protein (active phosphodiesterase) is synthesized leading to low level of intracellular cAMP and increased stress sensitivity. On the contrary, when stop codon readthrough mechanism is switched on, the C-terminal extension of 21 amino acids occurs leading to pde 2 protein destabilization which in its turn results in high level of cAMP in the cell and resistance to stress environment (Namy et al. 2002; von der Haar and Tuite, 2007). The $P D E 2$ is thus an example of an individual gene product in Saccharomyces cerevisiae where alterations in stop-codon readthrough are directly linked to phenotypic variations that have crucial consequence for cell physiology.

When physiological roles of canonical termination signals, leaky stop-codons and readthrough mechanisms are discussed, the principle difference between normal function of termination stop codon and abnormal role of premature stop codon(s) which may appear in the mRNA as result of mutations or alternative splicing to cryptic splice sites should be underlined (Frischmeyer and Dietz, 1999; Lewis et al. 2003). The nucleotide context surrounding the classical stop codon is genetically determined and promotes translational termination of the synthesized natural protein. The upstream and downstream contexts of leaky stop signal are also genetically determined for promotion of the readthrough activity which results in appearance of new protein isoform that is necessary for fulfillment of specific physiological function. Thus, the expression of terminated or extended proteins in these cases represents realization of specific steps in the normal cell program. The random appearance of the premature termination codon (PTC), or nonsense codon, in ORF of mRNA is not correlated with the inherited surrounding nucleotide context and therefore cannot be regulated by physiological translation mechanisms (Lewis et al. 2003).

Nonsense codon-bearing transcripts typically encode C-terminally truncated proteins which could possess dominant-negative or deleterious gain-of-function effects. Usually, PTCs trigger the rapid degradation of $m R N A$ by nonsense-mediated mRNA decay (NMD) mechanism that detects and degrades transcripts harboring nonsense codons (Frischmeyer and Dietz, 1999; Wilkinson, 2005). This downregulatory response is an important 
quality-control mechanism. Its function is safeguarding cells from abnormal mRNA function (Behm-Ansmant et al. 2007; Isken and Maquat, 2007). Surprisingly, recent studies strongly evidenced that components of NMD machinery (proteins UPF1, UPF2, UPF3, RNP21, Y14 and $\mathrm{MAGOH}$ ) also promote translation of normal mRNAs in mammalian cells (Nott et al. 2004; Wiegand et al. 2003; Wilkinson, 2005). It has been shown that the function of NMD proteins depends on their location. If located within an ORF, NMD factors stimulate translation and control highfidelity translation termination. If located downstream of an ORF, they elecit RNA decay (Lykke-Andersen et al. 2001; Maderazo et al. 2000; Wang et al. 2001; Wiegand et al. 2003; Wilkinson, 2005). Thus, NMD proteins also demonstrate multifunctionality participating in two oposite processes. On the one hand, by takeing part in NMD, they degrade mRNA and decrease the level of protein synthesis. On the other hand, by binding to mRNA within ORF, they stimulate protein syntesis and even correct naturally occurring mistakes (Wilkinson, 2005).

The described examples not only document the existence of several evolutionary conserved mechanisms of translation destined for production of multiple and functionally different isoforms of one gene product but also show that proteins involved in these mechanisms are multifunctional molecules that simultaneously may participate in opposite processes leading to decreasment and to increasment of protein synthesis. These mechanisms make a substantial impact in transformation of compact genetic information in diverse protein moiety.

\section{Post-translational modifications}

Although the amino acid structure of a protein is defined by the gene and mRNA encoding the protein, its final functional structure is achieved by numerous post-transclational modifications. The majority of all proteins undergo co- and/or post-translational modifications (Rehfeld and Goetze, 2003). Knowledge of these modifications is extremely important, since they may alter physical and chemical properties, conformation distribution, folding, stability, activity, and, consequently, function of the proteins. The protein precursor may undergo a wide variety of proteolytic cleavages, $\mathrm{N}$ - and $\mathrm{C}$-terminal trimmings and amino acid derivatization in cells that express the protein. Occasionally, the same precursor is differently processed in different cell types (Rehfeld and Goetze, 2003). According to Rehfeld and Goetze (Rehfeld and Goetze, 2003) all post-translational modifications may be divided in three groups [Table 1 cit. from (Rehfeld and Goetze, 2003)].

Although this table contains many types of posttranslational modification, it can not be considered as a complete list of possible modification. For example, it does not contain such modification as palmitoylation, ubiquitylation, methylation, protein folding and protein splicing which appear to be a powerful mechanism of protein diversity (Draper et al. 2007; Hanada et al. 2004; Mostaqul Huq et al. 2008; Nagradova, 2004; Perler, 2005; Schartner et al. 2007). The limit of the review volume does not allow discussion of all the possible post-translational modifications depicted in Fig. 1, F. Therefore, we will concentrate just on some of them - phosphorylation, glycosylation, palmitoylation, protein folding and protein splicing.

\section{Protein phosphorylation}

Protein phosphorylation is one of the most widespread type of post-translational modification of protein that allows the cell to control various cellular processes, including signal transduction, transcriptional and translational mechanisms,

Table 1. Post-translational modifications.

\section{Endoproteolytic cleavages: \\ 1. Dibasic sites \\ 2. Monobasic sites \\ 3. Post(poly) Clu/Asp sites \\ 4. Post Phe-sites \\ 5. Tri and tetrabasic sites}

\section{Exoproteolytic trimmings:}

1. Carboxyamidation

2. Glutaminyl cyclation

3. N-terminal dipeptidyl cleavage

\section{Amino acid derivatizations:}

1. Acylations

2. Disulfide bridgings

3. Gamma carboxylation

4. Glycosylations

5. Isomerisatios

6. Phosphorylations

7. Sulfations 
metabolism, growth, division, differentiation, motility, organelle trafficking, membrane transport, immunity, learning and memory (Manning et al. 2002a; Manning et al. 2002b). In eukaryotic cells, most phosphorylation occurs on Ser, Thr and Tyr residues (Ubersax and Ferrell, 2007). The phosphorylation state of phosphoproteins is controlled by the activity of protein kinases and phosphatases (Urner and Sakkas, 2003). According to calculation performed by Ubersax and Ferrell (Ubersax and Ferrell, 2007), a typical protein kinase must recognize between one and a few hundred bona fide phosphorylation sites in a background of about 700,000 potentially phosphorylatable residues in typical eukaryotic cell. Multiple mechanisms have evolved that contribute to this exquisite specificity, including the structure of the catalytic site, local and distant interactions between the kinase and substrate, the formation of complexes with scaffolding and adaptor proteins that spatially regulate the kinase etc (Ubersax and Ferrell, 2007).

Although different kinases demonstrate their individual specificities and peculiarities in phosphorylation processes, the main results of this post-translational modification are structural and functional changes of the substrate protein. Several examples can illustrate this statement.

Many nuclear receptors have been found to be modified by phosphorylation (Rochette-Egly, 2003). Testicular receptor 4 (TR4) is an orphan member of the nuclear receptor superfamily. In the absence of specific ligands the activity of TR 4 can be modulated by mitogen-activated protein kinase (MAPK)-mediated phosphorylation of its AF-1 domain (activation function 1). MAPK-mediated phosphorylation of the AF-1 domain renders TR4 a repressor while dephosphorylation of the AF-1 domain makes TR4 an activator (Huq et al. 2006). Reversible protein phosphorylation, like bidirectional regulation of TR4, is known to control a wide range of biological activities (Chen et al. 2005b; Collins et al. 2004; Kim et al. 2003; Koritschoner et al. 2001; Shyr et al. 2002; Tanabe et al. 2002).

Another example also may show the power of post-translational phosphorylation in determing the protein function. Glucose-mediated phosphorylation converts the transcription factor Rgt1 from a repressor to an activator (Mosley et al. 2003). In the yeast Saccharomyces cerevisiae, glucose induces the expression of the hexose transported /HXT/ genes by modulation the activity of transcription factor Rgt1 that functions as a repressor when glucose is absent. However, in the presence of high concentration of glucose, Rgtl is converted from a repressor to an activator by glucose-mediated phosphorylation. Rgtl activator is required for maximal induction of $H X T 1$ gene expression (Mosley et al. 2003).

Several transcription factors, as well as other proteins, have been shown to change their subcellular localization in response to external stimuli (De Vit et al. 1997; Komeili and O'Shea, 1999). Yeast protein Mig1 is phosphorylated by the Snf1 kinase in the absence of glucose and is trapped in the cytoplasm. High concentrations of glucose cause dephosphorylation of Mig1 and translocation into the nucleus (Komeili and O'Shea, 1999; Treitel et al. 1998). The subcellular localization of the other yeast protein, Pho4, is regulated in response to another agent, phosphate. At high concentrations of phosphate, Pho4 is phosphorylated and exported into cytoplasm, whereas starvation for phosphate causes dephosphorylation of Pho4 and translocation into the nucleus (Komeili and O'Shea, 1999).

These examples clearly demonstrate that definite functional potentials encoded in the primary protein structure by specific topology of Ser, Thr and Tyr residues may be uncovered and realized by specific phosphorylation events.

\section{Glycosylation}

Glycosylation is another widely observed posttranslational modification of proteins. Proteins can be glycosylated on certain amino acid side-chains, and these modifications are designated as $\mathrm{N}$ - and O-glycosylation (Medzihradszky, 2002). $\mathrm{N}$-glycosylated species are modified at Asn residues. O-glycosylation occurs at Ser or Thr-residues. It should be noted that characterization of both types of glycosylation is complicated by the fact that in some cases the same amino acids within a population of protein molecules may be derivatized with an array of different carbohydrate structures while in other cases they may remain unmodified. This site-specific heterogeneity may vary by species, tissue and may be affected by physiological changes (Medzihradszky, 2002). Thus, the same protein may be glycosylated in one type of cells and unmodified in another type of cell and the difference in glycosylation status will be reflected by different functions of a given protein in different 
cells (Bloom et al. 1996; Hironaka et al. 1993). The analogous situation can be observed even in the same cells, however, at different physiological conditions (Nemansky et al. 1998).

The purpose of glycosylation, as any other posttranslational modification, is to uncover functional activities hidden in the protein structure. By adding sugars to polypeptide molecule, glycosylation changes it structure in such a way that new function(s) may occur. For instance, Miranda et al. (Miranda et al. 2007) showed that neutralization properties of the HIV-specific antibody F240 were dramatically altered by glycosylation. This Ab, when produced in a hybridoma, is nonneutralizing. However, F240 IgG1 Ab expressed in CHO cells acquired a strong neutralization activity without a change in immunoreactivity. Sequencing of the F240 mRNA produced in the parental hybridoma and $\mathrm{CHO}$ cells revealed identical sequences, suggesting that acquired neutralization resulted from cell-specific post-translational modifications. Among different types of post-translational modification which the Abs may undergo during their intracellular maturation process, N-linked glycosylation is one of the best characterized. It is widely acknowledged that an $\mathrm{Ab}$ expressed in $\mathrm{CHO}$ cells is differentially glycosylated as compared with an $\mathrm{Ab}$ produced in other mammalian cells (Routier et al. 1997; Sheeley et al. 1997). Miranda et al. (Miranda et al. 2007) showed that the Ab produced by $\mathrm{CHO}$ cells is glycosylated to a greated extent than parental $\mathrm{Ab}$ produced by the hybridoma. It was found that the $\mathrm{F} 240 \mathrm{Ab}$ produced in $\mathrm{CHO}$ cell had significantly more terminal glycans and core fucose when compared with the F240 Ab from hybridoma. Moreover, treatment with peptide N-glycosidase F abrogated F240 neutralization. This study showed that structural changes induced by additional N-glycosylation in the F240 $\mathrm{Ab}$ determined functional changes in its neutralizing activity.

Two other examples show the effect of O-glycosylation on the conformation and biological activities of two other proteins, calcitonin and prion protein. Using different O-glycosylated calcitonin derivatives, each with a single GalNAc residue attached to either Ser or Thr, Tagashira et al. (Tagashira et al. 2001) have demonstrated that calcitonin conformation and its hypocalcemic activity were strongly dependent on O-glycosilation. Moreover, these authors evidenced that effect of glycosylation was clearly site-specific: glycosylation at Thr-6 affected both the structure and activity, at Ser-5 only activity and at Ser 2 none, indicating that the site dependence was very strict. The drastic difference in the hypocalcemic activity observed in this study could be explained by the steric inhibition of the interaction with the receptor (Tagashira et al. 2001).

It has been known for a long time that the structural transition from PrP-c, the normal product of the prion gene, to PrP-sc, the pathological form of the protein, leads to the prion formation and to disease, however, the mechanism of this transition was obscured. Based on prion peptide studies, Chen et al. (Chen et al. 2002) provided evidence for linking of O-glycosylation to the structural transition of PrP-c to PrP-sc. They found that O-linked $\alpha$-GalNAc at Ser-135 suppressed the development of the amyloid fibril formation of the prion peptide at physiological salt concentration, whereas the peptide with the same sugar but at different location, at Ser-132, showed the opposite effect. Moreover, this effect was sugar specific: replacing $\alpha$-GalNAc with $\beta$-GalNac did not yield the same effect (Chen et al. 2002).

As we have alredy noted, many types of posttranslational protein modifications have been described (Rehfeld and Goetze, 2003). They all are directed to modify structure of the parental polypeptide chain thus increasing number of protein's functions. It is apriori obviously, that for achieveing maximal functional variability and adaptivity to environment by post-translational modification, the compact polypeptide structure must contain sites that might be sensitive to different type of modification. Moreover, the same site could be sensitive to different modifying reactions, so the different modifying agents could compete for these sites (competitive modification). The correctness of such suggestion was confirmed by the discovery that phosphorylation and glycosylation may compete for and modify the same amino acid residues in targeted proteins (Kelly et al. 1993).

The O-linked $\beta$-N-acetylglucosamine (O-GlcNAc) is a monosaccharide modification abundant on serine and threonine residues of a multitude of nucleo-cytoplasmic proteins in virtually all higher eukaryotes, including plants and fungi (Comer and Hart, 2000; Hart, 1997; Hart et al. 2007; Torres and Hart, 1984; Wells and Hart, 2003). The attachment and removal of O-GlcNAc by O-GlcNAc-transferase and O-GlcNAcase, respectively, is rapid reactions analogous to 
dynamics of O-phosphate adding or removing controlled by kinases and phosphatases (Dong and Hart, 1994; Haltiwanger et al. 1992; Haltiwanger et al. 1990; Krebs, 1993; Kreppel et al. 1997; Kreppel and Hart, 1999; Lubas et al. 1997). It has been shown that O-GlcNAc sites resemble phosphorylation sites, and in many cases the two modifications are mutually exclusive (Kelly et al. 1993). Reversible phosphorylation and alternative glycosylation induce changes in secondary and tertiary structures and control the functional behaviour and modular interactions of proteins (Ahmad et al. 2007; Cheng and Hart, 2001; Pawson and Gish, 1992). For example, in case of estrogen receptor $\beta$ (Cheng et al. 2000), SV-40 large T antigen (Medina et al. 1998) and the c-Myc oncogen (Chou et al. 1995a; Chou et al. 1995b), O-GlcNAc and O-phosphate compete for the same hydroxyl moiety. Like phosphorylation, O-GlcNAcylation is responsive to the cell cycle, extracellular signals, glucose metabolism, cell growth and regulation of transcription and translation (Chou and Omary, 1994; Datta et al. 1989; Du et al. 2000; Han et al. 2000; Kearse and Hart, 1991; Roos et al. 1997; Roquemore et al. 1996).

The examples described above show once again that primary protein has many possibilities to be modified. What type of modification it will undergo depends on many factors such as cell type, cell cycle, extracellular and intracellular signals, $\mathrm{pH}$ gradient, local concentrations of specific modifying molecules etc. As a result, the protein will possess a specific function in an appropriate cell, at definite cell compartment and at the precise time.

\section{Protein palmitoylation}

The next type of protein modification that we would like to discuss is S-palmitoylation. A major mechanism by which cells regulate the subcellular localization of proteins is post-translational lipidation (Draper et al. 2007). S-palmitoylation is one of lipid modifications that is reversible thioester linkage of palmitate, a 16 carbon saturated fatty acid, to cystein residues (S-palmitoylation) catalyzed by membranebound palmitoyl-transferases (PATs). Palmitoylation increases the hydrofobicity of the modefied molecules (Greaves and Chamberlain, 2007).

It is apriori obviously, that simultaneous display of the principles of structural compactness with maximal functional variability demands that sites on the polypeptide molecule that may undergo different types of modification should be overlapped or even be the same, and different modifying agents should compete for these sites of proteins by altering their conformation. The changes in structure of proteins promotes their localization to specific cellular compartments, contributes to their membrane association and control protein-protein interactions. They also regulate subcellular trafficking of proteins between membrane organelles and within microdomains of the same membrane compartments and modulate their functions (Bijlmakers and Marsh, 2003; Casey and Seabra, 1996; Dunphy and Linder, 1998; el-Husseini Ael and Bredt, 2002; Milligan et al. 1995; Nadolski and Linder, 2007; Resh, 1999; Silvius, 2002).

For many palmitoylated proteins, the half life of the palmitate moieties is significantly shorter than that of the substrate proteins, indicating that the complex goes through cycles of depalmitoylation and repalmitoylation. The reversibility of palmitoylation suggests that it is a regulated modification much like protein phosphorylation. Depalmitoylation and repalmitoylation could provide a mechanism to regulate such processes as binding cytosolic proteins to membranes, segregating proteins to microdomains and mediating protein-protein interaction. For proteins involved in signal transduction, these cycles could be induced by activation and by controlling access to specific substrates (Bijlmakers and Marsh, 2003; Casey and Seabra, 1996; Dunphy and Linder, 1998; el-Husseini Ael and Bredt, 2002; Milligan et al. 1995; Nadolski and Linder, 2007; Resh, 1999; Silvius, 2002). Palmitate cycling on the scaffolding protein PSD-95 may illustrate this mechanism. Palmitoylation allows PSD-95 to cluster in the postsynaptic membrane. Blocking of PSD-95 palmitoylation leads to a loss of AMPA receptors from these domains by the rapid endocytosis of AMPA receptors which requires depalmitoylation of PSD-95 (el-Husseini Ael and Bredt, 2002; Nadolski and Linder, 2007).

Several other examples can additionally illustrate the roles of palmitoylation in protein functioning. It has been shown that palmitoylation controles the regulator of G-protein signaling (RGS). Palmitoylation of the Cys residue in the RGS box is essential for RGS16 GAP activity and their ability to regulate G-coupled signaling in mammalian cells. Enzymatic palmitoylation of RGS16 results in internal palmitoylation on residue Cys-98. 
Mutation of this residue to alanine reduces GAP activity of the 5-HT-1A/G $\alpha$ fusion protein (Osterhout et al. 2003).

S-palmitoylation, as shown by study of Marino et al. (Marino et al. 2006), can modulate estrogen receptor $\alpha(E R \alpha)$ localization and functions. In cells expressing wild-type of $E R \alpha$, a major population of estrogen receptor was membrane-associated whereas in cells expressing the ER $\alpha$ Cys447->Ala mutant no membrane-bound receptor has been detected. Moreover, ER $\alpha$ Cys447->Ala mutation does not allow E2-induced proliferative signaling via ERK/MAPK and P13K/AKT pathways in human cancer cells (Acconcia et al. 2005). As a whole, S-palmitoylation allows the extranuclear localization of ER $\alpha$ and promotion downstream of signaling for E2-mediated proliferation (Marino et al. 2006).

S-palmitoylation, like phosphorylation and glycosylation, is important post-translational modification that provides proteins with many important functions and controls cell processes dependent on these functions. Thus, as other posttranslational modifications, palmitoylation fulfills the main principle of protein structural/functional relationship: gaining maximal functional activities by introducing minimal but specific changings in the protein structure.

\section{Protein folding}

The protein architecture opens many ways for proteins to obtain multiple functions. Evolution gives many examples confirming this statement. In some cases, evolution can merge proteins by chaning tertiary to quaternary structure. For instance, five separate enzymes in the bacterium E.coli that catalyse successive steps in the pathway of biosynthesis of aromatic amino acids, correspond to five regions of a single protein in the fungus Aspergillius nidulans (Lesk, 2001).

To become functionally active, a newly synthesized polypeptide chain must fold a unique threedimentional structure. Although experiments in vitro have firmly established that the information on the three-dimentional structure of a protein is genetically determined and contained in its amino acid sequence (Anfinsen, 1973; Dobson and Karplus, 1999; Nagradova, 2004), protein folding in the cell cannot be regarded as occurring spontaneously (Nagradova, 2004). It has become clear that many proteins require assistance to fold in the cell and that this is provided by helper proteins (molecular chaperones) (Bukau and Horwich, 1998; Coyle et al. 1997; Fewell et al. 2001; Gutsche et al. 1999; Hartl and Hayer-Hartl, 2002).

The action of chaperones is based on two different mechanisms. The first mechanism consists of maintaining the polypeptide chain in a state capable of productive folding, which occurs spontaneously after release of unfolded chains into solution. Thus, interaction with the chaperone has no effect on the folding per se (Nagradova, 2004).

The second mechanism is used by chaperons, whose large cylindrical complexes create physically isolated compartments destined for the folding of polypeptides, partially folded or misfolded proteins, which become encapsulated inside the central cavity. Since only one molecule of the substrate protein can fit inside the cavity, its folding takes place under conditions, which completely exclude aggregation (Nagradova, 2004). However, the role of chaperons clearly is not limited to their ability to create isolated compartments where protein can fold spontaneously under condition simulating infinite dilution (the "Anfinsen cage" model) (Ellis and Hartl, 1996). A large body of information accumulated to date supports the notion that chaperons can play an active role in protein folding, accelerating this process and considerably increasing its efficiency (Nagradova, 2004). A special group of helper proteins so called foldases (Balbach, 2000; Wu and Matthews, 2002) and protein disulfide isomerases (Creighton, 2002; Frand et al.2000) assist protein folding by catalyzing the rate-limiting isomerization reactions.

\section{Protein splicing}

A simple view of protein expression is continually challenged by new examples of post-translational processing. These examples include non-ribosomal addition of moieties and proteolytic cleavage of polyprotein as well as excision and rearrangements such as intein-mediated protein splicing, splicing by reverse proteolysis, protein auto-processing and proteasome-mediated peptide ligation (David et al. 2004; Hanada et al. 2004; Noren et al. 2000; Paulus, 2001; Perler, 2005; Perler et al. 1994; Vigneron et al. 2004).

\section{a) Intein-mediated protein splicing}

Inteins are internal segments of precursor proteins that catalyze their ipso excision by an 
intramolecular process called protein splicing, with the concurrent ligation of the two flanking external regions ( $\mathrm{N}$ - and $\mathrm{C}$-exteins) through a native peptide bond (David et al. 2004; Perler, 2005). Inteins are found in proteins of unicellular organisms belonging to all three domains of life Archaea, Bacteria and Eukarya as well as in viral and phage proteins but have not jet been detected in higher organisms such as Vertebrata (Hanada and Yang, 2005). More than 100 inteins are known. Intein host proteins are very diverse, including DNA and RNA polymerases, ribonucleotide reductases, ATPases, proteases, metabolic enzymes, transcription and translation factors (Pietrokovski, 2001). The following properties differentiate intein-mediated protein splicing from other types of protein rearrangements: (a) intein signature sequence, (b) a self-catalytic reaction in the absence of exogenous proteins, cofactors or energy sources, and (c) the formation of a native peptide bond between the ligated exteins (Perler, 2005).

Inteins can be divided into four classes: the maxi inteins (with integrated endonuclease domain), mini inteins (lacking the endonuclease domain), trans-splicing inteins (where the splicing junctions are not covalently linked) and Ala inteins (Ala as the $\mathrm{N}$-terminal amino acid) (Evans and $\mathrm{Xu}, 2002$ ). The intein specific sequences have some characteristics in common. They appear in conserved regions of the host protein. All intein sequences harbor different blocks termed $\mathrm{A}$ and $\mathrm{B}$ at the $\mathrm{N}$-terminal splicing domain and $\mathrm{F}$ and $\mathrm{G}$ at the C-terminal splicing domain.

Inteins typically have N-terminal Cys, Ser or Ala residues and $\mathrm{C}$-terminal His or Asn and inserted into host proteins next to Cys, Ser or Tre (Hanada et al. 2004). Although amino acids indicated above are typical for inteins, many inteins have other amino acids at specific blocks. It is likely that each intein has specific combination of nucleophiles and assisting groups honed during evolution for optimal function. Structural studies have not identified more consensus facilitating residues because each intein has different residues with similar chemical functionalities at or near its active site (Perler, 2005). The smallest known intein consists of 134 amino acids (Evans et al. 1999), and most are much larger.

The role of inteins in the cell is as yet unclear, however, one can assume that because inteins are integrated in highly conserved protein regions, the function(s) of host protein before and after excision of intein might be different. If intein has to excise itself for activation the host protein function, it has to be sensitive to specific signals. There are some indications that this is the case (Chong et al. 1998; Southworth et al. 1999). It has been established that intein regulates activity of Synechocystis sp.PCC6803 DnaE functioning as internal regulator (Ghosh et al. 2001). Free inteins (after splicing) may perform regulatory as well as enzymatic function by itself (Klabunde et al. 1998; Starokadomskyy, 2007). Thus, although it has been evidenced only in limited number of proteins, inteins may determine different functions of host protein before and after splicing and to obtain new function(s) after self-excision.

b) Post-translational splicing by reverse proteolysis Another example of post-translational modification, protein splicing by reverse proteolysis, is a protein splicing discovered in plants. It was observed with the lectin concanavalin A (Con A) (Carrington et al. 1985). The following steps of this kind of protein splicing were described. The initial precursor of Con A (glyco-pro-Con A) is first activated by deglycosylation to pro-Con A. Pro-Con A is then cleaved to produce two distinct proteins that are transposed and relegated to become mature Con A. Although the exact mechanism of this splicing in plants is still not clear, in vitro study showed that asparaginyl endopeptidase can digest Con $\mathrm{A}$ and then re-ligate the digested fragments by its reverse proteolytic activity (Min and Jones, 1994).

\section{c) Proteasome-mediated protein splicing}

Recently it has been shown that proteasomes are cell compartments where not only protein degradation but also post-translational protein modifications occur (Hanada and Yang, 2005; Hanada et al. 2004; Vigneron et al. 2004). Hanada et al. (Hanada et al. 2004) discovered that antigen maturation and presentation may be performed in proteasome by protein splicing involving peptide excision and re-ligation. They showed that in contrast to intein splicing that usually excised polypeptide of not less than 134 amino acids in length (the smallest known intein is consist of 134 amino acids) the excised polypeptides in their system were as short as 18-40 amino acids. Using the proteasome inhibitor, clasto-lactacystin $\beta$-lactone, the authors 
evidenced that FGF-5 protein splicing observed in their system was proteasome-mediated (Hanada and Yang, 2005). Moreover, these authors showed for the first time that protein splicing may occur in human cells.

Another group also described an antigen production from a protein by splicing of noncontiguous peptides in the reverse order (Vigneron et al. 2004). This splicing was conducted by 20 S proteasome in vitro and in vivo. In the described systems the length of excised intervening region was only four amino acids (Noren et al. 2000; Vigneron et al. 2004). Thus, the proteasome-mediated splicing overcomes the limitation associated with the length of intervening sequences which is crucial for inteinmediated protein modification.

What are the implications of these findings? As Hanada et al. underlined these findings show that "immune system monitors non-contiguous peptide sequence generated post-translationally. This capability represents an enormous increase in the ability of CTLs to recognize self and forein proteins... In a broder context, the existence of protein splicing in vertebrates greatly increases the cell's options for converting genetic information into proteins" (Hanada et al. 2004). These results also show that protein splicing is a powerful mechanism allowing realization of the main principle of protein multifunctionalitytransformation of compact genetic information into wide diversity of protein structures and functions. "Processes such as DNA recombination and RNA splicing were already known to increase the number of different proteins produced by each of mammalian genes; the discovery of protein splicing adds to the tool kit" (Rammensee, 2004).

\section{Multifunctionality as Intrinsic Feature of Different Types of Proteins}

In the previous section we have described some of the mechanisms by which the Nature developes multifunctionality of the protein molecules. Below, we present examples of proteins belonging to different groups that demonstrate high extent of multifunctionality.

\section{Amino-acyl tRNA synthetases}

Amino-acyl tRNA synthetases, an ancient conserved family of proteins well known for its participation in protein synthesis, are a good paradigm of protein multifunctionality. Several studies have described numerous examples of these "housekeeping" proteins taking part in extensive critical cellular activities other than protein synthesis. These are cellular fidelity, cytokine-like activity, angiogenesis, RNA splicing, RNA trafficking, apoptosis, transcriptional and translational regulation. Amino-acyl tRNA synthetases can even block protein synthesis as established by the recent studies performed with glutamyl-prolyl-tRNA synthetase (Glu-ProRS) (Otani et al. 2002; Sampath et al. 2004; Wakasugi and Schimmel, 1999).

The lysil-tRNA synthetase (LysRS) has been shown to have a dual functionality. In addition to its contribution to the translation process, LysRS also function as a positive regulator of MITF and USF2 transcription factors via the synthesis of Ap4A (Lee et al. 2004; Lee and Razin, 2005; Plateau and Blanquet, 1982; Yannay-Cohen and Razin, 2006; Zamecnik et al. 1966).

Tyrosyl-tRNA synthetase and tryptophaniltRNA synthetase upon their release in intracellular environment become proinflammatory cytokines with multiple activities during apoptosis, angiogenesis and inflammation. In addition, these proteins play important role in cancer progression, modulation tumor angiogenesis and its escape from surveillance by immune system (Ivakhno and Kornelyuk, 2004).

\section{Cell-surface receptors}

\section{a) MUC1 protein}

The MUC1 is a mucin-like type I transmembrane glycoprotein normally expressed on the surface of epithelial, hematopoetic and some other cells (Baruch et al. 1997; Weiss et al. 1991; Zaretsky et al. 1990). It is generally accepted that MUC1 gene is transcriptionaly regulated (Zaretsky et al. 2006; Zaretsky et al. 1999). It is transcribed as a single pre-mRNA followed by alternative splicing leading to synthesis of isoform specific polypeptide chains. Several MUC1 isoforms, MUC1/TM, $\mathrm{MUC} 1 / \mathrm{X}, \mathrm{MUC1} / \mathrm{Y}, \mathrm{MUC1} / \mathrm{Z}$ and MUC1/SEC, have been identified (Tsarfaty et al. 1990; Williams et al. 1990; Wreschner et al. 1990; Zrihan-Licht et al. 1994). MUC1/TM and MUC1/X are synthesized by translation of alternativly spliced mRNAs as single polypeptides that undergo auto-cleavage while in the endoplasmic reticulum to yield the 
amino-terminal extracellular $\alpha$-subunit, which in case of MUC1/TM contains O-glycosylated tandem repeats of 20 amino acids, and the carboxyl-terminal $\beta$-subunit, containing the membrane anchor (transmembrane domain) and cytoplasmic tail (Altschuler et al. 2000; Hilkens and Buijs, 1988; Kinlough et al. 2004; Ligtenberg et al. 1992; Linsley et al. 1988; Litvinov and Hilkens, 1993; Zrihan-Licht et al. 1994). The resulting subunits remain tightly associated with each other composing the MUC1/TM and MUC1/X isoforms, respectively.

The MUC1/TM and MUC1/X contain the SEA domain which is responsible for the self-cleavage of the precursor protein molecules leading to development of $\alpha$ and $\beta$ subunits. The MUC1/Y isoform also contains SEA domain, however, it lakcs of 18 amino acids present in SEA domain of the $\mathrm{MUC1} / \mathrm{X}$ isoform. In contrast to $\mathrm{MUC1} 1 \mathrm{X}$, the $\mathrm{MUC1} / \mathrm{Y}$ is expressed as a single non-cleaved nascent polypeptide chain (Levitin et al. 2005b; Wreschner et al. 2002).

Translation of the MUC1/Z isoform is associated with frame shifting (Levitin et al. 2005a). The translation initiation of the MUC1 secreted form, MUC1/SEC, begins with the same AUG codon as other MUC1 isoforms, however, its termination stop codon is located in the first intron (Smorodinsky et al. 1996; Wreschner et al. 1990). The described structural peculiarities of MUC1 show its structural diversity which supposes also multiple different functions. Indeed, MUC1/TM, MUC1/X and MUC1/Y are expressed in plasma membrane and suppose to function as membrane receptors which cytoplasmic domains participate in different signal transduction pathways by interaction with the pathway specific transducer molecules (Li et al. 1998; Li et al. 2003a; Li et al. 2001a; Li et al. 2001b; Li et al. 2003b; Ren et al. 2002; Singh and Hollingsworth, 2006; Wen et al. 2003; Wreschner et al. 1994). It has been shown that besides participating in mucin forming layer, MUC1/SEC functions as ligand for MUC1/Y (Baruch et al. 1999). MUC1/ $\mathrm{Z}$ demonstrates structural homology with some cytokins suggesting participation in defense inflammation reactions. Recently, it has been established that Hkr1 and Msb2, the yeast analogs of human transmembrane mucins, are putative osmosensors (Tatebayashi et al. 2007). These results indicate on possible new function of the MUC1.

\section{b) LDL}

The members of the low-density lipoprotein (LDL) receptor family are evolutionary conserved cellsurface receptors produced by mammals and other organisms (Nykjaer and Willnow, 2002). Initially thought to be endocytic receptors that exclusively mediate the uptake of lipoproteins (Goldstein, 2001; Willnow et al. 1994), recent studies in various experimental systems including knockout mice and patients with receptor gene defects uncovered a plethora of additional activities performed by these receptors (Gliemann, 1998; Gotthardt et al. 2000; Herz and Strickland, 2001). The prototype of the gene family is the LDL receptor, an endocytic receptor that mediates cellular uptake of cholesterol-rich lipoproteins. The LDL receptor like other members of this family is built by several functionally different domains which may interact with numerous of cellular proteins. These domains are represented by EGF precursor homology domain, complement-type repeat domain, $O$-linked sugar domain and NPxYmotif. Among other molecules, these domains bind to proteases, protease inhibitors, signaling molecules, heat-shock proteins, vitamin carriers, toxins and antibiotics (Basu et al. 2001; Gliemann, 1998; Herz and Strickland, 2001; Howell and Herz, 2001). These receptors physiscally or functionally interact with other classes of cell-surface proteins such as seventransmembrane-span receptors, ion channels, glycosylphosphatidylinositol (GPI)-anchored proteins and adhesion molecules, thereby acquiring activities not usually observed for endocytic receptors. Binding of ligands not only results in endocytic uptake but also affects many cellular functions, including migration, Ca-influx, transcytosis, protein processing, antigen presentation, signal transduction, synaptic plasticity and cholesterol and vitamin homeostasis (Nykjaer and Willnow, 2002).

\section{Proteases}

Proteases compose one of the biggest groups of proteins. Approximately $2 \%$ of mammalian genes encode proteases (Kaiserman et al. 2006)[179]. Comparative genomics reveals that those involved in immunity and reproduction show the most interspecies diversity and multifunctionality selected during evolution. Granzymes, the cytotoxic serine proteases used by cytotoxic lymphocytes to destroy virus-infected and malignant cells, are the examples of this protein group. 
There are 5 granzyme genes in humans and 10 in mice, and it is suggested that granzymes have evolved through gene duplication. Although high sequence homology and conserved primary cleavage specificity of human and mouse granzymes were observed, they are structurally and functionally divergent (Bell et al. 2003; Kaiserman et al. 2006).

Human granzyme B (GrB) has multiple paralogues in the mouse and rat, suggesting that the roles fulfilled by a single enzyme in humans may be split among several in rodents (Pham et al. 1996; Revell et al. 2005). Although functioning primarily as a cytotoxin, GrB has other roles also. In humans it is found in testis and has been implicated in reproduction (Hirst et al. 2001). It is also involved in extracellular matrix remodeling (Buzza et al. 2005).

\section{Protein kinases}

Numerous protein kinases regulate multiple pathways of signal transduction. For instance, human platelets express at least six protein kinase $\mathrm{C}$ (PKC) isoforms which phosphorylate multiple proteins during platelet activation (Quinton et al. 2002; Tsukuda et al. 1988). During hemostasis and thrombosis, platelets have two distinct but additive functions in thromboformation, aggregation and procoagulant activity. Recently, the stimulating and inhibitory properties of all $\mathrm{PKC}$ isoforms in the thrombus-forming process have been studied. It was found that platelet $\mathrm{PKC}$ isoforms have a dual controlling role in thrombus formation as follows: (1) by mediating secretion and integrin activation required for platelet aggregation under blood flow, and (2) by suppressing $\mathrm{Ca}^{2+}$-dependent phosphatidylserine exposure, and consequently thrombin generation and coagulation. Thus, platelet PKC is the signaling protein that balances the proaggregatory and procoagulant functions of thrombi (Strehl et al. 2007).

\section{Cholinesterases}

Cholinesterases A and B, AChE and BChE, are two enzymes which classical roles are "cholinergic functions" that originate from their cholinolytic capacity (Layer et al. 2005). However, recently non-classical functions of these enzymes have been uncovered (Johnson and Moore, 2004; Layer et al. 1993; Paraoanu and Layer, 2004). A high degree of sequence homology between $\mathrm{AChE}$ and a family of synaptic cell adhesion proteins, e.g. neuroligins, suggested that AChE may act also as a heterophilic cell adhesion molecule. Indeed, AChE was found to bind laminin- $\beta 1$, an extracellular matrix protein involved in neuronal differentiation and adhesion. AChE binds to the laminin- $\beta 1$ chain and through it can activate integrin receptor which in its turn activates intracellular signaling pathways. Thus, the complexing of $\mathrm{AChE}$ with laminin-1 represents a major signaling mechanism of $\mathrm{AChE}$ in cell formation process and pathfinding (Layer et al. 2005).

Besides of the described functions, both types of cholinesterases exhibit also aryl acylamidase activities (called AAA-AChE and AAA-BChE, respectively), which have been suggested to be involved in developmental processes (Layer et al. 2005).

\section{Deglycosylation enzymes}

Deglycosylation enzemes represents of group of proteins that catalyze separation of peptide component of glycoprotein from its carbohydrate part. As a paradigm of polyfunctional member of this group we chose the peptide: $\mathrm{N}$-glycanase (PNGase). PNGase releases intact $\mathrm{N}$-glycans from misfolded glycopeptides or glycoproteins which undergo deglycosylation during their degradation (Suzuki et al. 2002; Suzuki et al. 2007). The PNGase is a member of the transglutaminase (TGase) superfamily (Makarova et al. 1999). The orthologues of this enzyme are widely distributed throughout eukaryotes. While the "core" TGase domain is well conserved, a key difference is that orthologoues in higher eukaryotes have additional domains at both $\mathrm{N}$ - and C-termini of the core domain. The PNGase of $S$. cerevisiae contains only TGase/PNGase domain, while $C$. elegans enzyme in addition to TGase domain has thioredoxin domain and Man-binding domain located $\mathrm{N}$ - and C-terminally, respectively. S. cerevisiae possesses only deglycosylation activity whereas PNGase from $S$. elegans exhibits dual enzyme functions, not only as PNGase but also as an oxidoreductase (thioredoxin). Thus, structural changes associated with additional domains exhibited additional function to modified molecule.

\section{Growth factors}

Growth facrors are typically multifunctional proteins. Two examples will illuctrate this notion. 
FGFs are heparin-binding multifunctional growth factors which play a crucial role in a variety of developing processes (Bohlen, 1989). FGF-2 is one of the currently known members of the fibroblast growth factor family. It has been established that FGF-2 functions as 1) a differentiation factor for sympathoadrenal progenitor cells; 2) a targetderived neurotrophic factor for the preganglionic sympathetic neurons of the spinal cord and 3) an element of the auto-/-paracrine chain in the adrenal medulla (Grothe and Meisinger, 1997).

Growth-colony stimulating factor (G-CSF), named for its specific stimulation of the growth of neutrophil progenitor cells in vitro (Roberts, 2005), is a growth factor known as a major extracellular regulator of haemopoesis and innate immune system. G-CSF influences the survival, proliferation and differentiation of all cells in the neutrophil lineage, from haemopoetic stem cell to mature neutrophils. Recent researches uncovered initially unsuspected polyfunctionality for G-CSF. This growth factor is well recognized now as a signaling molecule as well as mobiliser of haemopoetic stem cells from bone marrow into the blood. Beside that G-CSF influences T-cell function and dendritic cell activation (Roberts, 2005).

\section{Cytokines/chemokines}

Chemokines are small cytokines that function in immune responses, wound healing, inflammation and tumorogenesis (Sorg, 1989). This multifunctionality has been attributed primarily to ligand interaction with multiple receptors. Recent studies have shown that their multifunctionality could also result from interactions of the receptors with small peptides produced by precessing of the chemokines. Li et al. (Li et al. 2004) have analyzed the interactions between the two forms of human interleukin 8 (hIL8), N- and C-peptides, with the chemokine receptors hCXCR 1 and hCXCR2 and showed that the $\mathrm{N}$ and $\mathrm{C}$ termini of the chemokine could stimulate the respective CXCR1 to induce intracellular $\mathrm{Ca}^{2+}$ release and MAPK activation independent of the other regions of molecule. These peptides could also stimulate chemotaxis of several cell types and this function is specific and mediated by hCXCR1 and/or hCXCR2. These findings advance understanding of the multifunctionality exhibited by chemokines.

\section{Growth hormone}

The growth hormone $(\mathrm{GH})$ is a large multifunctional protein. It exhibits extensive heterogeneity. Some GH molecules/fragments are generated and secreted directly from the pituitary gland without any post-translational modification, whereas other molecules or fragments do arise from post-synthetic modifications (De Palo et al. 2006; Lewis et al. 2000; Wood, 2001). The link between molecular structures (different fragments of the GHmolecule) and biological effects were studied and analysis of functional activities possessing by different fragments of the $\mathrm{GH}$ molecule confirmed this statement.

It has been shown that the GH1-43 a.a. fragment possesses an important insulin-like activity, but does not appear to have growth-promoting activity. The insulin-like action of this amino-terminal segment has been confirmed in a series of GH peptide fragments including GH1-20 a.a., GH1-15 a.a. and GH6-13 a.a. All these GH fragments have been demonstrated to induce hypoglycaemia in vivo and amplify the actions of insulin in vitro (Ohkura and Hori, 2000).

GH44-191 a.a. fragment demonstrates neither growth-promoting nor insulin-like activities. On the contrary, it possesses $\mathrm{GH}$ antagonist activity (Clerico et al. 2000; Heffernan et al. 2000). GH108-129 a.a. fragment appears to possess mitogenic activity although intact $\mathrm{GH}$ demonstrates anti-mitogenic activity (De Palo et al. 2006). These data evidently demonstrate that different domains of the same protein molecule possess different and sometimes opposite functions.

\section{Lactoferrin}

Lactoferrin, a component of mammalian milk, is a member of the transfer proteins family (Brock, 2002; Kanyshkova et al. 2001). These glycoproteins transfer $\mathrm{Fe}^{3+}$ ions (Brock, 2002; Suzuki and Lonnerdal, 2002). Lactoferrin is a polyfunctional protein that influences cell proliferation and differentiation (Baveye et al. 1999). It regulates also granulopoiesis and DNA synthesis. Lactoferrin inhibits prostaglandin synthesis in human milk macrophages and activates the nonspecific immune response by stimulating phagocytosis and complement (Baveye et al. 1999; Mann et al. 1994; Ward et al. 2002). It interacts with macromolecules such as DNA, RNA, proteins, polysaccharides and heparin-like polyanions (Elass-Rochard et al. 
1995; He and Furmanski, 1995; Son et al. 2002). In some cells lactoferrin functions as transcription factor (He and Furmanski, 1995; Mariller et al. 2007). It was recently demonstrated that lactoferrin also possesses ribonuclease activity (Kanyshkova et al. 2001).

\section{Protein synthesis regulatory proteins}

Protein synthesis regulatory proteins as well as proteins of other groups demonstrate extensive polyfunctionality. Sometimes, the functions they possess are unrelated or even opposite. As a paradigm of these proteins we will discuss the iron regulatory protein 1 (IRP1). IRP1 is a cytosolic, RNA binding protein that regulates the translation and stability of mRNAs encoding proteins for iron transport, storage, and use (Walden et al. 2006). IRP1 has an alternate function as cytosolic (c)-aconitase when the iron sulfur [4Fe-4S] cluster is bound (Eisenstein, 2000; Henderson and Kuhn, 1995; Hentze and Kuhn, 1996; Hentze et al. 2004; Kennedy et al. 1992; Theil and Eisenstein, 2000). The distribution of IRP1 between these mutually exclusive functions requires no new protein synthesis; iron excess promotes (c)-aconitase activity while starvation activates RNA binding function (Henderson and Kuhn, 1995). Assembly and disassembly of the iron-sulfur cluster appears to be effective mechanism for regulation IRP1 activity, dependnt on facile interchange between the two functional conformations.

The RNA-binding and enzyme active sites are extensively overlapped in IRP1, with many amino acids serving important, but different, roles in each functional state of the protein. The functional plasticity of amino acids serving both catalytic and RNA binding roles reflects the conformational flexibility of the protein, particularly in the vicinity of the Fe-S and RNA binding sites (Walden et al. 2006).

\section{Transcriptional factors}

Proteins regulating transcription belong to a huge group of DNA binding proteins. Zinc-finger containing proteins represent one of the subgroups of these proteins. The WT1, zinc-finger containing transcription factor, is a multifunctional protein. Two allels of WT1 gene is described: one contains insertion of three amino acids (+KTS) immediately after the zinc-finger $3 \mathrm{~b}$ and another which does not contain this insertion (-KTS). In its transcriptional roles the WT1(-KTS) acts as an activator (Lee et al. 1999) while WT1(+KTS) functions as a repressor of transcription (Loeb et al. 2002). The WT1(-KTS) also binds RNA and interacts with SF1 (steroidogenic factor nuclear hormone receptor). On the contrary, the WT1(+KTS) weakly interact with SF1 but strongly binds to U2snRNP-associated splice factor (Ladomery and Dellaire, 2002).

Another zink-finger protein coding gene, ZNF74, can produce multiple protein isoforms through alternative promoter usage and splicing: these exhibit differences in their transcriptional activities and nuclear partitioning (Cote et al. 2001). The original isoform, ZNF74-I, lacks the canonical N-terminal sequences of KRAB box A, localizes to speckle domains and exhibits weak transcriptional repression. In contrast to this, the ZNF74-II isoform contains the full KRAB A and $B$ boxes, exhibits strong transcriptional repression and localizes in a diffuse pattern throughout the nucleus (Ladomery and Dellaire, 2002).

The presented data show that these and probably other Zn-finger proteins possess functional versitality of the zinc finger motif and suggest that both alternative splicing and sub-cellular compartmentalization may modulate their multifunctionality.

\section{Bacterial toxins}

Bacterial toxins represent interesting examples of protein multifunctionality. Many toxins that act intracellularly have multidomain organization, with each domain capable of mediating a separate step of the intoxication process. There are numerous different mechanisms by which a bacterial toxin can produce pleiotropic cellular effects. On the basis of their ability to cause pleotropic cellular effects, bacterial toxins may be regarded as multifunctional proteins (Cover and Blanke, 2005).

Two of the most extensively studied examples of multifunctional bacterial toxins are ExoS and ExoT from Pseudomonas aeruginosa. These toxins have multiple effector domains, each of which is associated with a discrete activity against the host cell. The N-terminal domains of ExoS and ExoT are GTPase-activating proteins (GAPs) that target members of the Rho family of small GTPases, which regulate processes in cytoskeleton (Goehring et al. 1999). The C-terminal domains are ADPrybosyltransferases that modify multiple host proteins, including Ras and Ras-like GTPases 
(Vincent et al. 1999). The discrete effector domains of these toxins may retain functional activity if expressed as individual proteins. The RhiGAP activities of EXoS and ExoT are almost identical, whereas ExoS and ExoT ADP-ribosylation effects are directed to different substrates (Barbieri and Sun, 2004).

Another example of a multifunctional toxin is the binary toxin produced by Bacillus anthracis. The B subunit of this toxin (protective antigen) can translocate two different A subunits into host cells. The A subunits may function as a metalloproteinase known as lethal factor or as adenylate cyclase known as oedema factor. On entry into host cells, lethal factor can cause many different effects, including alteration of dendritic-cell functions, repression of glucocorticoid-receptor transactivation, lysis of macrophages and apoptosis (Agrawal et al. 2003; Friedlander, 1986; Kirby, 2004).

The VacA toxin of Helicobacter pylori also possesses multiple functions producing upon entry into the cell: alterations in late endosomes, alterations in mitochondrial membrane permeability and inhibition of T-cell proliferation (Cover and Blanke, 2005).

Thus, many bacterial toxins are multifunctional proteins. By producing toxins with multifunctional properties, bactera are able to use a single protein to produce a range of effects at different sites in the host, depending on which cell types and tissues are targeted. Consolidating multiple functions within a single protein has several advantages to the bacteria, including conservation of genome space, conservation of energy and resources that would be needed to regulate, produce and secrete multiple gene products, and stoichiometric, special, and temporal control of multiple host-modulating activities.

\section{Plant $A B C$ transporters}

The ABC-transporter superfamily is one of the largest protein families known. Its members can be found in bacteria, fungi, plants and animals (Henikoff et al. 1997; Martinoia et al. 2002). All ABC transporters consisit of two pairs of basic structural elements: integral membrane-spanning domains and nucleotide-binding folds oriented towards the cytoplasm. In bacteria, most members of this family are responsible for the high-affinity uptake of small molecules (for example, maltose and histidine) (Higgins, 1992). Eukaryotic ABC transporters mediate diverse cellular transport processes, such as excretion of potentially toxic compounds, lipid translocation, excretion of the mating factor of yeast, conferring heavy-metal tolerance, multidrug resistance, and antigen presentation, as well as exhibiting ion channel activity (Balzi and Goffeau, 1994; de Souza et al. 2000; Gottesman and Pastan, 1993; Higgins, 1995; Kelly et al. 1992; Kuchler et al. 1989; McGrath and Varshavsky, 1989; Szczypka et al. 1994). The first reports on plant ABC transporters showed that they are implicated in detoxification processes. Recent results indicate that the function of this protein family is not restricted to detoxifixation. Plant ABC transporters have been demonstrated to participate in chlorophyll biosynthesis, formation of Fe/S clusters, stromal movement and ion fluxes. They may also transport steroids and participate in signal transduction. Hence, plant ABC transporters play multifunctional central role in plant growth and development (Higgins, 1992).

\section{"Hidden" protein functions}

The list of the multifunctional proteins is not limited to the described examples and could be extended. The multifunctionality appears to be a general feature of proteins. It is most likely, that in cases where proteins exhibit monofunctionality, the other functions of a protein have simply not jet been identified. These are "hidden" functions.

The "hidden or eclipsed" function is not a rear phenomenone. Many causes may lead to situation when one or several protein isoforms can not be detected while they were synthesized and present in the cell. One such a cause is a very short half-life time of some mRNA and/or protein. Another cause is the efficiency of the mRNA detection methods. The generally used analysis of expressed sequence tags (ESTs) is not perfect because the EST collection does not represent all protein coding sequences and for most genes ESTs cover only a portion of the transcripts. For instance, only half of the genes located on human chromosome 22 are represented in the current EST database (Dias Neto et al. 2000). Moreover, $26 \%$ and $65 \%$ of the ESTs correspond to the extreme 5' and 3' ends, respectively, of any given transcript (Graveley, 2001; Regev-Rudzki and Pines, 2007). Because much of the functionally significant alternative splicing occurs in the coding region of the transcript, many alternative splicing 
events might be overlooked by EST comparisons (Graveley, 2001).

Speaking about the causes leading to "loss of protein functions", one should consider the phenomenone of dual- or multi-targeting of proteins and its consequence. The precise subcellular localization of a protein is ctitical for its function. Eukaryotic cells synthesize thousands of proteins, each having a specific function in a specific subcellular compartment. In recent years, a growing number of examples of single genes whose products are located to two (or more) separate compartments have been discovered (Huh et al. 2003; Karniely and Pines, 2005; Mackenzie, 2005).

There is a growing number of studies designed to develop a global screens of protein localization in order to characterize location-specific function (Kumar et al. 2002; Regev-Rudzki et al. 2005; Yook et al. 2004). However, these "large-scale" analyses often fail to detect one of the isoproteins in one of the locations of a dual targeted protein due to a highly uneven distribution between compartments. In frame of this phenomenon called by N. Regev-Rudzki and O. Pines 'eclipsed distribution' (Regev-Rudzki and Pines, 2007), the relatively large amount of an isoprotein in one subcellular compartment obscures the detection of the small amount of the other isoprotein in the other location (Levay and Viljoen, 1995).

As underlined by Regev-Rudzki and Pines (Regev-Rudzki and Pines, 2007), 'such eclipsed distribution phenomena have a wider occurance than recorded currently; the reason being that, in most cases, the small fraction of one of the isoproteins, in one of the locations, makes its detection very difficult. This is particularly true for the cytosol which occupies several fold larger volume than other compartments thus diluting a significant amount of a dual targeted protein, so that it is easily missed by the currently used large-scale visualization methods'.

\section{Conclusion}

The data presented in this review evidently show that genetic information embedded in nucleotide sequences of a genome contains a program of multiple structural and functional transformations of this information into real protein molecules that are involved in mirriads of reactions which ultimately determine physiology of a cell. Moreover, the encoded physico-chemical potentials of the molecules allows intermolecular interactions in such a way that one molecules may modify the other molecules thus increasing structural and functional diversity of the proteins produced by a given gene. After all, thousands of protein molecules that build the multiple mechanisms responsible for protein synthesis and different post-translational modifications are encoded in a compact form in cell genome. Hence, the cell may be considered as a very economic self-coding and self-realizing system which effectivity is beeing achieved by usage of multifunctional protein molecules. Thus, the multifunctionality is not an exceptional feature of a particular protein but to the contrary it is a fundamental basic property of most or all proteins which allows the cell effective accomplishment of multiple and complex physiological processes.

\section{Acknowledgements}

JZZ and DHW were supported in part by the Israel Cancer Research Fund, The Ela Kodesz Institute for Research on Cancer and Prevention, Tel Aviv University, Israel and the Cancer Biology Research Center, Tel Aviv University, Israel.

\section{References}

Acconcia, F., Ascenzi, P., Bocedi, A., Spisni, E., Tomasi, V., Trentalance, A., Visca, P. and Marino, M. 2005. Palmitoylation-dependent estrogen receptor alpha membrane localization: regulation by 17 beta-estradiol. Mol. Biol. Cell., 16:231-7.

Adamski, F.M., Donly, B.C. and Tate, W.P. 1993. Competition between frameshifting, termination and suppression at the frameshift site in the Escherichia coli release factor-2 mRNA. Nucleic Acids Res., 21:5074-8.

Agrawal, A., Lingappa, J., Leppla, S.H., Agrawal, S., Jabbar, A., Quinn, C. and Pulendran, B. 2003. Impairment of dendritic cells and adaptive immunity by anthrax lethal toxin. Nature, 424:329-34.

Ahmad, I., Hoessli, D.C., Gupta, R., Walker-Nasir, E., Rafik, S.M., Choudhary, M.I. and Shakoori, A.R. 2007. In silico determination of intracellular glycosylation and phosphorylation sites in human selectins: implications for biological function. J. Cell Biochem., 100:1558-72.

Allen, S.H., Bennett, J.A., Mizejewski, G.J., Andersen, T.T., Ferraris, S. and Jacobson, H.I. 1993. Purification of alpha-fetoprotein from human cord serum with demonstration of its antiestrogenic activity. Biochim. Biophys. Acta., 1202:135-42.

Altschuler, Y., Kinlough, C.L., Poland, P.A., Bruns, J.B., Apodaca, G., Weisz, O.A. and Hughey, R.P. 2000. Clathrin-mediated endocytosis of MUC1 is modulated by its glycosylation state. Mol. Biol. Cell., 11:819-31.

Anfinsen, C.B. 1973. Principles that govern the folding of protein chains. Science, 181:223-30.

Aoyagi, Y., Ikenaka, T. and Ichida, F. 1979. alpha-Fetoprotein as a carrier protein in plasma and its bilirubin-binding ability. Cancer Res., 39:3571-4.

Apic, G., Huber, W. and Teichmann, S.A. 2003. Multi-domain protein families and domain pairs: comparison with known structures and a random model of domain recombination. J. Struct. Funct. Genomics, 4:67-78. 
Arai, R., Wriggers, W., Nishikawa, Y., Nagamune, T. and Fujisawa, T. 2004. Conformations of variably linked chimeric proteins evaluated by synchrotron X-ray small-angle scattering. Proteins, 57:829-38.

Atkins, J.F., Baranov, P.V., Fayet, O., Herr, A.J., Howard, M.T., Ivanov, I.P., Matsufuji, S., Miller, W.A., Moore, B., Prere, M.F., Wills, N.M., Zhou, J. and Gesteland, R.F. 2001. Overriding standard decoding: implications of recoding for ribosome function and enrichment of gene expression. Cold Spring Harb Symp. Quant. Biol., 66:217-32.

Aussel, C. and Negrel, R. 1986. Effect of alpha-fetoprotein on arachidonic acid metabolism in the preadipocyte cell line OB. 17. Prostaglandins Leukot. Med., 21:69-76.

Baird, S.D., Turcotte, M., Korneluk, R.G. and Holcik, M. 2006. Searching for IRES. Rna., 12:1755-85.

Balbach, JAS. and FX, . 2000. In Mechanisms of protein folding (R. Pain, Ed.), pp. 212-249, IRL Press, Oxford.

Balzi, E. and Goffeau, A. 1994. Genetics and biochemistry of yeast multidrug resistance. Biochim. Biophys. Acta., 1187:152-62.

Barbato, G., Ikura, M., Kay, L.E., Pastor, R.W. and Bax, A. 1992. Backbone dynamics of calmodulin studied by $15 \mathrm{~N}$. relaxation using inverse detected two-dimensional NMR. spectroscopy: the central helix is flexible. Biochemistry, 31:5269-78.

Barbieri, J.T. and Sun, J. 2004. Pseudomonas aeruginosa ExoS and ExoT. Rev. Physiol. Biochem. Pharmacol., 152:79-92.

Baruch, A., Hartmann, M., Yoeli, M., Adereth, Y., Greenstein, S., Stadler, Y., Skornik, Y., Zaretsky, J., Smorodinsky, N.I., Keydar, I. and Wreschner, D.H. 1999. The breast cancer-associated MUC1 gene generates both a receptor and its cognate binding protein. Cancer Res., 59:1552-61.

Baruch, A., Hartmann, M., Zrihan-Licht, S., Greenstein, S., Burstein, M., Keydar, I., Weiss, M., Smorodinsky, N. and Wreschner, D.H. 1997. Preferential expression of novel MUC1 tumor antigen isoforms in human epithelial tumors and their tumor-potentiating function. Int. J. Cancer, 71:741-9.

Basu, S., Binder, R.J., Ramalingam, T. and Srivastava, P.K. 2001. CD91 is a common receptor for heat shock proteins gp 96, hsp90, hsp70, and calreticulin. Immunity, 14:303-13.

Baveye, S., Elass, E., Mazurier, J., Spik, G. and Legrand, D. 1999. Lactoferrin: a multifunctional glycoprotein involved in the modulation of the inflammatory process. Clin. Chem. Lab. Med., 37:281-6.

Behm-Ansmant, I., Kashima, I., Rehwinkel, J., Sauliere, J., Wittkopp, N. and Izaurralde, E. 2007. mRNA quality control: an ancient machinery recognizes and degrades mRNAs with nonsense codons. FEBS Lett, 581:2845-53.

Bell, J.K., Goetz, D.H., Mahrus, S., Harris, J.L., Fletterick, R.J. and Craik, C.S. 2003. The oligomeric structure of human granzyme A is a determinant of its extended substrate specificity. Nat. Struct. Biol., 10:527-34.

Berry, M.J., Banu, L., Chen, Y.Y., Mandel, S.J., Kieffer, J.D., Harney, J.W. and Larsen, P.R. 1991a. Recognition of UGA as a selenocysteine codon in type I deiodinase requires sequences in the 3' untranslated region. Nature, 353:273-6.

Berry, M.J., Banu, L. and Larsen, P.R. 1991b. Type I iodothyronine deiodinase is a selenocysteine-containing enzyme. Nature, 349:438-40.

Bijlmakers, M.J. and Marsh, M. 2003. The on-off story of protein palmitoylation. Trends Cell Biol., 13:32-42.

Birkenmeier, G., Usbeck, E., Saro, L. and Kopperschlager, G. 1983. Triazine dye binding of human alpha-fetoprotein and albumin. J. Chromatogr., 265:27-35.

Black, D.L. 2003. Mechanisms of alternative pre-messenger RNA splicing. Annu. Rev. Biochem., 72:291-336.

Bloom, J.W., Madanat, M.S. and Ray, M.K. 1996. Cell. line and site specific comparative analysis of the N.-linked oligosaccharides on human ICAM-1des454-532 by electrospray ionization mass spectrometry. Biochemistry, 35:1856-64.

Bohlen, P. 1989. Fibroblast growth factor. In Macrophage-derived cell regulatory factors. Cytokines (C. Sorg, Ed.), Karger, Basel.
Bonetti, B., Fu, L., Moon, J. and Bedwell, D.M. 1995. The efficiency of translation termination is determined by a synergistic interplay between upstream and downstream sequences in Saccharomyces cerevisiae. J. Mol. Biol., 251:334-45.

Bork, P., Schultz, J. and Ponting, C.P. 1997. Cytoplasmic signalling domains: the next generation. Trends Biochem. Sci., 22:296-8.

Brierley, I. and Pennell, S. 2001. Structure and function of the stimulatory RNAs involved in programmed eukaryotic-1 ribosomal frameshifting. Cold Spring Harb Symp. Quant. Biol., 66:233-48.

Brock, J.H. 2002. The physiology of lactoferrin. Biochem. Cell Biol., $80: 1-6$.

Bukau, B. and Horwich, A.L. 1998. The Hsp70 and Hsp60 chaperone machines. Cell., 92:351-66.

Burk, R.F., Hill, K.E., Awad, J.A., Morrow, J.D., Kato, T., Cockell, K.A. and Lyons, P.R. 1995. Pathogenesis of diquat-induced liver necrosis in selenium-deficient rats: assessment of the roles of lipid peroxidation and selenoprotein P. Hepatology, 21:561-9.

Buzza, M.S., Zamurs, L., Sun, J., Bird, C.H., Smith, A.I., Trapani, J.A., Froelich, C.J., Nice, E.C. and Bird, P.I. 2005. Extracellular matrix remodeling by human granzyme B. via cleavage of vitronectin, fibronectin, and laminin. J. Biol. Chem., 280:23549-58.

Cai, J., Huang, Y., Li, F. and Li, Y. 2006. Alteration of protein subcellular location and domain formation by alternative translational initiation. Proteins, 62:793-9.

Cai, X. 2007. Molecular evolution and structural analysis of the $\mathrm{Ca}(2+)$ release-activated $\mathrm{Ca}(2+)$ channel subunit, Orai. J. Mol. Biol., 368:1284-91.

Candeias, M.M., Powell, D.J., Roubalova, E., Apcher, S., Bourougaa, K., Vojtesek, B., Bruzzoni-Giovanelli, H. and Fahraeus, R. 2006. Expression of $\mathrm{p} 53$ and $\mathrm{p} 53 / 47$ are controlled by alternative mechanisms of messenger RNA translation initiation. Oncogene., 25:6936-47.

Carrington, D.M., Auffret, A. and Hanke, D.E. 1985. Polypeptide ligation occurs during post-translational modification of concanavalin A. Nature, 313:64-7.

Casey, P.J. and Seabra, M.C. 1996. Protein prenyltransferases. J. Biol. Chem., 271:5289-92.

Cesareni, G. 2004. Modular Protein Domains, (Wiley-Verlag).

Chen, A., Kao, Y.F. and Brown, C.M. 2005a. Translation of the first upstream ORF in the hepatitis B. virus pregenomic RNA modulates translation at the core and polymerase initiation codons. Nucleic Acids Res., 33:1169-81.

Chen, P.Y., Lin, C.C., Chang, Y.T., Lin, S.C. and Chan, S.I. 2002. One O-linked sugar can affect the coil-to-beta structural transition of the prion peptide. Proc. Natl. Acad. Sci. U.S.A., 99:12633-8.

Chen, Y.T., Collins, L.L., Uno, H. and Chang, C. 2005b. Deficits in motor coordination with aberrant cerebellar development in mice lacking testicular orphan nuclear receptor 4. Mol. Cell Biol., $25: 2722-32$

Cheng, X., Cole, R.N., Zaia, J. and Hart, G.W. 2000. Alternative O-glycosylation/O-phosphorylation of the murine estrogen receptor beta. Biochemistry, 39:11609-20.

Cheng, X. and Hart, G.W. 2001. Alternative O-glycosylation/ O-phosphorylation of serine-16 in murine estrogen receptor beta: post-translational regulation of turnover and transactivation activity. J. Biol. Chem., 276:10570-5.

Cheung, W.Y. 1970. Cyclic 3', 5'-nucleotide phosphodiesterase. Demonstration of an activator. Biochem. Biophys. Res. Commun., 38:533-8.

Chittum, H.S., Himeno, S., Hill, K.E. and Burk, R.F. 1996. Multiple forms of selenoprotein P in rat plasma. Arch. Biochem. Biophys., 325:124-8.

Chong, S., Williams, K.S., Wotkowicz, C. and Xu, M.Q. 1998. Modulation of protein splicing of the Saccharomyces cerevisiae vacuolar membrane ATPase intein. J. Biol. Chem., 273:10567-77.

Chou, C.F. and Omary, M.B. 1994. Mitotic arrest with anti-microtubule agents or okadaic acid is associated with increased glycoprotein terminal GlcNAc's. J. Cell Sci., 107(Pt 7):1833-43.

Chou, T.Y., Dang, C.V. and Hart, G.W. 1995a. Glycosylation of the c-Myc transactivation domain. Proc. Natl. Acad. Sci. U.S.A., 92:4417-21. 
Chou, T.Y., Hart, G.W. and Dang, C.V. 1995b. c-Myc is glycosylated at threonine 58, a known phosphorylation site and a mutational hot spot in lymphomas. J. Biol. Chem., 270:18961-5.

Clerico, A., Del Ry, S. and Giannessi, D. 2000. Measurement of cardiac natriuretic hormones (atrial natriuretic peptide, brain natriuretic peptide, and related peptides) in clinical practice: the need for a new generation of immunoassay methods. Clin. Chem., 46:1529-34.

Cocquerel, L., Duvet, S., Meunier, J.C., Pillez, A., Cacan, R., Wychowski, C. and Dubuisson, J. 1999. The transmembrane domain of hepatitis $\mathrm{C}$ virus glycoprotein $\mathrm{E} 1$ is a signal for static retention in the endoplasmic reticulum. J. Virol., 73:2641-9.

Cocquerel, L., Meunier, J.C., Pillez, A., Wychowski, C. and Dubuisson, J. 1998. A retention signal necessary and sufficient for endoplasmic reticulum localization maps to the transmembrane domain of hepatitis C virus glycoprotein E2. J. Virol., 72:2183-91.

Cocquerel, L., Op de Beeck, A., Lambot, M., Roussel, J., Delgrange, D., Pillez, A., Wychowski, C., Penin, F. and Dubuisson, J. 2002. Topological changes in the transmembrane domains of hepatitis $\mathrm{C}$ virus envelope glycoproteins. Embo. J., 21:2893-902.

Cocquerel, L., Wychowski, C., Minner, F., Penin, F. and Dubuisson, J. 2000. Charged residues in the transmembrane domains of hepatitis $\mathrm{C}$ virus glycoproteins play a major role in the processing, subcellular localization, and assembly of these envelope proteins. J. Virol., 74:3623-33

Cohen, P., Burchell, A., Foulkes, J.G. and Cohen, P.T. 1978. Identification of the $\mathrm{Ca} 2+$-dependent modulator protein as the fourth subunit of rabbit skeletal muscle phosphorylase kinase. FEBS Lett, 92:287-93.

Collins, L.L., Lee, Y.F., Heinlein, C.A., Liu, N.C., Chen, Y.T., Shyr, C.R., Meshul, C.K., Uno, H., Platt, K.A. and Chang, C. 2004. Growth retardation and abnormal maternal behavior in mice lacking testicular orphan nuclear receptor 4. Proc. Natl. Acad. Sci. U.S.A., 101:15058-63.

Comer, F.I. and Hart, G.W. 2000. O-Glycosylation of nuclear and cytosolic proteins. Dynamic interplay between O-GlcNAc and O-phosphate. J. Biol. Chem., 275:29179-82.

Cote, F., Boisvert, F.M., Grondin, B., Bazinet, M., Goodyer, C.G., Bazett-Jones, D.P. and Aubry, M. 2001. Alternative promoter usage and splicing of ZNF74 multifinger gene produce protein isoforms with a different repressor activity and nuclear partitioning. DNA Cell Biol., 20:159-73.

Cover, T.L. and Blanke, S.R. 2005. Helicobacter pylori VacA, a paradigm for toxin multifunctionality. Nat. Rev. Microbiol., 3:320-32.

Coyle, J.E., Jaeger, J., Gross, M., Robinson, C.V. and Radford, S.E. 1997. Structural and mechanistic consequences of polypeptide binding by GroEL. Fold Des., 2:R.93-104.

Creighton, T. 2002. In Mechanisms of protein folding (R. Pain, Ed.), pp. 250-278 IRL Press, Oxford.

Cridge, A.G., Major, L.L., Mahagaonkar, A.A., Poole, E.S., Isaksson, L.A. and Tate, W.P. 2006. Comparison of characteristics and function of translation termination signals between and within prokaryotic and eukaryotic organisms. Nucleic Acids Res., 34:1959-73.

Datta, B., Ray, M.K., Chakrabarti, D., Wylie, D.E. and Gupta, N.K. 1989. Glycosylation of eukaryotic peptide chain initiation factor 2 (eIF-2)associated $67-\mathrm{kDa}$ polypeptide (p67) and its possible role in the inhibition of eIF-2 kinase-catalyzed phosphorylation of the eIF-2 alpha-subunit. J. Biol. Chem., 264:20620-4.

Dauphinee, M.J. and Mizejewski, G.J. 2002. Human alpha-fetoprotein contains potential heterodimerization motifs capable of interaction with nuclear receptors and transcription/growth factors. Med. Hypotheses, 58:453-61.

David, R., Richter, M.P. and Beck-Sickinger, A.G. 2004. Expressed protein ligation. Method and applications. Eur. J. Biochem., 271:663-77.

De Palo, E.F., Gatti, R., Antonelli, G. and Spinella, P. 2006. Growth hormone isoforms, segments/fragments: does a link exist with multifunctionality? Clin. Chim. Acta., 364:77-81. de Souza, S.J., Camargo, A.A., Briones, M.R., Costa, F.F., Nagai, M.A., Verjovski-Almeida, S., Zago, M.A., Andrade, L.E., Carrer, H., El-Dorry, H.F., Espreafico, E.M., Habr-Gama, A., Giannella-Neto, D., Goldman, G.H., Gruber, A., Hackel, C., Kimura, E.T., Maciel, R.M., Marie, S.K., Martins, E.A., Nobrega, M.P., Paco-Larson, M.L., Pardini, M.I., Pereira, G.G., Pesquero, J.B., Rodrigues, V., Rogatto, S.R., da Silva, I.D., Sogayar, M.C., de Fatima Sonati, M., Tajara, E.H., Valentini, S.R., Acencio, M., Alberto, F.L., Amaral, M.E., Aneas, I., Bengtson, M.H., Carraro, D.M., Carvalho, A.F., Carvalho, L.H., Cerutti, J.M., Correa, M.L., Costa, M.C., Curcio, C., Gushiken, T., Ho, P.L., Kimura, E., Leite, L.C., Maia, G., Majumder, P., Marins, M., Matsukuma, A., Melo, A.S., Mestriner, C.A., Miracca, E.C., Miranda, D.C., Nascimento, A.N., Nobrega, F.G., Ojopi, E.P., Pandolfi, J.R., Pessoa, L.G., Rahal, P., Rainho, C.A., da Ros, N., de Sa, R.G., Sales, M.M., da Silva, N.P., Silva, T.C., da Silva, WJr., Simao, D.F., Sousa, J.F., Stecconi, D., Tsukumo, F., Valente, V., Zalcbeg, H., Brentani, R.R., Reis, F.L., Dias-Neto, E. and Simpson, A.J. 2000. Identification of human chromosome 22 transcribed sequences with ORF expressed sequence tags. Proc. Natl. Acad. Sci. U.S.A., 97:12690-3.

De Vit, M.J., Waddle, J.A. and Johnston, M. 1997. Regulated nuclear translocation of the Mig1 glucose repressor. Mol. Biol. Cell., $8: 1603-18$.

Dias Neto, E., Correa, R.G., Verjovski-Almeida, S., Briones, M.R., Nagai, M.A., da Silva, WJr., Zago, M.A., Bordin, S., Costa, F.F., Goldman, G.H., Carvalho, A.F., Matsukuma, A., Baia, G.S., Simpson, D.H., Brunstein, A., de Oliveira, P.S., Bucher, P., Jongeneel, C.V., O'Hare, M.J., Soares, F., Brentani, R.R., Reis, L.F., de Souza, S.J. and Simpson, A.J. 2000. Shotgun sequencing of the human transcriptome with ORF expressed sequence tags. Proc. Natl. Acad. Sci. U.S.A., 97:3491-6.

Dobson, C.M. 1990. Protein conformation. Hinge-bending and folding. Nature, 348:198-9.

Dobson, C.M. and Karplus, M. 1999. The fundamentals of protein folding: bringing together theory and experiment. Curr. Opin. Struct. Biol., 9:92-101.

Dong, D.L. and Hart, G.W. 1994. Purification and characterization of an O-GlcNAc selective N.-acetyl-beta-D-glucosaminidase from rat spleen cytosol. J. Biol. Chem., 269:19321-30.

Doronina, V.A. and Brown, J.D. 2006. [Non-canonical decoding events at stop codons in eukaryotes]. Mol. Biol. (Mosk), 40:731-41.

Draper, J.M., Xia, Z. and Smith, C.D. 2007. Cellular palmitoylation and trafficking of lipidated peptides. J. Lipid Res., 48:1873-84.

Du, X.L., Edelstein, D., Rossetti, L., Fantus, I.G., Goldberg, H., Ziyadeh, F., Wu, J. and Brownlee, M. 2000. Hyperglycemia-induced mitochondrial superoxide overproduction activates the hexosamine pathway and induces plasminogen activator inhibitor-1 expression by increasing Sp1 glycosylation. Proc. Natl. Acad. Sci. U.S.A., 97:12222-6.

Dunphy, J.T. and Linder, M.E. 1998. Signalling functions of protein palmitoylation. Biochim. Biophys. Acta., 1436:245-61.

Eisenstein, R.S. 2000. Iron regulatory proteins and the molecular control of mammalian iron metabolism. Annu. Rev. Nutr., 20:627-62.

el-Husseini Ael, D. and Bredt, D.S. 2002. Protein palmitoylation: a regulator of neuronal development and function. Nat. Rev. Neurosci., 3:791-802.

Elass-Rochard, E., Roseanu, A., Legrand, D., Trif, M., Salmon, V., Motas, C., Montreuil, J. and Spik, G. 1995. Lactoferrin-lipopolysaccharide interaction: involvement of the 28-34 loop region of human lactoferrin in the high-affinity binding to Escherichia coli 055B5 lipopolysaccharide. Biochem. J., 312 (Pt 3):839-45.

Ellis, R.J. and Hartl, F.U. 1996. Protein folding in the cell: competing models of chaperonin function. Faseb J., 10:20-6.

Evans, T.C. Jr, Benner, J. and Xu, M.Q. 1999. The in vitro ligation of bacterially expressed proteins using an intein from Methanobacterium thermoautotrophicum. J. Biol. Chem., 274:3923-6.

Evans, T.J.T. and Xu, M.Q. 2002. Mechanistic and kinetic considerations of protein splicing. Chem. Rev., 102:4869-84. 
Fearon, K., McClendon, V., Bonetti, B. and Bedwell, D.M. 1994. Premature translation termination mutations are efficiently suppressed in a highly conserved region of yeast Ste6p, a member of the ATP-binding cassette (ABC) transporter family. J. Biol. Chem., 269:17802-8.

Fewell, S.W., Travers, K.J., Weissman, J.S. and Brodsky, J.L. 2001. The action of molecular chaperones in the early secretory pathway. Annu. Rev. Genet., 35:149-91.

Filippou, P.S., Lioliou, E.E., Panagiotidis, C.A., Athanassopoulos, C.M., Garnelis, T., Papaioannou, D. and Kyriakidis, D.A. 2007. Effect of polyamines and synthetic polyamine-analogues on the expression of antizyme (AtoC) and its regulatory genes. $B M C$ Biochem., 8:1.

Finol-Urdaneta, R.K., Struver, N. and Terlau, H. 2006. Molecular and Functional Differences between Heart mKv1.7 Channel Isoforms. J. Gen. Physiol., 128:133-45.

Frand, A.R., Cuozzo, J.W. and Kaiser, C.A. 2000. Pathways for protein disulphide bond formation. Trends Cell Biol., 10:203-10.

Friedlander, A.M. 1986. Macrophages are sensitive to anthrax lethal toxin through an acid-dependent process. J. Biol. Chem., 261:7123-6.

Frischmeyer, P.A. and Dietz, H.C. 1999. Nonsense-mediated mRNA decay in health and disease. Hum. Mol. Genet., 8:1893-900.

Gandre, S., Bercovich, Z. and Kahana, C. 2003. Mitochondrial localization of antizyme is determined by context-dependent alternative utilization of two AUG initiation codons. Mitochondrion, 2:245-56.

Gasdaska, P.Y., Gasdaska, J.R., Cochran, S. and Powis, G. 1995. Cloning and sequencing of a human thioredoxin reductase. FEBS Lett, 373:5-9.

Gebauer, F. and Hentze, M.W. 2004. Molecular mechanisms of translational control. Nat. Rev. Mol. Cell Biol., 5:827-35.

Gesteland, R.F. and Atkins, J.F. 1996. Recoding: dynamic reprogramming of translation. Annu. Rev. Biochem., 65:

Gesteland, R.F., Weiss, R.B. and Atkins, J.F. 1992. Recoding: reprogrammed genetic decoding. Science, 257:1640-1.

Ghosh, I., Sun, L. and Xu, M.Q. 2001. Zinc inhibition of protein transsplicing and identification of regions essential for splicing and association of a split intein*. J. Biol. Chem., 276:24051-8.

Gliemann, J. 1998. Receptors of the low density lipoprotein (LDL) receptor family in man. Multiple functions of the large family members via interaction with complex ligands. Biol. Chem., 379:951-64.

Goehring, U.M., Schmidt, G., Pederson, K.J., Aktories, K. and Barbieri, J.T. 1999. The N-terminal domain of Pseudomonas aeruginosa exoenzyme $\mathrm{S}$ is a GTPase-activating protein for Rho GTPases. J. Biol. Chem., 274:36369-72.

Gokhale, R.S. and Khosla, C. 2000. Role of linkers in communication between protein modules. Curr. Opin. Chem. Biol., 4:22-7.

Goldstein, J. 2001. Familial hypercholesteremia. In Metabolic and Molecular Bases of Inherited Disease (C. Scriver, Ed.), pp. 2863-2913, McGraw-Hill.

Gopinath, R.M. and Vincenzi, F.F. 1977. Phosphodiesterase protein activator mimics red blood cell cytoplasmic activator of $(\mathrm{Ca} 2+-\mathrm{Mg} 2+)$ ATPase. Biochem. Biophys. Res. Commun., 77:1203-9.

Goto, C., Osaka, T. and Mizutani, T. 2001. A model for Sec incorporation with the regions upstream of the UGA Sec codon to play a key role. Biofactors, 14:25-35.

Gottesman, M.M. and Pastan, I. 1993. Biochemistry of multidrug resistance mediated by the multidrug transporter. Annu. Rev. Biochem., 62:385-427.

Gotthardt, M., Trommsdorff, M., Nevitt, M.F., Shelton, J., Richardson, J.A., Stockinger, W., Nimpf, J. and Herz, J. 2000. Interactions of the low density lipoprotein receptor gene family with cytosolic adaptor and scaffold proteins suggest diverse biological functions in cellular communication and signal transduction. J. Biol. Chem., 275:25616-24.

Graveley, B.R. 2001. Alternative splicing: increasing diversity in the proteomic world. Trends Genet., 17:100-7.

Greaves, J. and Chamberlain, L.H. 2007. Palmitoylation-dependent protein sorting. J. Cell Biol., 176:249-54.
Gritli-Linde, A., Nilsson, J., Bohlooly, Y.M., Heby, O. and Linde, A. 2001. Nuclear translocation of antizyme and expression of ornithine decarboxylase and antizyme are developmentally regulated. Dev. Dyn., 220:259-75.

Groisman, I. and Engelberg-Kulka, H. 1995. Translational bypassing: a new reading alternative of the genetic code. Biochem. Cell Biol., 73:1055-9.

Grothe, C. and Meisinger, C. 1997. The multifunctionality of FGF-2 in the adrenal medulla. Anat. Embryol. (Berl), 195:103-11.

Gu, Z., Cavalcanti, A., Chen, F.C., Bouman, P. and Li, W.H. 2002. Extent of gene duplication in the genomes of Drosophila, nematode, and yeast. Mol. Biol. Evol., 19:256-62.

Gutsche, I., Essen, L.O. and Baumeister, W. 1999. Group II chaperonins: new TRiC(k)s and turns of a protein folding machine. J. Mol. Biol., 293:295-312.

Haltiwanger, R.S., Blomberg, M.A. and Hart, G.W. 1992. Glycosylation of nuclear and cytoplasmic proteins. Purification and characterization of a uridine diphospho- $\mathrm{N}$-acetylglucosamine:polypeptide beta$\mathrm{N}$-acetylglucosaminyltransferase. J. Biol. Chem., 267:9005-13.

Haltiwanger, R.S., Holt, G.D. and Hart, G.W. 1990. Enzymatic addition of O-GlcNAc to nuclear and cytoplasmic proteins. Identification of a uridine diphospho-N-acetylglucosamine:peptide beta-N-acetylglucosaminyltransferase. J. Biol. Chem., 265:2563-8.

Han, I., Oh, E.S. and Kudlow, J.E. 2000. Responsiveness of the state of O-linked N.-acetylglucosamine modification of nuclear pore protein p62 to the extracellular glucose concentration. Biochem. J., 350 Pt 1:109-14.

Hanada, K. and Yang, J.C. 2005. Novel biochemistry: post-translational protein splicing and other lessons from the school of antigen processing. J. Mol. Med., 83:420-8.

Hanada, K., Yewdell, J.W. and Yang, J.C. 2004. Immune. recognition of a human renal cancer antigen through post-translational protein splicing. Nature, 427:252-6.

Hanke, J., Brett, D., Zastrow, I., Aydin, A., Delbruck, S., Lehmann, G., Luft, F., Reich, J. and Bork, P. 1999. Alternative splicing of human genes: more the rule than the exception? Trends Genet., 15:389-90.

Harrison, S.C. 1981. Molecular organization of virus particles: implications for assembly. Prog. Clin. Biol. Res., 64:3-18.

Hart, G.W. 1997. Dynamic O-linked glycosylation of nuclear and cytoskeletal proteins. Annu. Rev. Biochem., 66:315-35.

Hart, G.W., Housley, M.P. and Slawson, C. 2007. Cycling of O-linked beta$\mathrm{N}$-acetylglucosamine on nucleocytoplasmic proteins. Nature, 446:1017-22.

Hartl, F.U. and Hayer-Hartl, M. 2002. Molecular chaperones in the cytosol: from nascent chain to folded protein. Science, 295:1852-8.

He, J. and Furmanski, P. 1995. Sequence specificity and transcriptional activation in the binding of lactoferrin to DNA. Nature, 373:721-4.

Heffernan, M.A., Jiang, W.J., Thorburn, A.W. and Ng, F.M. 2000. Effects of oral administration of a synthetic fragment of human growth hormone on lipid metabolism. Am. J. Physiol. Endocrinol. Metab., 279:E501-7.

Heller, J.S., Fong, W.F. and Canellakis, E.S. 1976. Induction of a protein inhibitor to ornithine decarboxylase by the end products of its reaction. Proc. Natl. Acad. Sci. U.S.A., 73:1858-62.

Henderson, B.R. and Kuhn, L.C. 1995. Differential modulation of the RNAbinding proteins IRP-1 and IRP-2 in response to iron. IRP-2 inactivation requires translation of another protein. J. Biol. Chem., 270:20509-15.

Henikoff, S., Greene, E.A., Pietrokovski, S., Bork, P., Attwood, T.K. and Hood, L. 1997. Gene families: the taxonomy of protein paralogs and chimeras. Science, 278:609-14.

Henkel, T., Zabel, U., van Zee, K., Muller, J.M., Fanning, E. and Baeuerle, P.A. 1992. Intramolecular masking of the nuclear location signal and dimerization domain in the precursor for the p $50 \mathrm{NF}-k a p p a \mathrm{~B}$. subunit. Cell, 68:1121-33.

Hentze, M.W. and Kuhn, L.C. 1996. Molecular control of vertebrate iron metabolism: mRNA-based regulatory circuits operated by iron, nitric oxide, and oxidative stress. Proc. Natl. Acad. Sci. U.S.A., 93:8175-82. 
Hentze, M.W., Muckenthaler, M.U. and Andrews, N.C. 2004. Balancing acts: molecular control of mammalian iron metabolism. Cell, 117:285-97.

Herr, A.J., Atkins, J.F. and Gesteland, R.F. 2000a. Coupling of open reading frames by translational bypassing. Annu. Rev. Biochem., 69:343-72.

Herr, A.J., Gesteland, R.F. and Atkins, J.F. 2000b. One protein from two open reading frames: mechanism of a $50 \mathrm{nt}$ translational bypass. Embo. J., 19:2671-80.

Herz, J. and Strickland, D.K. 2001. LRP: a multifunctional scavenger and signaling receptor. J. Clin. Invest, 108:779-84.

Higgins, C.F. 1992. ABC transporters: from microorganisms to man. Annu Rev. Cell Biol., 8:67-113.

Higgins, C.F. 1995. The ABC of channel regulation. Cell., 82:693-6.

Hilkens, J. and Buijs, F. 1988. Biosynthesis of MAM-6, an epithelial sialomucin. Evidence for involvement of a rare proteolytic cleavage step in the endoplasmic reticulum. J. Biol. Chem., 263:4215-22.

Hill, K.E., Lloyd, R.S., Yang, J.G., Read, R. and Burk, R.F. 1991. The cDNA for rat selenoprotein $\mathrm{P}$ contains 10 TGA codons in the open reading frame. J. Biol. Chem., 266:10050-3.

Hinnebusch, A.G. and Natarajan, K. 2002. Gcn4p, a master regulator of gene expression, is controlled at multiple levels by diverse signals of starvation and stress. Eukaryot. Cell., 1:22-32.

Hironaka, T., Furukawa, K., Esmon, P.C., Yokota, T., Brown, J.E., Sawada, S., Fournel, M.A., Kato, M., Minaga, T. and Kobata, A. 1993. Structural study of the sugar chains of porcine factor VIII - tissue- and species-specific glycosylation of factor VIII. Arch. Biochem. Biophys., 307:316-30.

Hirst, C.E., Buzza, M.S., Sutton, V.R., Trapani, J.A., Loveland, K.L. and Bird, P.I. 2001. Perforin-independent expression of granzyme B. and proteinase inhibitor 9 in human testis and placenta suggests a role for granzyme B-mediated proteolysis in reproduction. Mol. Hum. Reprod., 7:1133-42.

Holcik, M., Sonenberg, N. and Korneluk, R.G. 2000. Internal ribosome initiation of translation and the control of cell death. Trends Genet., 16:469-73.

Howell, B.W. and Herz, J. 2001. The LDL receptor gene family: signaling functions during development. Curr. Opin. Neurobiol., 11:74-81.

Huez, I., Bornes, S., Bresson, D., Creancier, L. and Prats, H. 2001. New vascular endothelial growth factor isoform generated by internal ribosome entry site-driven CUG translation initiation. Mol. Endocrinol., 15:2197-210.

Huez, I., Creancier, L., Audigier, S., Gensac, M.C., Prats, A.C. and Prats, H. 1998. Two independent internal ribosome entry sites are involved in translation initiation of vascular endothelial growth factor mRNA. Mol. Cell Biol., 18:6178-90.

Huh, W.K., Falvo, J.V., Gerke, L.C., Carroll, A.S., Howson, R.W., Weissman, J.S. and O'Shea, E.K. 2003. Global analysis of protein localization in budding yeast. Nature, 425:686-91.

Huq, M.D., Gupta, P., Tsai, N.P. and Wei, L.N. 2006. Modulation of testicular receptor 4 activity by mitogen-activated protein kinasemediated phosphorylation. Mol. Cell. Proteomics, 5:2072-82.

Ichiba, T., Matsufuji, S., Miyazaki, Y., Murakami, Y., Tanaka, K., Ichihara, A. and Hayashi, S. 1994. Functional regions of ornithine decarboxylase antizyme. Biochem. Biophys. Res. Commun., 200:1721-7.

Ichtchenko, K., Hata, Y., Nguyen, T., Ullrich, B., Missler, M., Moomaw, C. and Sudhof, T.C. 1995. Neuroligin 1: a splice site-specific ligand for beta-neurexins. Cell., 81:435-43.

Ikura, M. and Ames, J.B. 2006. Genetic polymorphism and protein conformational plasticity in the calmodulin superfamily: two ways to promote multifunctionality. Proc. Natl. Acad. Sci. U.S.A., 103:1159-64.

Ikura, M., Clore, G.M., Gronenborn, A.M., Zhu, G., Klee, C.B. and Bax, A. 1992. Solution structure of a calmodulin-target peptide complex by multidimensional NMR. Science, 256:

Isken, O. and Maquat, L.E. 2007. Quality control of eukaryotic mRNA: safeguarding cells from abnormal mRNA function. Genes Dev., $21: 1833-56$
Iturralde, M., Alava, M.A., Gonzalez, B., Anel, A. and Pineiro, A. 1991. Effect of alpha-fetoprotein and albumin on the uptake of polyunsaturated fatty acids by rat hepatoma cells and fetal rat hepatocytes. Biochim. Biophys. Acta., 1086:81-8.

Ivakhno, S.S. and Kornelyuk, A.I. 2004. Cytokine-like activities of some aminoacyl-tRNA synthetases and auxiliary $\mathrm{p} 43$ cofactor of aminoacylation reaction and their role in oncogenesis. Exp. Oncol., 26:250-5.

Jacobson, H.I., Bennett, J.A. and Mizejewski, G.J. 1990. Inhibition of estrogen-dependent breast cancer growth by a reaction product of alpha-fetoprotein and estradiol. Cancer Res., 50:415-20.

Janzen, D.M. and Geballe, A.P. 2004. The effect of eukaryotic release factor depletion on translation termination in human cell lines. Nucleic Acids Res., 32:4491-502.

Jarrett, H.W. and Penniston, J.T. 1977. Partial purification of the Ca2+-Mg2+ ATPase activator from human erythrocytes: its similarity to the activator of 3':5' - cyclic nucleotide phosphodiesterase. Biochem. Biophys. Res. Commun., 77:1210-6.

Johnson, G. and Moore, S.W. 2004. Identification of a structural site on acetylcholinesterase that promotes neurite outgrowth and binds laminin-1 and collagen IV. Biochem. Biophys. Res. Commun., 319:448-55.

Kaiserman, D., Bird, C.H., Sun, J., Matthews, A., Ung, K., Whisstock, J.C., Thompson, P.E., Trapani, J.A. and Bird, P.I. 2006. The major human and mouse granzymes are structurally and functionally divergent. J. Cell Biol., 175:619-30.

Kakiuchi, S. and Yamazaki, R. 1970. Calcium dependent phosphodiesterase activity and its activating factor (PAF) from brain studies on cyclic 3', 5'-nucleotide phosphodiesterase (3). Biochem. Biophys. Res. Commun., 41:1104-10.

Kanyshkova, T.G., Buneva, V.N. and Nevinsky, G.A. 2001. Lactoferrin and its biological functions. Biochemistry (Mosc), 66:1-7.

Kapp, L.D. and Lorsch, J.R. 2004. The molecular mechanics of eukaryotic translation. Annu. Rev. Biochem., 73:657-704.

Karniely, S. and Pines, O. 2005. Single translation-dual destination: mechanisms of dual protein targeting in eukaryotes. EMBO Rep., 6:420-5.

Karunakaran, K.P., Noguchi, Y., Read, T.D., Cherkasov, A., Kwee, J., Shen, C., Nelson, C.C. and Brunham, R.C. 2003. Molecular analysis of the multiple GroEL proteins of Chlamydiae. J. Bacteriol., 185:1958-66.

Kearse, K.P. and Hart, G.W. 1991. Lymphocyte activation induces rapid changes in nuclear and cytoplasmic glycoproteins. Proc. Natl. Acad. Sci. U.S.A., 88:1701-5.

Keeling, K.M., Lanier, J., Du, M., Salas-Marco, J., Gao, L., KaenjakAngeletti, A. and Bedwell, D.M. 2004. Leaky termination at premature stop codons antagonizes nonsense-mediated mRNA decay in S. cerevisiae. Rna, 10:691-703.

Kelly, A., Powis, S.H., Kerr, L.A., Mockridge, I., Elliott, T., Bastin, J., Uchanska-Ziegler, B., Ziegler, A., Trowsdale, J. and Townsend, A. 1992. Assembly and function of the two ABC transporter proteins encoded in the human major histocompatibility complex. Nature, 355:641-4.

Kelly, W.G., Dahmus, M.E. and Hart, G.W. 1993. RNA polymerase II is a glycoprotein. Modification of the $\mathrm{COOH}$-terminal domain by O-GlcNAc. J. Biol. Chem., 268:10416-24.

Kennedy, M.C., Mende-Mueller, L., Blondin, G.A. and Beinert, H. 1992. Purification and characterization of cytosolic aconitase from beef liver and its relationship to the iron-responsive element binding protein. Proc. Natl. Acad. Sci. U.S.A., 89:11730-4.

Kim, E., Xie, S., Yeh, S.D., Lee, Y.F., Collins, L.L., Hu, Y.C., Shyr, C.R., $\mathrm{Mu}$, X.M., Liu, N.C., Chen, Y.T., Wang, P.H. and Chang, C. 2003. Disruption of TR.4 orphan nuclear receptor reduces the expression of liver apolipoprotein E/C-I/C-II gene cluster. J. Biol. Chem., 278:46919-26.

Kinlough, C.L., Poland, P.A., Bruns, J.B., Harkleroad, K.L. and Hughey, R.P. 2004. MUC1 membrane trafficking is modulated by multiple interactions. J. Biol. Chem., 279:53071-7. 
Kirby, J.E. 2004. Anthrax lethal toxin induces human endothelial cell apoptosis. Infect. Immun., 72:430-9.

Klabunde, T., Sharma, S., Telenti, A., Jacobs, WRJr and Sacchettini, J.C. 1998. Crystal structure of GyrA intein from Mycobacterium xenopi reveals structural basis of protein splicing. Nat. Struct. Biol., 5:31-6.

Kochetov, A.V. 2006. [Alternative translation start sites and their significance for eukaryotic proteome]. Mol. Biol. (Mosk), 40:788-95.

Kochetov, A.V., Sarai, A., Rogozin, I.B., Shumny, V.K. and Kolchanov, N. A. 2005. The role of alternative translation start sites in the generation of human protein diversity. Mol. Genet. Genomics, 273:491-6.

Komeili, A. and O'Shea, E.K. 1999. Roles of phosphorylation sites in regulating activity of the transcription factor Pho4. Science, 284:977-80.

Koritschoner, N.P., Madruga, J., Knespel, S., Blendinger, G., Anzinger, B., Otto, A., Zenke, M. and Bartunek, P. 2001. The nuclear orphan receptor TR.4 promotes proliferation of myeloid progenitor cells. Cell. Growth Differ., 12:563-72.

Kozak, M. 1980. Influence of mRNA secondary structure on binding and migration of 40S ribosomal subunits. Cell., 19:79-90.

Kozak, M. 2002. Pushing the limits of the scanning mechanism for initiation of translation. Gene, 299:1-34.

Krebs, E.G. 1993. Nobel Lecture. Protein phosphorylation and cellular regulation I. Biosci. Rep., 13:127-42.

Kreppel, L.K., Blomberg, M.A. and Hart, G.W. 1997. Dynamic glycosylation of nuclear and cytosolic proteins. Cloning and characterization of a unique O-GlcNAc transferase with multiple tetratricopeptide repeats. J. Biol. Chem., 272:9308-15.

Kreppel, L.K. and Hart, G.W. 1999. Regulation of a cytosolic and nuclear O-GlcNAc transferase. Role of the tetratricopeptide repeats. J. Biol. Chem., 274:32015-22.

Kretsinger, R.H. and Nockolds, C.E. 1973. Carp muscle calcium-binding protein. II. Structure determination and general description. J. Biol. Chem., 248:3313-26.

Kuchler, K., Sterne, R.E. and Thorner, J. 1989. Saccharomyces cerevisiae STE6 gene product: a novel pathway for protein export in eukaryotic cells. Embo. J., 8:3973-84.

Kumar, A., Agarwal, S., Heyman, J.A., Matson, S., Heidtman, M., Piccirillo, S., Umansky, L., Drawid, A., Jansen, R., Liu, Y., Cheung, K.H., Miller, P., Gerstein, M., Roeder, G.S. and Snyder, M. 2002. Subcellular localization of the yeast proteome. Genes Dev., 16:707-19.

Ladomery, M. and Dellaire, G. 2002. Multifunctional zinc finger proteins in development and disease. Ann. Hum. Genet., 66:331-42.

Layer, P.G., Allebrandt, K., Andermann, P., Bodur, E., Boopathy, R., Bytyqi, A.H. and Paraoanu, L.E. 2005. On the multifunctionality of cholinesterases. Chem. Biol. Interact., 157-158:37-41.

Layer, P.G., Weikert, T. and Alber, R. 1993. Cholinesterases regulate neurite growth of chick nerve cells in vitro by means of a non-enzymatic mechanism. Cell Tissue Res., 273:219-26.

Lee, S.B., Huang, K., Palmer, R., Truong, V.B., Herzlinger, D., Kolquist, K.A., Wong, J., Paulding, C., Yoon, S.K., Gerald, W., Oliner, J.D. and Haber, D.A. 1999. The Wilms tumor suppressor WT1 encodes a transcriptional activator of amphiregulin. Cell., 98:663-73.

Lee, Y.N., Nechushtan, H., Figov, N. and Razin, E. 2004. The function of lysyl-tRNA synthetase and Ap4A as signaling regulators of MITF activity in FcepsilonRI-activated mast cells. Immunity, 20:145-51.

Lee, Y.N. and Razin, E. 2005. Nonconventional involvement of LysRS in the molecular mechanism of USF2 transcriptional activity in FcepsilonRI-activated mast cells. Mol. Cell Biol., 25:8904-12.

Leffert, H.L. and Sell, S. 1974. Alpha1-fetoprotein biosynthesis during the growth cycle of differentiated fetal rat hepatocytes in primary monolayer culture. J. Cell Biol., 61:823-9.

Leissring, M.A., Farris, W., Wu, X., Christodoulou, D.C., Haigis, M.C., Guarente, L. and Selkoe, D.J. 2004. Alternative translation initiation generates a novel isoform of insulin-degrading enzyme targeted to mitochondria. Biochem. J., 383:439-46.

Lesk, A.M. 2001. Introduction to Protein Architecture, Oxford University Press, Oxford New York.
Levay, P.F. and Viljoen, M. 1995. Lactoferrin: a general review. Haematologica., 80:252-67.

Levitin, F., Baruch, A., Weiss, M., Stiegman, K., Hartmann, M.L., YoeliLerner, M., Ziv, R., Zrihan-Licht, S., Shina, S., Gat, A., Lifschitz, B., Simha, M., Stadler, Y., Cholostoy, A., Gil, B., Greaves, D., Keydar, I., Zaretsky, J., Smorodinsky, N. and Wreschner, D.H. 2005a. A novel protein derived from the MUC1 gene by alternative splicing and frameshifting. J. Biol. Chem., 280:10655-63.

Levitin, F., Stern, O., Weiss, M., Gil-Henn, C., Ziv, R., Prokocimer, Z., Smorodinsky, N.I., Rubinstein, D.B. and Wreschner, D.H. 2005b. The MUC1 SEA module is a self-cleaving domain. J. Biol. Chem., 280:33374-86.

Lewis, B.P., Green, R.E. and Brenner, S.E. 2003. Evidence for the widespread coupling of alternative splicing and nonsense-mediated mRNA decay in humans. Proc. Natl. Acad. Sci. U.S.A., 100:189-92.

Lewis, U.J., Sinha, Y.N. and Lewis, G.P. 2000. Structure and properties of members of the hGH family: a review. Endocr. J., 47(Suppl):S1-8.

Li, M.S., Li, P.F., Yang, F.Y., He, S.P., Du, G.G. and Li, G. 2002. The intracellular mechanism of alpha-fetoprotein promoting the proliferation of NIH 3T3 cells. Cell Res., 12:151-6.

Li, Q.J., Yao, M., Wong, W., Parpura, V. and Martins-Green, M. 2004. The $\mathrm{N}$ - and C-terminal peptides of hIL8/CXCL8 are ligands for hCXCR1 and hCXCR2. Faseb J., 18:776-8.

Li, Y., Bharti, A., Chen, D., Gong, J. and Kufe, D. 1998. Interaction of glycogen synthase kinase 3beta with the DF3/MUC1 carcinomaassociated antigen and beta-catenin. Mol. Cell Biol., 18:7216-24.

Li, Y., Chen, W., Ren, J., Yu, W.H., Li, Q., Yoshida, K. and Kufe, D. 2003 a. DF3/MUC1 signaling in multiple myeloma cells is regulated by interleukin-7. Cancer Biol. Ther., 2:187-93.

Li, Y., Kuwahara, H., Ren, J., Wen, G. and Kufe, D. 2001a. The c-Src tyrosine kinase regulates signaling of the human DF3/MUC1 carcinoma-associated antigen with GSK3 beta and beta-catenin. J. Biol. Chem., 276:6061-4.

Li, Y., Ren, J., Yu, W., Li, Q., Kuwahara, H., Yin, L., Carraway, KL3rd and Kufe, D. 2001b. The epidermal growth factor receptor regulates interaction of the human DF3/MUC1 carcinoma antigen with c-Src and beta-catenin. J. Biol. Chem., 276:35239-42.

Li, Y., Yu, W.H., Ren, J., Chen, W., Huang, L., Kharbanda, S., Loda, M. and Kufe, D. 2003b. Heregulin targets gamma-catenin to the nucleolus by a mechanism dependent on the DF3/MUC1 oncoprotein. Mol. Cancer Res., 1:765-75.

Ligtenberg, M.J., Kruijshaar, L., Buijs, F., van Meijer, M., Litvinov, S.V. and Hilkens, J. 1992. Cell.-associated episialin is a complex containing two proteins derived from a common precursor. J. Biol. Chem., 267:6171-7.

Linsley, P.S., Kallestad, J.C. and Horn, D. 1988. Biosynthesis of high molecular weight breast carcinoma associated mucin glycoproteins. J. Biol. Chem., 263:8390-7.

Liou, J., Kim, M.L., Heo, W.D., Jones, J.T., Myers, J.W., Ferrell, JEJr and Meyer, T. 2005. STIM is a Ca2+ sensor essential for Ca2+-storedepletion-triggered Ca2+ influx. Curr. Biol., 15:1235-41.

Litvinov, S.V. and Hilkens, J. 1993. The epithelial sialomucin, episialin, is sialylated during recycling. J. Biol. Chem., 268:21364-71.

Loeb, D.M., Korz, D., Katsnelson, M., Burwell, E.A., Friedman, A.D. and Sukumar, S. 2002. Cyclin E is a target of WT1 transcriptional repression. J. Biol. Chem., 277:19627-32.

Loftfield, R.B. and Vanderjagt, D. 1972. The frequency of errors in protein biosynthesis. Biochem. J., 128:1353-6.

Lopez-Lastra, M., Rivas, A. and Barria, M.I. 2005. Protein synthesis in eukaryotes: the growing biological relevance of cap-independent translation initiation. Biol. Res., 38:121-46.

Lu, P.D., Harding, H.P. and Ron, D. 2004. Translation reinitiation at alternative open reading frames regulates gene expression in an integrated stress response. J. Cell Biol., 167:27-33.

Lubas, W.A., Frank, D.W., Krause, M. and Hanover, J.A. 1997. O-Linked GlcNAc transferase is a conserved nucleocytoplasmic protein containing tetratricopeptide repeats. J. Biol. Chem., 272:9316-24. 
Lykke-Andersen, J., Shu, M.D. and Steitz, J.A. 2001. Communication of the position of exon-exon junctions to the mRNA surveillance machinery by the protein RNPS1. Science, 293:1836-9.

Ma, S., Hill, K.E., Caprioli, R.M. and Burk, R.F. 2002. Mass spectrometric characterization of full-length rat selenoprotein $\mathrm{P}$ and three isoforms shortened at the $\mathrm{C}$ terminus. Evidence that three UGA codons in the mRNA open reading frame have alternative functions of specifying selenocysteine insertion or translation termination. J. Biol. Chem., 277:12749-54.

Mackenzie, S.A. 2005. Plant organellar protein targeting: a traffic plan still under construction. Trends Cell Biol., 15:548-54.

Maderazo, A.B., He, F., Mangus, D.A. and Jacobson, A. 2000. Upflp control of nonsense mRNA translation is regulated by Nmd2p and Upf3p. Mol. Cell Biol., 20:4591-603.

Makarova, K.S., Aravind, L. and Koonin, E.V. 1999. A superfamily of archaeal, bacterial, and eukaryotic proteins homologous to animal transglutaminases. Protein Sci., 8:1714-9.

Manch-Citron, J.N., Dey, A., Schneider, R. and Nguyen, N.Y. 1999. The translational hop junction and the 5 ' transcriptional start site for the Prevotella loescheii adhesin encoded by plaA. Curr. Microbiol., 38:22-6.

Mann, D.M., Romm, E. and Migliorini, M. 1994. Delineation of the glycosaminoglycan-binding site in the human inflammatory response protein lactoferrin. J. Biol. Chem., 269:23661-7.

Manning, G., Plowman, G.D., Hunter, T. and Sudarsanam, S. 2002a. Evolution of protein kinase signaling from yeast to man. Trends Biochem. Sci., 27:514-20.

Manning, G., Whyte, D.B., Martinez, R., Hunter, T. and Sudarsanam, S. $2002 \mathrm{~b}$. The protein kinase complement of the human genome. Science, 298:1912-34.

Mariller, C., Benaissa, M., Hardiville, S., Breton, M., Pradelle, G., Mazurier, J. and Pierce, A. 2007. Human delta-lactoferrin is a transcription factor that enhances Skp1 (S-phase kinase-associated protein) gene expression. Febs J., 274:2038-53.

Marino, M., Ascenzi, P. and Acconcia, F. 2006. S-palmitoylation modulates estrogen receptor alpha localization and functions. Steroids, 71:298-303

Martinoia, E., Klein, M., Geisler, M., Bovet, L., Forestier, C., Kolukisaoglu, U., Muller-Rober, B. and Schulz, B. 2002. Multifunctionality of plant ABC transporters - more than just detoxifiers. Planta, 214:345-55.

Matsufuji, S., Matsufuji, T., Miyazaki, Y., Murakami, Y., Atkins, J.F., Gesteland, R.F. and Hayashi, S. 1995. Autoregulatory frameshifting in decoding mammalian ornithine decarboxylase antizyme. Cell., 80:51-60.

McCaughan, K.K., Brown, C.M., Dalphin, M.E., Berry, M.J. and Tate, W.P. 1995. Translational termination efficiency in mammals is influenced by the base following the stop codon. Proc. Natl. Acad. Sci. U.S.A., 92:5431-5.

McGrath, J.P. and Varshavsky, A. 1989. The yeast STE6 gene encodes a homologue of the mammalian multidrug resistance P-glycoprotein. Nature, 340:400-4.

McNally, D. and Fares, M.A. 2007. In silico identification of functional divergence between the multiple groEL gene paralogs in Chlamydiae. BMC Evol. Biol., 7:81.

Meador, W.E., Means, A.R. and Quiocho, F.A. 1992. Target enzyme recognition by calmodulin: $2.4 \mathrm{~A}$ structure of a calmodulin-peptide complex. Science, 257:1251-5.

Medina, L., Grove, K. and Haltiwanger, R.S. 1998. SV40 large T antigen is modified with O-linked N.-acetylglucosamine but not with other forms of glycosylation. Glycobiology, 8:383-91.

Medzihradszky, K.F. 2002. Characterization of site-specific glycosylation. In Posttranslational modifications of proteins (C. Kannicht, Ed.), pp. 101-102, Humana Press.

Milligan, G., Parenti, M. and Magee, A.I. 1995. The dynamic role of palmitoylation in signal transduction. Trends Biochem. Sci., 20:181-7.

Milligan, S.R., Khan, O. and Nash, M. 1998. Competitive binding of xenobiotic oestrogens to rat alpha-fetoprotein and to sex steroid binding proteins in human and rainbow trout (Oncorhynchus mykiss) plasma. Gen. Comp. Endocrinol., 112:89-95.
Min, W. and Jones, D.H. 1994. In vitro splicing of concanavalin A is catalyzed by asparaginyl endopeptidase. Nat. Struct. Biol., 1:502-4.

Miranda, L.R., Duval, M., Doherty, H., Seaman, M.S., Posner, M.R. and Cavacini, L.A. 2007. The neutralization properties of a HIV-specific antibody are markedly altered by glycosylation events outside the antigen-binding domain. J. Immunol., 178:7132-8.

Mironov, A.A., Fickett, J.W. and Gelfand, M.S. 1999. Frequent alternative splicing of human genes. Genome. Res., 9:1288-93.

Missler, M., Fernandez-Chacon, R. and Sudhof, T.C. 1998. The making of neurexins. J. Neurochem., 71:1339-47.

Missler, M. and Sudhof, T.C. 1998. Neurexins: three genes and 1001 products. Trends Genet., 14:20-6.

Mizejewski, G.J. 1993. An apparent dimerization motif in the third domain of alpha-fetoprotein: molecular mimicry of the steroid/thyroid nuclear receptor superfamily. Bioessays, 15:427-32.

Mizejewski, G.J., Vonnegut, M. and Jacobson, H.I. 1983. Estradiol-activated alpha-fetoprotein suppresses the uterotropic response to estrogens. Proc. Natl. Acad. Sci. U.S.A., 80:2733-7.

Mosley, A.L., Lakshmanan, J., Aryal, B.K. and Ozcan, S. 2003. Glucosemediated phosphorylation converts the transcription factor Rgt1 from a repressor to an activator. J. Biol. Chem., 278:10322-7.

Mostaqul Huq, M.D., Gupta, P. and Wei, L.N. 2008. Post-translational modifications of nuclear co-repressor RIP140: a therapeutic target for metabolic diseases. Curr. Med. Chem., 15:386-92.

Murai, N., Murakami, Y. and Matsufuji, S. 2003. Identification of nuclear export signals in antizyme-1. J. Biol. Chem., 278:44791-8.

Murakami, Y., Matsufuji, S., Kameji, T., Hayashi, S., Igarashi, K., Tamura, T., Tanaka, K. and Ichihara, A. 1992. Ornithine decarboxylase is degraded by the $26 \mathrm{~S}$ proteasome without ubiquitination. Nature, 360:597-9.

Nadolski, M.J. and Linder, M.E. 2007. Protein lipidation. Febs J., 274:5202-10.

Nagai, M., Becker, J.L. and Deutsch, H.F. 1982. The fatty acid levels of rat alpha-fetoprotein derived from fetuses, pregnancy and hepatoma sera. Oncodev. Biol. Med., 3:343-50.

Nagradova, N.K. 2004. Protein folding in the cell: on the mechanisms of its acceleration. Biochemistry (Mosc), 69:830-43.

Namy, O., Duchateau-Nguyen, G. and Rousset, J.P. 2002. Translational readthrough of the PDE2 stop codon modulates cAMP levels in Saccharomyces cerevisiae. Mol. Microbiol., 43:641-52.

Namy, O., Rousset, J.P., Napthine, S. and Brierley, I. 2004. Reprogrammed genetic decoding in cellular gene expression. Mol. Cell., 13:157-68.

Naval, J., Villacampa, M.J., Goguel, A.F. and Uriel, J. 1985. Cell-typespecific receptors for alpha-fetoprotein in a mouse T-lymphoma cell line. Proc. Natl. Acad. Sci. U.S.A., 82:3301-5.

Nemansky, M., Thotakura, N.R., Lyons, C.D., Ye, S., Reinhold, B.B., Reinhold, V.N. and Blithe, D.L. 1998. Developmental changes in the glycosylation of glycoprotein hormone free alpha subunit during pregnancy. J. Biol. Chem., 273:12068-76.

Nishi, S., Matsue, H., Yoshida, H., Yamaoto, R. and Sakai, M. 1991. Localization of the estrogen-binding site of alpha-fetoprotein in the chimeric human-rat proteins. Proc. Natl. Acad. Sci. U.S.A., $88: 3102-5$.

Noren, C.J., Wang, J. and Perler, F.B. 2000. Dissecting the Chemistry of Protein Splicing and Its Applications. Angew Chem. Int. Ed. Engl., 39:450-66.

Nott, A., Le Hir, H. and Moore, M.J. 2004. Splicing enhances translation in mammalian cells: an additional function of the exon junction complex. Genes Dev., 18:210-22.

Nykjaer, A. and Willnow, T.E. 2002. The low-density lipoprotein receptor gene family: a cellular Swiss army knife? Trends Cell Biol., 12:273-80.

Ohkura, K. and Hori, H. 2000. Analyses of insulin-potentiating fragments of human growth hormone by computative simulation; essential unit for insulin-involved biological responses. Bioorg Med. Chem., $8: 1733-40$. 
Ohno, S. 1970. Evolution by gene duplication, Springer-Verlag, Berlin.

Osterhout, J.L., Waheed, A.A., Hiol, A., Ward, R.J., Davey, P.C., Nini, L., Wang, J., Milligan, G., Jones, T.L. and Druey, K.M. 2003. Palmitoylation regulates regulator of G-protein signaling (RGS) 16 function. II. Palmitoylation of a cysteine residue in the RGS box is critical for RGS16 GTPase accelerating activity and regulation of Gi-coupled signalling. J. Biol. Chem., 278:19309-16.

Otani, A., Slike, B.M., Dorrell, M.I., Hood, J., Kinder, K., Ewalt, K.L., Cheresh, D., Schimmel, P. and Friedlander, M. 2002. A fragment of human TrpRS as a potent antagonist of ocular angiogenesis. Proc. Natl. Acad. Sci. U.S.A., 99:178-83.

Packham, G., Brimmell, M. and Cleveland, J.L. 1997. Mammalian cells express two differently localized Bag-1 isoforms generated by alternative translation initiation. Biochem. J., 328 (Pt 3):807-13.

Paraoanu, L.E. and Layer, P.G. 2004. Mouse acetylcholinesterase interacts in yeast with the extracellular matrix component laminin-1 beta. FEBS Lett, 576:161-4.

Paulus, H. 2001. Inteins as enzymes. Bioorg Chem., 29:119-29.

Pawson, T. and Gish, G.D. 1992. SH2 and SH3 domains: from structure to function. Cell., 71:359-62.

Pawson, T. and Nash, P. 2003. Assembly of cell regulatory systems through protein interaction domains. Science, 300:445-52.

Perler, F.B. 2005. Protein splicing mechanisms and applications. IUBMB. Life, 57:469-76.

Perler, F.B., Davis, E.O., Dean, G.E., Gimble, F.S., Jack, W.E., Neff, N., Noren, C.J., Thorner, J. and Belfort, M. 1994. Protein splicing elements: inteins and exteins - a definition of terms and recommended nomenclature. Nucleic Acids Res., 22:1125-7.

Persechini, A. and Kretsinger, R.H. 1988. The central helix of calmodulin functions as a flexible tether. J. Biol. Chem., 263:12175-8.

Pestova, T.V. and Hellen, C.U. 1999. Ribosome recruitment and scanning: what's new? Trends Biochem. Sci., 24:85-7.

Pham, C.T., MacIvor, D.M., Hug, B.A., Heusel, J.W. and Ley, T.J. 1996. Long-range disruption of gene expression by a selectable marker cassette. Proc. Natl. Acad. Sci. U.S.A., 93:13090-5.

Pietrokovski, S. 2001. Intein spread and extinction in evolution. Trends Genet., 17:465-72.

Plant, E.P., Jacobs, K.L., Harger, J.W., Meskauskas, A., Jacobs, J.L., Baxter, J.L., Petrov, A.N. and Dinman, J.D. 2003. The 9-A solution: how mRNA pseudoknots promote efficient programmed-1 ribosomal frameshifting. Rna., 9:168-74.

Plateau, P. and Blanquet, S. 1982. Zinc-dependent synthesis of various dinucleoside 5', 5'-P1,P3-Tri- or 5', 5'-P1,P4-tetraphosphates by Escherichia coli lysyl-tRNA synthetase. Biochemistry, 21:5273-9.

Porras, P., Padilla, C.A., Krayl, M., Voos, W. and Barcena, J.A. 2006. One single in-frame AUG codon is responsible for a diversity of subcellular localizations of glutaredoxin 2 in Saccharomyces cerevisiae. J. Biol. Chem., 281:16551-62.

Qiao, F. and Bowie, J.U. 2005. The many faces of SAM. Sci. STKE 2005: re7.

Quinton, T.M., Kim, S., Dangelmaier, C., Dorsam, R.T., Jin, J., Daniel, J.L. and Kunapuli, S.P. 2002. Protein kinase C- and calcium-regulated pathways independently synergize with Gi pathways in agonistinduced fibrinogen receptor activation. Biochem. J., 368:535-43.

Rammensee, H.G. 2004. Immunology: protein surgery. Nature, 427:203-4.

Regev-Rudzki, N., Karniely, S., Ben-Haim, N.N. and Pines, O. 2005. Yeast aconitase in two locations and two metabolic pathways: seeing small amounts is believing. Mol. Biol. Cell., 16:4163-71.

Regev-Rudzki, N. and Pines, O. 2007. Eclipsed distribution: a phenomenon of dual targeting of protein and its significance. Bioessays, 29:772-82.

Rehfeld, J.F. and Goetze, J.P. 2003. The posttranslational phase of gene expression: new possibilities in molecular diagnosis. Curr. Mol. Med., 3:25-38.

Ren, J., Li, Y. and Kufe, D. 2002. Protein kinase C delta regulates function of the DF3/MUC1 carcinoma antigen in beta-catenin signaling. J. Biol. Chem., 277:17616-22.
Resh, M.D. 1999. Fatty acylation of proteins: new insights into membrane targeting of myristoylated and palmitoylated proteins. Biochim. Biophys. Acta., 1451:1-16.

Revell, P.A., Grossman, W.J., Thomas, D.A., Cao, X., Behl, R., Ratner, J.A., Lu, Z.H. and Ley, T.J. 2005. Granzyme B. and the downstream granzymes $\mathrm{C}$ and/or $\mathrm{F}$ are important for cytotoxic lymphocyte functions. J. Immunol., 174:2124-31.

Richardson, J.S. 1981. The anatomy and taxonomy of protein structure. Adv. Protein Chem., 34:167-339.

Roberts, A.W. 2005. G-CSF: a key regulator of neutrophil production, but that's not all! Growth Factors, 23:33-41.

Robinson, D.N. and Cooley, L. 1997. Examination of the function of two kelch proteins generated by stop codon suppression. Development, 124:1405-17.

Rochette-Egly, C. 2003. Nuclear receptors: integration of multiple signalling pathways through phosphorylation. Cell Signal, 15:355-66.

Rom, E. and Kahana, C. 1994. Polyamines regulate the expression of ornithine decarboxylase antizyme in vitro by inducing ribosomal frameshifting. Proc. Natl. Acad. Sci. U.S.A., 91:3959-63.

Roos, J., DiGregorio, P.J., Yeromin, A.V., Ohlsen, K., Lioudyno, M., Zhang, S., Safrina, O., Kozak, J.A., Wagner, S.L., Cahalan, M.D., Velicelebi, G. and Stauderman, K.A. 2005. STIM1, an essential and conserved component of store-operated $\mathrm{Ca} 2+$ channel function. J. Cell Biol., 169:435-45.

Roos, M.D., Su, K., Baker, J.R. and Kudlow, J.E. 1997. O glycosylation of an Sp1-derived peptide blocks known Sp1 protein interactions. Mol. Cell. Biol., 17:6472-80.

Roquemore, E.P., Chevrier, M.R., Cotter, R.J. and Hart, G.W. 1996. Dynamic O-GlcNAcylation of the small heat shock protein alpha B-crystallin. Biochemistry, 35:3578-86.

Routier, F.H., Davies, M.J., Bergemann, K. and Hounsell, E.F. 1997. The glycosylation pattern of humanized IgGI antibody (D1.3) expressed in CHO cells. Glycoconj J., 14:201-7.

Ruiz-Gutierrez, V., Moreno, R., Moreda, W., Copado, M.A. and RodriguezBurgos, A. 2001. Detection of squalene in alpha-fetoprotein and fetal serum albumin from bovine. J. Protein Chem., 20:19-23.

Ruoslahti, E., Estes, T. and Seppala, M. 1979. Binding of bilirubin by bovine and human alpha-fetoprotein. Biochim. Biophys. Acta., 578:511-9.

Sampath, P., Mazumder, B., Seshadri, V., Gerber, C.A., Chavatte, L., Kinter, M., Ting, S.M., Dignam, J.D., Kim, S., Driscoll, D.M. and Fox, P.L. 2004. Noncanonical function of glutamyl-prolyl-tRNA synthetase: genespecific silencing of translation. Cell, 119:195-208.

Santonico, E., Castagnoli, L. and Cesareni, G. 2005. Methods to reveal domain networks. Drug Discov. Today, 10:1111-7.

Sass, E., Blachinsky, E., Karniely, S. and Pines, O. 2001. Mitochondrial and cytosolic isoforms of yeast fumarase are derivatives of a single translation product and have identical amino termini. J. Biol. Chem., 276:46111-7.

Schartner, J.M., Fathman, C.G. and Seroogy, C.M. 2007. Preservation of self: an overview of E3 ubiquitin ligases and T cell tolerance. Semin. Immunol., 19:188-96.

Scheiffele, P., Fan, J., Choih, J., Fetter, R. and Serafini, T. 2000. Neuroligin expressed in nonneuronal cells triggers presynaptic development in contacting axons. Cell, 101:657-69.

Schmucker, D., Clemens, J.C., Shu, H., Worby, C.A., Xiao, J., Muda, M., Dixon, J.E. and Zipursky, S.L. 2000. Drosophila Dscam is an axon guidance receptor exhibiting extraordinary molecular diversity. Cell, 101:671-84.

Sheeley, D.M., Merrill, B.M. and Taylor, L.C. 1997. Characterization of monoclonal antibody glycosylation: comparison of expression systems and identification of terminal alpha-linked galactose. Anal Biochem., 247:102-10.

Shyr, C.R., Collins, L.L., Mu, X.M., Platt, K.A. and Chang, C. 2002. Spermatogenesis and testis development are normal in mice lacking testicular orphan nuclear receptor 2. Mol. Cell. Biol., 22:4661-6.

Silvius, J.R. 2002. Mechanisms of Ras protein targeting in mammalian cells. J. Membr. Biol., 190:83-92. 
Singh, P.K. and Hollingsworth, M.A. 2006. Cell. surface-associated mucins in signal transduction. Trends Cell. Biol., 16:467-76.

Smorodinsky, N., Weiss, M., Hartmann, M.L., Baruch, A., Harness, E., Yaakobovitz, M., Keydar, I. and Wreschner, D.H. 1996. Detection of a secreted MUC1/SEC protein by MUC1 isoform specific monoclonal antibodies. Biochem. Biophys. Res. Commun., 228:115-21.

Son, K.N., Park, J., Chung, C.K., Chung, D.K., Yu, D.Y., Lee, K.K. and Kim, J. 2002. Human lactoferrin activates transcription of IL-1beta gene in mammalian cells. Biochem. Biophys. Res. Commun., 290:236-41.

Sorg, C. 1989. Macrophage-derived cell regulatory factors. Cytokines, Karger, Basel.

Southworth, M.W., Amaya, K., Evans, T.C., Xu, M.Q. and Perler, F.B. 1999. Purification of proteins fused to either the amino or carboxy terminus of the Mycobacterium xenopi gyrase A intein. Biotechniques, 27:110-4;116:118-20.

Stahl, G., Ben Salem, S., Li, Z., McCarty, G., Raman, A., Shah, M. and Farabaugh, P.J. 2001. Programmed +1 translational frameshifting in the yeast Saccharomyces cerevisiae results from disruption of translational error correction. Cold Spring Harb Symp. Quant. Biol., 66:249-58.

Stansfield, I., Jones, K.M., Herbert, P., Lewendon, A., Shaw, W.V. and Tuite, M.F. 1998. Missense translation errors in Saccharomyces cerevisiae. J. Mol. Biol., 282:13-24.

Starokadomskyy, P. 2007. Protein splicing. Molecular Biology, 41:278-93.

Stein, I., Itin, A., Einat, P., Skaliter, R., Grossman, Z. and Keshet, E. 1998. Translation of vascular endothelial growth factor mRNA by internal ribosome entry: implications for translation under hypoxia. Mol. Cell Biol., 18:3112-9.

Steneberg, P. and Samakovlis, C. 2001. A novel stop codon readthrough mechanism produces functional Headcase protein in Drosophila trachea. EMBO Rep., 2:593-7.

Strehl, A., Munnix, I.C., Kuijpers, M.J., van der Meijden, P.E., Cosemans, J.M., Feijge, M.A., Nieswandt, B. and Heemskerk, J.W. 2007. Dual role of platelet protein kinase $\mathrm{C}$ in thrombus formation: stimulation of pro-aggregatory and suppression of procoagulant activity in platelets. J. Biol. Chem., 282:7046-55.

Stuehr, D.J., Cho, H.J., Kwon, N.S., Weise, M.F. and Nathan, C.F. 1991. Purification and characterization of the cytokine-induced macrophage nitric oxide synthase: an FAD- and FMN-containing flavoprotein. Proc. Natl. Acad. Sci. U.S.A., 88:7773-7.

$\mathrm{Su}, \mathrm{Z}$., Wang, J., Yu, J., Huang, X. and Gu, X. 2006. Evolution of alternative splicing after gene duplication. Genome. Res., 16:182-9.

Sugita, S., Khvochtev, M. and Sudhof, T.C. 1999. Neurexins are functional alpha-latrotoxin receptors. Neuron, 22:489-96.

Sukenaga, Y., Ishida, K., Takeda, T. and Takagi, K. 1987. cDNA sequence coding for human glutathione peroxidase. Nucleic Acids Res., 15:7178

Sunderland, P.A., West, C.E., Waterworth, W.M. and Bray, C.M. 2006. An evolutionarily conserved translation initiation mechanism regulates nuclear or mitochondrial targeting of DNA ligase 1 in Arabidopsis thaliana. Plant J., 47:356-67.

Suzuki, T., Park, H. and Lennarz, W.J. 2002. Cytoplasmic peptide: $\mathrm{N}$-glycanase (PNGase) in eukaryotic cells: occurrence, primary structure, and potential functions. Faseb J., 16:635-41.

Suzuki, T., Tanabe, K., Hara, I., Taniguchi, N. and Colavita, A. 2007. Dual enzymatic properties of the cytoplasmic peptide: $\mathrm{N}$-glycanase in C. elegans. Biochem. Biophys. Res. Commun., 358:837-41.

Suzuki, Y., Zeng, C.Q. and Alpert, E. 1992. Isolation and partial characterization of a specific alpha-fetoprotein receptor on human monocytes. J. Clin. Invest, 90:1530-6.

Suzuki, Y.A. and Lonnerdal, B. 2002. Characterization of mammalian receptors for lactoferrin. Biochem. Cell Biol., 80:75-80.

Szczypka, M.S., Wemmie, J.A., Moye-Rowley, W.S. and Thiele, D.J. 1994. A yeast metal resistance protein similar to human cystic fibrosis transmembrane conductance regulator (CFTR.) and multidrug resistance-associated protein. J. Biol. Chem., 269:22853-7.
Tagashira, M., Iijima, H., Isogai, Y., Hori, M., Takamatsu, S., Fujibayashi, Y., Yoshizawa-Kumagaye, K., Isaka, S., Nakajima, K., Yamamoto, T., Teshima, T. and Toma, K. 2001. Site-dependent effect of $\mathrm{O}$-glycosylation on the conformation and biological activity of calcitonin. Biochemistry, 40:11090-5.

Tanabe, O., Katsuoka, F., Campbell, A.D., Song, W., Yamamoto, M., Tanimoto, K. and Engel, J.D. 2002. An embryonic/fetal beta-type globin gene repressor contains a nuclear receptor TR2/TR4 heterodimer. Embo J., 21:3434-42.

Tatarinov, Y.S., Terentiev, A.A., Moldogazieva, N.T. and Tagirova, A.K. 1991. Human alpha-fetoprotein and its purification by chromatography on immobilized estrogens. Tumour. Biol., 12:125-30.

Tate, W.P., Mansell, J.B., Mannering, S.A., Irvine, J.H., Major, L.L. and Wilson, D.N. 1999. UGA: a dual signal for 'stop' and for recoding in protein synthesis. Biochemistry (Mosc), 64:1342-53.

Tatebayashi, K., Tanaka, K., Yang, H.Y., Yamamoto, K., Matsushita, Y., Tomida, T., Imai, M. and Saito, H. 2007. Transmembrane mucins Hkr1 and Msb2 are putative osmosensors in the SHO1 branch of yeast HOG pathway. Embo J., 26:3521-33.

Terentiev, A.A. and Moldogazieva, N.T. 2006. Structural and functional mapping of alpha-fetoprotein. Biochemistry (Mosc), 71:120-32.

Theil, E.C. and Eisenstein, R.S. 2000. Combinatorial mRNA regulation: iron regulatory proteins and iso-iron-responsive elements (Iso-IREs). J. Biol. Chem., 275:40659-62.

Torres, C.R. and Hart, G.W. 1984. Topography and polypeptide distribution of terminal N.-acetylglucosamine residues on the surfaces of intact lymphocytes. Evidence for O-linked GlcNAc. J. Biol. Chem., 259:3308-17.

Torres, J.M., Darracq, N. and Uriel, J. 1992. Membrane proteins from lymphoblastoid cells showing cross-affinity for alpha-fetoprotein and albumin. Isolation and characterization. Biochim. Biophys. Acta., 1159:60-6.

Torres, J.M., Laborda, J., Naval, J., Darracq, N., Calvo, M., Mishal, Z. and Uriel, J. 1989. Expression of alpha-fetoprotein receptors by human T-lymphocytes during blastic transformation. Mol. Immunol., 26:851-7.

Touriol, C., Bornes, S., Bonnal, S., Audigier, S., Prats, H., Prats, A.C. and Vagner, S. 2003. Generation of protein isoform diversity by alternative initiation of translation at non-AUG codons. Biol. Cell, 95:169-78.

Treitel, M.A., Kuchin, S. and Carlson, M. 1998. Snf1 protein kinase regulates phosphorylation of the Mig1 repressor in Saccharomyces cerevisiae. Mol. Cell Biol., 18:6273-80.

Trewhella, J. 1992. The solution structures of calmodulin and its complexes with synthetic peptides based on target enzyme binding domains. Cell Calcium, 13:377-90.

Tsarfaty, I., Hareuveni, M., Horev, J., Zaretsky, J., Weiss, M., Jeltsch, J.M., Garnier, J.M., Lathe, R., Keydar, I. and Wreschner, D.H. 1990. Isolation and characterization of an expressed hypervariable gene coding for a breast-cancer-associated antigen. Gene, 93:313-8.

Tsukuda, M., Asaoka, Y., Sekiguchi, K., Kikkawa, U. and Nishizuka, Y. 1988. Properties of protein kinase C subspecies in human platelets. Biochem. Biophys. Res. Commun., 155:1387-95.

Ubersax, J.A. and Ferrell, JEJr. 2007. Mechanisms of specificity in protein phosphorylation. Nat. Rev. Mol. Cell Biol., 8:530-41.

Ullrich, B., Ushkaryov, Y.A. and Sudhof, T.C. 1995. Cartography of neurexins: more than 1000 isoforms generated by alternative splicing and expressed in distinct subsets of neurons. Neuron, 14:497-507.

Urner, F. and Sakkas, D. 2003. Protein phosphorylation in mammalian spermatozoa. Reproduction, 125:17-26.

Vigneron, N., Stroobant, V., Chapiro, J., Ooms, A., Degiovanni, G., Morel, S., van der Bruggen, P., Boon, T. and Van den Eynde, B.J. 2004. An antigenic peptide produced by peptide splicing in the proteasome. Science, 304:587-90.

Vincent, T.S., Fraylick, J.E., McGuffie, E.M. and Olson, J.C. 1999. ADPribosylation of oncogenic Ras proteins by pseudomonas aeruginosa exoenzyme S in vivo. Mol. Microbiol., 32:1054-64. 
von der Haar, T. and Tuite, M.F. 2007. Regulated translational bypass of stop codons in yeast. Trends Microbiol., 15:78-86.

Wakasugi, K. and Schimmel, P. 1999. Two distinct cytokines released from a human aminoacyl-tRNA synthetase. Science, 284:147-51.

Walden, W.E., Selezneva, A.I., Dupuy, J., Volbeda, A., Fontecilla-Camps, J.C., Theil, E.C. and Volz, K. 2006. Structure of dual function iron regulatory protein 1 complexed with ferritin IRE-RNA. Science, 314:1903-8.

Wang, W., Czaplinski, K., Rao, Y. and Peltz, S.W. 2001. The role of Upf proteins in modulating the translation read-through of nonsensecontaining transcripts. Embo J., 20:880-90.

Ward, P.P., Uribe-Luna, S. and Conneely, O.M. 2002. Lactoferrin and host defense. Biochem. Cell Biol., 80:95-102.

Weiss, M., Zaretsky, J., Zimlichman, R., Smorodinsky, N., Dion, A.S., Keydar, I. and Wreschner, D.H. 1991. Expression of a gene coding for breast tumor-associated antigen in thyroid papillary carcinoma. Cancer Lett, 58:125-30.

Wells, L. and Hart, G.W. 2003. O-GlcNAc turns twenty: functional implications for post-translational modification of nuclear and cytosolic proteins with a sugar. FEBS Lett, 546:154-8.

Wen, Y., Caffrey, T.C., Wheelock, M.J., Johnson, K.R. and Hollingsworth, M.A. 2003. Nuclear association of the cytoplasmic tail of MUC1 and beta-catenin. J. Biol. Chem., 278:38029-39.

Wiegand, H.L., Lu, S. and Cullen, B.R. 2003. Exon junction complexes mediate the enhancing effect of splicing on mRNA expression. Proc. Natl. Acad. Sci. U.S.A., 100:11327-32.

Wilchek, M. and Miron, T. 1974. Polymers coupled to agarose as stable and high capacity spacers. Methods Enzymol, 34:72-6.

Wilkinson, M.F. 2005. A new function for nonsense-mediated mRNA-decay factors. Trends Genet., 21:143-8.

Williams, C.J., Wreschner, D.H., Tanaka, A., Tsarfaty, I., Keydar, I. and Dion, A.S. 1990. Multiple protein forms of the human breast tumorassociated epithelial membrane antigen (EMA) are generated by alternative splicing and induced by hormonal stimulation. Biochem. Biophys. Res. Commun., 170:1331-8.

Williams, I., Richardson, J., Starkey, A. and Stansfield, I. 2004. Genomewide prediction of stop codon readthrough during translation in the yeast Saccharomyces cerevisiae. Nucleic Acids Res., 32:6605-16.

Williams, R.T., Manji, S.S., Parker, N.J., Hancock, M.S., Van Stekelenburg, L., Eid, J.P., Senior, P.V., Kazenwadel, J.S., Shandala, T., Saint, R., Smith, P.J. and Dziadek, M.A. 2001. Identification and characterization of the STIM (stromal interaction molecule) gene family: coding for a novel class of transmembrane proteins. Biochem. J., 357:673-85.

Willnow, T.E., Sheng, Z., Ishibashi, S. and Herz, J. 1994. Inhibition of hepatic chylomicron remnant uptake by gene transfer of a receptor antagonist. Science, 264:1471-4.

Wilson, R.B., Renault, G., Jacquet, M. and Tatchell, K. 1993. The pde2 gene of Saccharomyces cerevisiae is allelic to rcal and encodes a phosphodiesterase which protects the cell from extracellular cAMP. FEBS Lett, 325:191-5.

Wilson, R.B. and Tatchell, K. 1988. SRA5 encodes the low-Km cyclic AMP phosphodiesterase of Saccharomyces cerevisiae. Mol. Cell Biol., 8:505-10.

Wood, P. 2001. Growth hormone: its measurement and the need for assay harmonization. Ann. Clin. Biochem., 38:471-82.

Wreschner, D.H., Hareuveni, M., Tsarfaty, I., Smorodinsky, N., Horev, J., Zaretsky, J., Kotkes, P., Weiss, M., Lathe, R., Dion, A. et al. 1990. Human epithelial tumor antigen cDNA sequences. Differential splicing may generate multiple protein forms. Eur. J. Biochem., 189:463-73.
Wreschner, D.H., McGuckin, M.A., Williams, S.J., Baruch, A., Yoeli, M., Ziv, R., Okun, L., Zaretsky, J., Smorodinsky, N., Keydar, I., Neophytou, P., Stacey, M., Lin, H.H. and Gordon, S. 2002. Generation of ligand-receptor alliances by SEA module-mediated cleavage of membrane-associated mucin proteins. Protein Sci., 11:698-706.

Wreschner, D.H., Zrihan-Licht, S., Baruch, A., Sagiv, D., Hartman, M.L., Smorodinsky, N. and Keydar, I. 1994. Does a novel form of the breast cancer marker protein, MUC1, act as a receptor molecule that modulates signal transduction? Adv Exp. Med. Biol., 353:17-26.

Wriggers, W., Chakravarty, S. and Jennings, P.A. 2005. Control of protein functional dynamics by peptide linkers. Biopolymers, 80:736-46.

Wu, Y. and Matthews, C.R. 2002. A cis-prolyl peptide bond isomerization dominates the folding of the alpha subunit of Trp synthase, a TIM barrel protein. J. Mol. Biol., 322:7-13.

Yannay-Cohen, N. and Razin, E. 2006. Translation and transcription: the dual functionality of LysRS in mast cells. Mol. Cells, 22:127-32.

Yap, K.L., Kim, J., Truong, K., Sherman, M., Yuan, T. and Ikura, M. 2000. Calmodulin target database. J. Struct. Funct. Genomics, 1:8-14.

Yook, S.H., Oltvai, Z.N. and Barabasi, A.L. 2004. Functional and topological characterization of protein interaction networks. Proteomics, 4:928-42.

Yoshinaka, Y., Katoh, I., Copeland, T.D. and Oroszlan, S. 1985. Murine leukemia virus protease is encoded by the gag-pol gene and is synthesized through suppression of an amber termination codon. Proc. Natl. Acad. Sci. U.S.A., 82:1618-22.

Yueh, A. and Schneider, R.J. 1996. Selective translation initiation by ribosome jumping in adenovirus-infected and heat-shocked cells. Genes Dev., 10:1557-67.

Zamecnik, P.C., Stephenson, M.L., Janeway, C.M. and Randerath, K. 1966. Enzymatic synthesis of diadenosine tetraphosphate and diadenosine triphosphate with a purified lysyl-sRNA synthetase. Biochem. Biophys. Res. Commun., 24:91-7.

Zaretsky, J.Z., Barnea, I., Aylon, Y., Gorivodsky, M., Wreschner, D.H. and Keydar, I. 2006. MUC1 gene overexpressed in breast cancer: structure and transcriptional activity of the MUC1 promoter and role of estrogen receptor alpha (ERalpha) in regulation of the MUC1 gene expression. Mol. Cancer, 5:57.

Zaretsky, J.Z., Sarid, R., Aylon, Y., Mittelman, L.A., Wreschner, D.H. and Keydar, I. 1999. Analysis of the promoter of the MUC1 gene overexpressed in breast cancer. FEBS Lett, 461:189-95.

Zaretsky, J.Z., Weiss, M., Tsarfaty, I., Hareuveni, M., Wreschner, D.H. and Keydar, I. 1990. Expression of genes coding for pS2, c-erbB2, estrogen receptor and the $\mathrm{H} 23$ breast tumor-associated antigen. A comparative analysis in breast cancer. FEBS Lett, 265:46-50.

Zhang, S.L., Yu, Y., Roos, J., Kozak, J.A., Deerinck, T.J., Ellisman, M.H., Stauderman, K.A. and Cahalan, M.D. 2005. STIM1 is a Ca2+ sensor that activates CRAC channels and migrates from the $\mathrm{Ca} 2+$ store to the plasma membrane. Nature, 437:902-5.

Zipursky, S.L., Wojtowicz, W.M. and Hattori, D. 2006. Got diversity? Wiring the fly brain with Dscam. Trends Biochem. Sci., 31:581-8.

Zrihan-Licht, S., Vos, H.L., Baruch, A., Elroy-Stein, O., Sagiv, D., Keydar, I., Hilkens, J. and Wreschner, D.H. 1994. Characterization and molecular cloning of a novel MUC1 protein, devoid of tandem repeats, expressed in human breast cancer tissue. Eur. J. Biochem., 224:787-95. 